University of Louisville

ThinkIR: The University of Louisville's Institutional Repository

Electronic Theses and Dissertations

$12-2016$

\title{
Practical knowledge in electrical engineering : applying lessons from industry to the classroom.
}

Tayce Lassiter

University of Louisville

Follow this and additional works at: https://ir.library.louisville.edu/etd

Part of the Electrical and Computer Engineering Commons

\section{Recommended Citation}

Lassiter, Tayce, "Practical knowledge in electrical engineering : applying lessons from industry to the classroom." (2016). Electronic Theses and Dissertations. Paper 2559.

https://doi.org/10.18297/etd/2559

This Master's Thesis is brought to you for free and open access by ThinkIR: The University of Louisville's Institutional Repository. It has been accepted for inclusion in Electronic Theses and Dissertations by an authorized administrator of ThinkIR: The University of Louisville's Institutional Repository. This title appears here courtesy of the author, who has retained all other copyrights. For more information, please contact thinkir@louisville.edu. 
Tayce Lassiter

B.S., University of Louisville, 2016

\author{
A Thesis \\ Submitted to the Faculty of the \\ University of Louisville \\ J. B. Speed School of Engineering \\ as Partial Fulfillment of the Requirements \\ for the Professional Degree
}

\title{
MASTERS OF ENGINEERING
}

Department of Electrical and Computer Engineering

December 2016 
PRACTICAL KNOWLEDGE IN ELECTRICAL ENGINEERING: APPLYING LESSONS FROM INDUSTRY TO THE CLASSROOM

Submitted by:

Tayce McCune Lassiter

A Thesis Approved on

Dr. M. McIntyre, Thesis Director

By the Following Reading and Examination Committee:

Dr. M. McIntyre, Thesis Director

(Date)

\begin{tabular}{c}
\hline Dr. J. Hieb \\
\hline Dr. J. Zurada
\end{tabular}

Dr. J. Zurada 


\section{$\underline{\text { Acknowledgements }}$}

I would like to thank Dr. McIntyre and Dr. Hieb for taking on this thesis topic as my advisors. I would also like to thank Dr. Zurada for taking the time to participate in my committee. I acknowledge that this took a lot of time from all three of your busy schedules.

Another group of people that I need to thank for their help are my editors, this paper became very long and editing it with me was a time consuming process. Thank you to Daniel T. Lassiter, Dr. Maureen Lassiter, Professor Linda McCune, and Heather R. Cole for their patience with helping me edit this thesis. 


\begin{abstract}
Objective: To identify and develop solutions for known gaps in existing electrical engineering curricula, by creating instruction modules applicable in a variety of settings. These instructional packages include: conductor sizing, conduit routing, how to read and create a P\&ID, arc flash calculations, and area classification. With regards to conductor sizing, the importance of specifying the correct size of conductor, the standard sizes of conductors, the types of conductor insulation, and finally detail the calculations of conductor sizing and voltage drop will be discussed. The conduit routing module will introduce the student to basic guidelines of conduit routing as well as to different fittings and seals needed in the running of conduit. This is achieved by walking students through the conduit sizing process, including standard conduit sizes. The P\&ID module introduces the standard symbols needed to read and understand a piping and instrumentation diagram. Reserved letters are the first topic discussed in this module, then the types of "bubbles" and connection lines, and finally the types of end equipment. The arc flash module will focus on several ways to calculate the energy of an arc flash, as well as the safe working distance for a given piece of electrical equipment. The area classification course will introduce the importance of designing with this identification system in mind. It emphasizes the four different ways of calculating a hazard radius for equipment, both indoors and outdoors. All of the modules have example calculations as well as design projects for the student to check their understanding.
\end{abstract}




\section{Table of Contents}

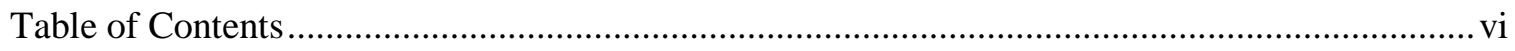

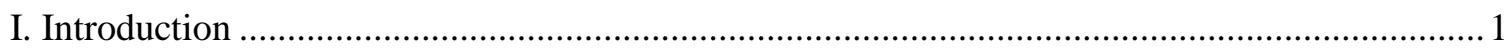

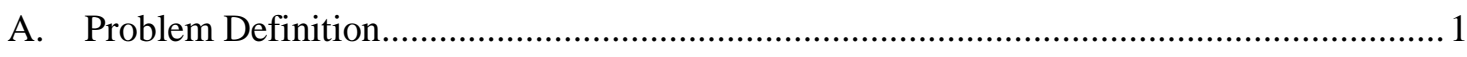

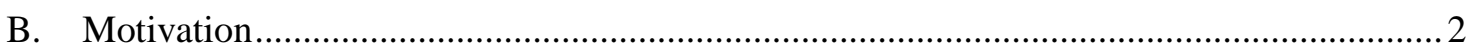

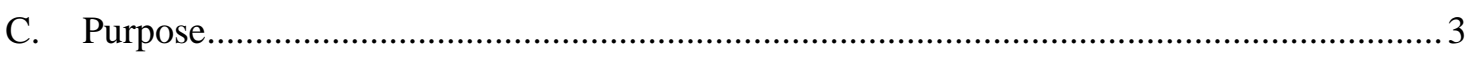

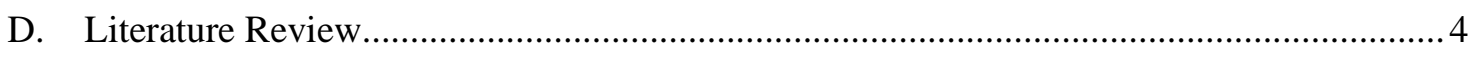

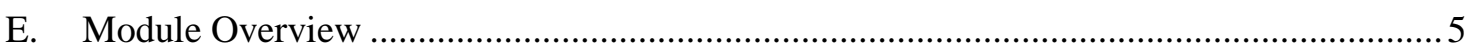

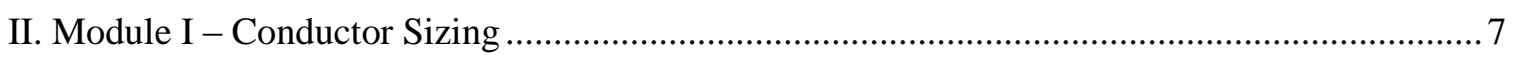

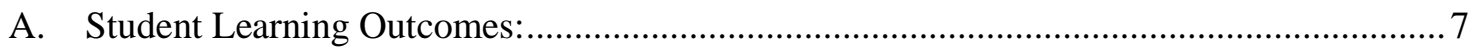

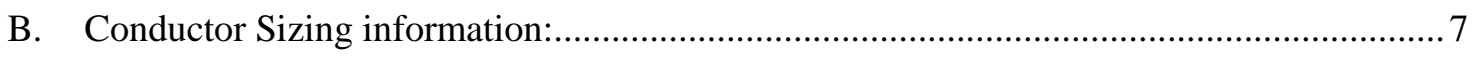

C. Module 1 Design Project: Conductor Sizing .............................................................. 15

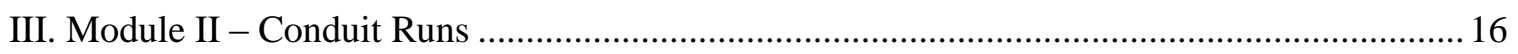

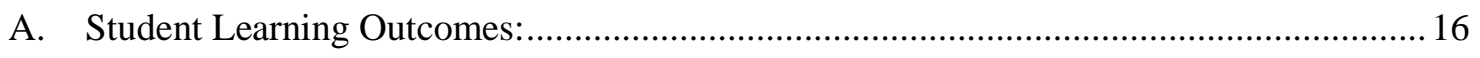

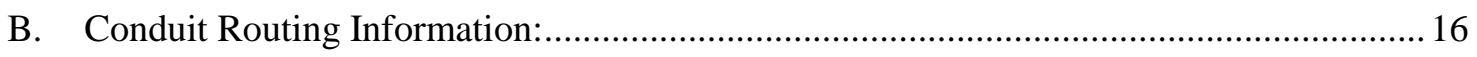

C. Module 2 Design Project Conduit Design: .................................................................. 22

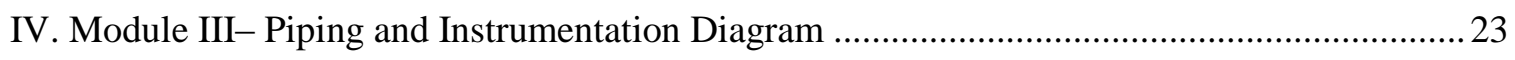

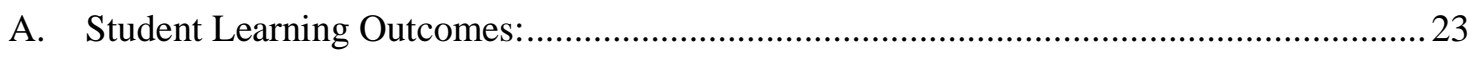

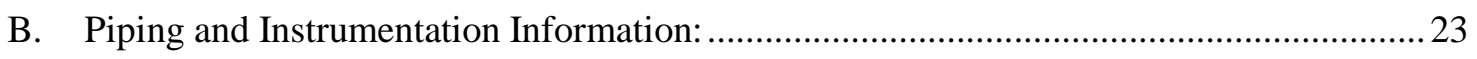

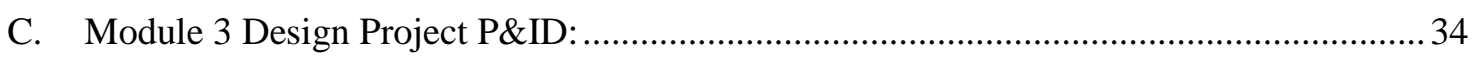

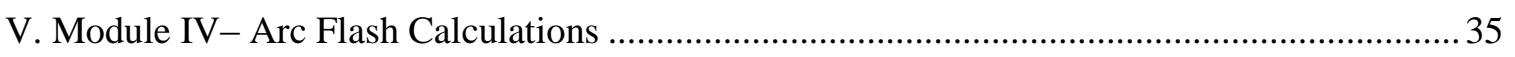

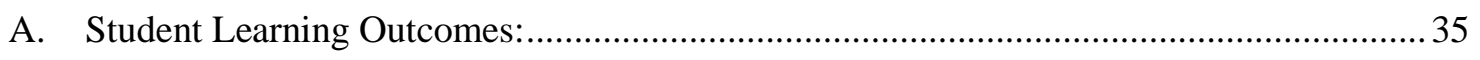

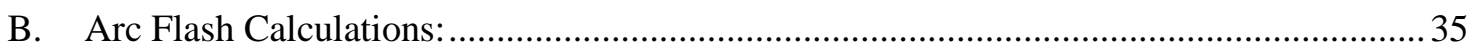

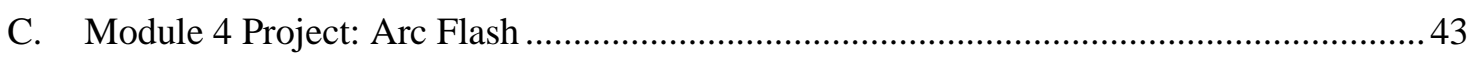

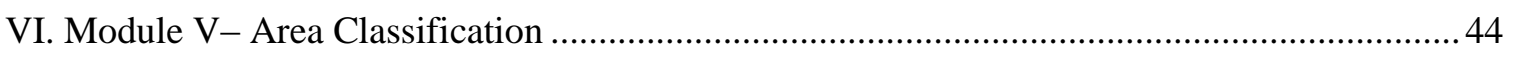

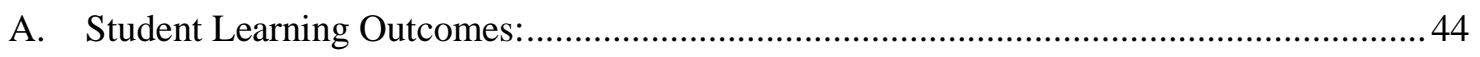

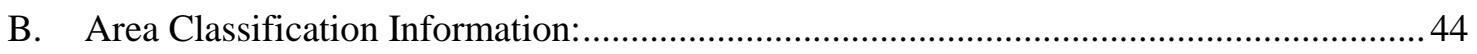

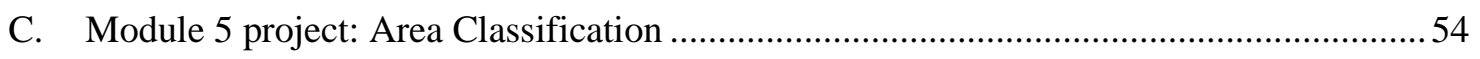

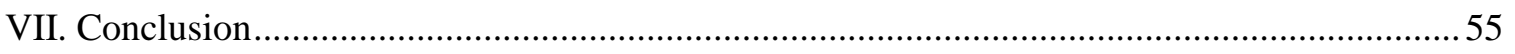

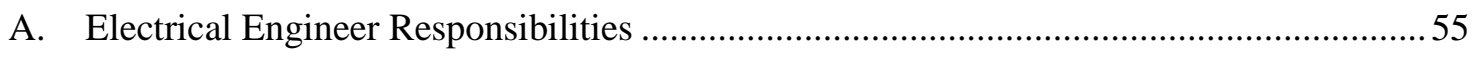

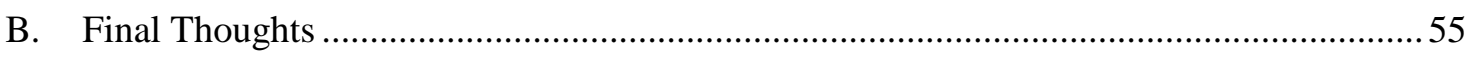

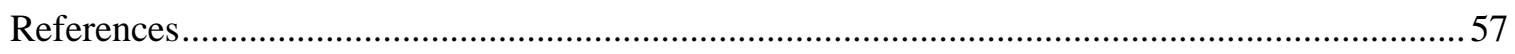

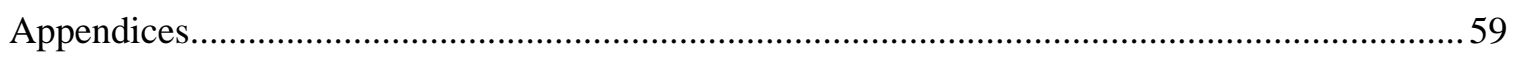

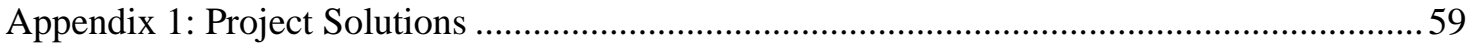

Appendix 2: Power Point Presentations: ......................................................................... 72 


\section{List of Tables}

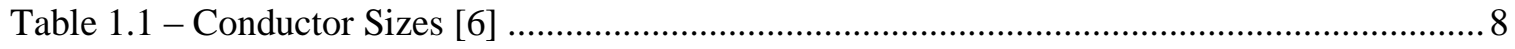

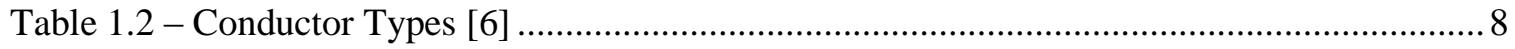

Table 1.3 - NEC Tables for Allowable Ampacities[6] …........................................................... 9

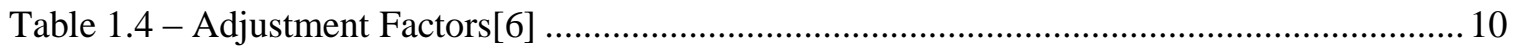

Table 2.1 - Electrical Metallic Tubing - Steel (Weights and Dimensions)[7] .............................. 18

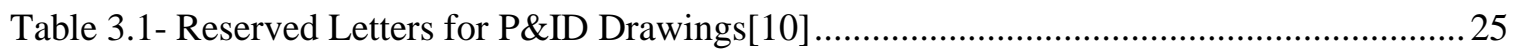

Table 3.2- Instrumentation Device and Function Symbols[10] ................................................ 27

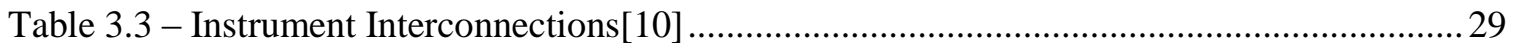

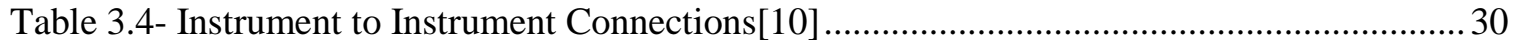

Table 3.5 -P\&ID Measurement Notations[10] ............................................................................ 32

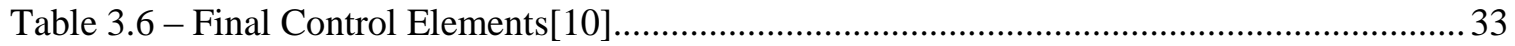

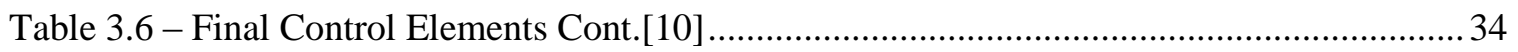

Table 4.1 - Classes of Equipment and Typical Bus Gaps[12] ....................................................... 39

Table 4.2 - Classes of Equipment and Typical Working Distances[12] ...................................... 41

Table 4.3 - Factors for Equipment and Voltage Classes[12] .................................................... 41

Table 5.1- Area Classification Table[18] .................................................................................... 47 


\section{List of Figures}

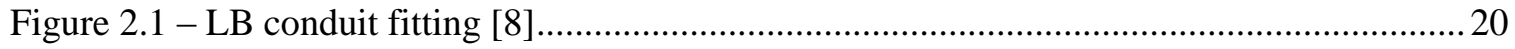

Figure 2.2 - Eaton's Patented Design Expansion Joint …..........................................................2 20

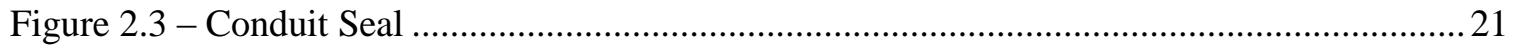

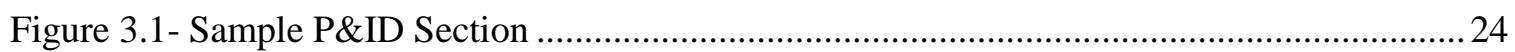

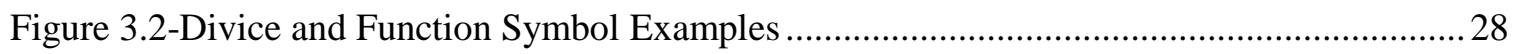

Figure 3.3-Temperature Element Connected to Temperature Transmitter .................................. 31

Figure 4.1 - Electrical Treeing in Polymethyl Methacrylate[14] ............................................... 36

Figure 4.2 - Arc Flash circuit Model[15] .............................................................................. 41

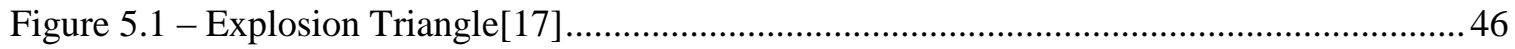

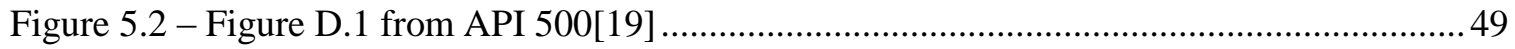

Figure 5.3- Figure D.3 from API 500 Adequately Ventilated Process Area with heavier-than-air Gas or Vapor Source Located near or above grade[19] ..........................................................50

Figure 5.4 - Figure D.3 Accompanied Diagram[19] .................................................................51 


\section{Introduction}

"The man who graduates today and stops learning tomorrow is uneducated the day after." Newton D. Baker, mayor of Cincinnati 1915-1921.

\section{A. Problem Definition}

Engineering students are expected to learn quite a bit in four years. Everything

from calculus to controls, power systems to physics, programming to polynomials; every year brings new topics and ideas that are considered essential to the core education of tomorrow's builders, programmers, designers and technical specialists.

Of course, it's impossible to cover everything. Students still have an expectation that they will graduate in four years; educators and administrative officials must engage in an increasingly complex balancing act of deciding what is and isn't relevant. Fortunately, well rounded engineers do not stop seeking new knowledge and understanding simply because they can now hang a frame on their wall with the word "Engineer" in it.

After extensive research the author found that there was very little educational material for the topics presented in this thesis. The information is available; however, a comprehensive guide for these topics is not. Therefore, the author took it upon herself to compile the information needed to learn about the topics contained in this document in an effort to make the process of continuing education more accessible. Ideally, these modules will provide relevant, compartmentalized practical knowledge that allow interested educators and students to rapidly grasp the concepts as presented and apply them in real world scenarios. 


\section{B. Motivation}

The author's direct educational experience exposed gaps in present day engineering curricula; further experience in industry identified a clear need for matriculating students to have prior knowledge of particular practical topics rather than uneven and inconsistent on the job training. Part of the undergraduate degree at the University of Louisville involves completing a year of work experience through the cooperative learning curricula. When the author started the first portion of this program, she found that the theoretical topics that were presented in the classroom were of little use in industry. These topics, focused on heavily during classes, only gave the background information an engineer would need; on the other hand, practical topics that were frequently needed on a daily basis got passing mentions in the lecture hall, if any at all, and with none of the practical knowledge needed to apply these theories. The author spent most of the first semester just learning the different topics that are presented in this thesis. The author also realized that the co-op year was only as good as the company that a student worked for. Some co-op positions did not provide an opportunity for the student to discover the inadequacies in their knowledge base. This thesis is a guide for students that feel they lack necessary practical knowledge they will require when they enter the workforce. The modules that are included in this thesis are condensed so that the reader does not have to spend months researching the different topics. 


\section{Purpose}

It is the intention of the author, that this paper be included among the many materials that form a basis for the ongoing education of electrical engineering students and recent graduates in electrical engineering who seek to stay current in today's rapidly changing technical environment.

Presently in electrical engineering curricula, a large variety of course topics are usually covered; these include but are not limited to circuit theory, transmission line theory, signal theory, uses of semiconductors, physical electronics, calculus, particle physics, microelectronics, computer programming, and computer design. However, once a 'traditionally' trained engineer leaves academia and enters the workforce, several significant gaps tend to appear in this knowledge base. There are several detailed practical knowledge topics that simply are not covered in the current curriculum. These practical topics are, generally: relay logic, ladder logic, conductor sizing, voltage drop considerations and calculations, plc programming, conduit sizing and routing, arc flash energy calculations, as well as the ability to read and interpret a piping and instrumentation diagram (P\&ID) and area classification drawings.

The overarching goal of this thesis is to design and develop learning modules which may be used in a number of ways to help fill in the knowledge gaps left by a traditional accredited engineering education. These approaches will address issues associated with the education of newly hired engineers and professional development of current engineers. The development of a senior level course for students that want to 
work in the power and controls industry or as retraining modules for non-engineers to better understand engineering decisions will also be addressed.

\section{Literature Review}

This effort attempt to use evidenced based educational strategies for the developed modules. This following literature review justifies the selection of designed base learning as an instructional strategy for the developed modules.

Problem based learning focuses on presenting the student with risky, open ended and highly situational challenges, usually with multiple different solutions which may or may not be commensurately effective. This philosophy differs from the standard model of teaching in most collegiate and university level courses, which rely primarily upon lecture and testing, which leads to unequivocal, single answer outcomes that do not adequately account for the real world variables in play.

Based on research performed on anagogy the author of this paper has determined that for engineering courses, design or problem based learning is superior to the prevailing traditional methods of teaching. As Linda Nilson states in her book Teaching At It's Best: A Research-Based Resource for College Instructors:

\footnotetext{
"An enormous amount of research on STEM education all leads to the same conclusion: inquiryguided, problem-focused, and collaborative, alternative teaching strategies are more effective than traditional lecture. Students who learn by these newer approaches leave their STEM courses with better skills in higher -order thinking, problem solving and experimental design." [1]
} 
Ms. Nilson speaks of STEM (Science, Technology, Engineering, and Mathematics) fields throughout her book specifically when introducing the problem based and collaborative learning styles. [1-4] Therefore, the objective of the modules will be to present the student with a practical challenge or obstacles that must be solved. The pupil will be expected to apply the knowledge gained in order to design a solution to the problem at the end of the module. [1-4]

Design based learning is not the only way that the student will be assessed; the modules will also include some traditional problem based assessment for the student to gauge their skill before attempting the design project. Studies have also shown that hands on learning activities lend practicality to engineering students. Many engineering students have side projects that they work on in their spare time that complements what is being learned in theoretical classes. These students, if properly engaged in hands on learning, will be more likely to graduate from an engineering curriculum.[2, 4, 5] To successfully complete the modules herein the author recommends the student acquire a copy of the Ugly's Electrical References [6].

\section{E. Module Overview}

After experiencing the gaps in knowledge between the curriculum and practical experience firsthand, and discussing the issue with power and controls professionals, including engineers, the author has chosen several topics for the educational modules. The first of these modules covers the basics of conductor sizing. This module will discuss the importance of specifying the correct size of conductor, the standard sizes of conductors, the types of conductor insulation, and finally detail the calculations of 
conductor sizing and voltage drop. The second module includes the basics of designing conduit runs. This module will also introduce the student to different fittings and seals needed in the running of conduit. This module will walk a student through the conduit sizing process, including standard conduit sizes, then detail several types of conduit fittings that are frequently used in industry. The third module will introduce the standard symbols needed to read and understand a piping and instrumentation diagram. Reserved letters are the first topic discussed in this module, then the types of "bubbles" and connection lines, finally the types of end equipment. The fourth module will discuss arc flash. This module will include several ways to calculate the energy of an arc flash, as well as the safe working distance for a piece of electrical equipment. Finally, the fifth module will introduce the topic of area classification, and the importance of designing with this classification in mind. This module will discuss four different ways of calculating a hazard radius for equipment both indoors and outdoors. Each module is presented in a separate sections, with module 1 being in section II, module 2 being section III, etc. Each module begins with student learning outcomes, followed by background information on the topic, and then a design project. Lecture slides and comments on a solution for the design project are included the appendices. Conclusions and recommendations are provided in section VIII. 


\section{Module I - Conductor Sizing \\ A. Student Learning Outcomes:}

The student with $70 \%$ or higher on the project will:

1. Assess and calculate the conductor sizes and voltage drop by utilizing the charts in Ugly's Electrical References and the formulas provided herein to answer the project question within the parameters given.

2. Assess the type of insulation needed by using the charts in Ugly's Electrical References to answer the project question within the parameters given.

\section{B. Conductor Sizing information:}

Before one can understand conductor sizing there are a few topics that need to be discussed. First, how conductor sizes are expressed and, secondly, what the different types of conductors are. Conductor is measured in gauges and kilocircularmills (kcmil). Smaller conductor is measured by gauges; usually the smallest that is used for an industrial conductor is a \#12. As the conductor becomes larger the gauge number becomes smaller. For example, a \#3 conductor is much larger than a \#10. This trend continues until one reaches the \#1. The next size larger is a $1 / 0$; this continues until one reaches a 4/0. After the 4/0 conductor, larger conductors are measured in kcmils, which reflects the diameter of a given conductor instead of an arbitrary number, see Table 1.1 from the Ugly's Electrical References Table titled "Dimensions of Insulated Conductors and Fixture Wires". The second topic one must understand is the different types of 
conductor. This is best described in the Ugly's Electrical References table titled "Conductor Applications and Insulations" Table 1.2 has a sample from this table.

Table 1.1 - Conductor Sizes [6]

\begin{tabular}{|l|l|l|}
\hline Type & Size & $\begin{array}{l}\text { Approximate Area (square } \\
\text { Inches) }\end{array}$ \\
\hline THHN & 14 & 0.0097 \\
THWN & 12 & 0.0133 \\
THWN-2 & 10 & 0.0211 \\
\hline
\end{tabular}

Table 1.2 - Conductor Types [6]

\begin{tabular}{|l|l|l|l|}
\hline Trade Name & Letter & Max Temp. & Application Provisions \\
\hline Heat-Resistant & THHN & $90^{\circ} \mathrm{C}$ & Dry and Damp \\
Thermoplastic & & $\left(194^{\circ} \mathrm{F}\right)$ & Locations \\
\hline
\end{tabular}

It is imperative that an engineer knows what medium he or she will be running the conductor though - such as air, soil, concrete, or conduit, see Table 1.3 an excerpt from the Ugly's Electrical References table titled "Allowable Ampacities of Conductors: Raceway, Cable or Earth.” There are different sizing tables for these mediums because of the issue of residual heat. An additional important factor to consider is how the conductor is insulated against these environmental circumstances; in most cases the insulation can be optimized to withstand these conditions by specifically countering any corrosive 
elements present based on the chemical composition of the insulation itself. For example, in a chemical process where benzene is present, the insulation might consist of elements that do not react with that compound. Failure to properly account for environmental conditions leads to insulation breakdown and ultimately can compromise the conductor run in an unsafe manner.

Table 1.3 - NEC Tables for Allowable Ampacities[6]

\begin{tabular}{|c|c|c|c|c|c|c|c|}
\hline Size & $60^{\circ} \mathrm{C}$ & $75^{\circ} \mathrm{C}$ & $90^{\circ} \mathrm{C}$ & $60^{\circ} \mathrm{C}$ & $75^{\circ} \mathrm{C}$ & $90^{\circ} \mathrm{C}$ & Size \\
\hline AWG & Types & Types & Types & Types & Types & Types & AWG \\
or & TW,UF & RHW, & TBS, SA, & TW,UF & RHW, & TBS, SA, \\
kcmil & & THHW, etc & etc. & & THHW, etc & etc. & kcmil \\
\hline \multicolumn{7}{|c|}{ Copper } & \multicolumn{3}{|c|}{ Aluminum or Copper-Clad Aluminum } \\
\hline 8 & 40 & 50 & 55 & 35 & 40 & 45 & 8 \\
\hline
\end{tabular}

When considering any conduit of multiple conductor runs, if there are more than three conductors that need to be run together then it is necessary to use an adjustment factor, see Table 1.4 a sample of the Adjustment Factor table in Ugly's Electrical References. Adjustment factor, commonly called the de-rate factor, is a method by which the excess heat generated by a conductor is accounted for, in order to prevent breakdown of the conductor or cable run. If there are four to six conductors run together, the upper limit of current that may be safely utilized can only equal $80 \%$ of the rated capacity of the particular gauge of conductor. 
The NEC also explains how to use the adjustment factor based on the number of conductors that are included in a bundle. For example, if you needed to run five THHN conductors though a conduit, and you needed to deliver 75 amps, the NEC states that when the specification is for three conductors, they should be size \#6. However, there are five conductors in this bundle, so a \#6 conductor is too small. Using the adjustment factor principle, size \#4 conductors must be run. To calculate the conductor size with adjustment you take the rated amps of the larger conductor - in this case, a \#4 conductor is rated up to 95 amps - and multiply it by the adjustment factor. This example gives 95 amps $* .8=76$ amps.

This solution does meet the requirements for the original problem; however, in practice some companies like to make a more conservative size choice. In order to implement a margin for error, the specification would now push the conductor size up one more step to \#3. In this manner, even if there were an over-current event the conductor would be able to handle the excess amperage without issue. In a later module, the size of the conduit that would need to be specified to hold these conductors will be examined (this module is focusing strictly on conductor sizing).

Table 1.4 - Adjustment Factors[6]

\begin{tabular}{|l|c|}
\hline Number of Current Carrying & Percent of Values in Tables 310.15(B) \\
& $(15)$ Through 310.15(B)(19) as Adjusted \\
& for Ambient Temperature if Necessary \\
\hline $4-6$ & 80 \\
\hline
\end{tabular}


Overheating is not the only problem an engineer must face when sizing conductor. When a conductor run is very long, the engineer will have to consider voltage drop as well. Voltage drop becomes an issue when the conductor is too long and/or narrow for the full amount of carried voltage to reach the other end of the conductor run. This issue can impact the function of the system by starving components of the necessary power they require to operate. This can cause unacceptable power interruptions in critical components or even cause components to fail catastrophically.

Generally speaking, the acceptable level of voltage drop is three percent of the total voltage required by the system. To obtain an acceptable percentage of voltage drop an engineer can compensate by increasing the conductor size so that the system functions normally. To fully explain voltage drop first one must equate it to the most recognizable formula in electrical engineering, Ohm's Law.

$$
v=i R
$$

In the above equation $v$ is the voltage across a section of circuit, $i$ is the current running through the conductor, and $R$ is the resistance of the component; this can include the conductor or another electrical component. This looks very similar to the voltage drop formulas where the difference is resistance is broken down into its elementary parts, resulting in the following equation:

$$
R=\rho \frac{l}{A}
$$


In the equation above $\rho$ is the resistivity of the material, $l$ is the length of the material and $A$ is the area of a cross section of the material. If one uses these same variables in the voltage drop formula, we arrive at:

$$
R=K \frac{L}{C m}
$$

In the above equation $K$ is the resistivity of the material, $L$ is the length of the material and $\mathrm{Cm}$ is the cross sectional area of the material. Replacing resistance in Ohm's law with this new definition changes the equation thusly:

$$
v=i K \frac{L}{C m} .
$$

There is a correction factor for three phase and single phase circuits in the voltage drop calculations that allows the formula to output a percentage versus a voltage. Thus, the following equations are used.

For single phase circuits:

$$
V d=\frac{2 K L I}{C m}
$$

For three phase circuits:

$$
V d=\frac{1.73 K L I}{C m}
$$

In the above equations $V d$ is voltage drop a percentage, $I$ is current in amps, $L$ is length of the run in feet, $\mathrm{Cm}$ is the cross sectional area of the conductor in circular mils and $\mathrm{K}$ is the resistance in ohms of 1 circular mil foot of the conductor. For $167^{\circ} \mathrm{F} \mathrm{K}=12.9$ for copper and $\mathrm{K}=21.2$ for aluminum. 
For example, the engineer must run $5 \# 3$ THHN conductors. Assuming that the run is very long, the engineer will use 500 feet. What is the voltage drop for these conductors?

First the engineer must know if this is a single phase or three phase circuit. Five conductors are being run this is indicative of one three phase and one single phase circuit. First calculate the three phase voltage drop.

$$
\begin{gathered}
V d=\frac{1.73 K L I}{C m} \\
V d=\frac{(1.73)(12.9)(500)(75)}{52620} \\
V d=15.9 \%
\end{gathered}
$$

The amount of voltage drop that is acceptable is around $3 \%$, so this conductor is too small for the circuit to function properly. Therefore, the engineer must raise the conductor size to accommodate the length of the run. A voltage drop of $15.9 \%$ is very large; by interpolation the engineer must raise the size of the conductor several sizes, trying a 2/0 size conductor, generating the following calculation:

$$
\begin{gathered}
V d=\frac{1.73 K L I}{C m} \\
V d=\frac{(1.73)(12.9)(500)(75)}{133100} \\
V d=6.3 \%
\end{gathered}
$$

This voltage drop is still too large; therefore, the conductor must be larger than a $2 / 0$ conductor. Trying a 300KCMIL conductor:

$$
V d=\frac{1.73 K L I}{C m}
$$




$$
\begin{gathered}
V d=\frac{(1.73)(12.9)(500)(75)}{300000} \\
V d=2.79 \%
\end{gathered}
$$

The final conductor size that must be used is a 300KCMIL conductor. This size is the smallest that allows the voltage drop to be within specifications. Now the engineer must calculate the single phase voltage drop, because the formulas are very similar to each other the engineer can safely assume that the single phase conductor size will be close to the three phase conductor size.

$$
\begin{gathered}
V d=\frac{2 K L I}{C m} \\
V d=\frac{(2)(12.9)(500)(75)}{300000} \\
V d=3.2 \%
\end{gathered}
$$

This voltage drop is close to the value that the engineer wants but, it is still too high. The engineer must raise the size of the conductor once again. Calculating for a 350KCMIL conductor:

$$
\begin{gathered}
V d=\frac{2 K L I}{C m} \\
V d=\frac{(2)(12.9)(500)(75)}{350000} \\
V d=2.8 \%
\end{gathered}
$$

This exercise has successfully shown that the length of the conductor run can impact the sizing of the conductor dramatically. 


\section{Module 1 Design Project: Conductor Sizing}

The customer has a system that is composed of a three phase space heater $(75 \mathrm{~A})$ and a single phase lighting circuit (50A). If the customer specifications state everything in the plant must be able to endure temperatures that exceed $150^{\circ} \mathrm{F}$. The power panel is 250 feet from the loads, and the single conduit must be run overhead. a) What type of conductor would you need to use? b) How big must the conductor be? c) What is the voltage drop over the length of the conductor? Explain your choices. 


\section{Module II - Conduit Runs}

\section{A. Student Learning Outcomes:}

The student with $70 \%$ or higher on the project will:

1. Assess and calculate the conduit size utilizing the charts and the formulas provided herein to answer the project question within the parameters given.

2. Originate the route of the conduit by using the charts herein and revising the drawing to answer the project question within the parameters stated.

\section{B. Conduit Routing Information:}

Conduit runs are one of the most overlooked duties an engineer can perform. However, like a good chef performs mise en place (French for "everything in its place"), a good engineer responsible for designing a facility spends a good deal of time and attention on conduit runs. Efficient and effective conduit runs simplify maintenance, allow for optimum placement of necessary components to the functioning of the plant or factory, and prevent conductors and cabling from causing impediments to employees performing their daily duties. Good conduit runs are invisible; awkward or badly laid conduit is like a pebble in the shoe, always there and annoying everyone who must deal with it. 
There are several questions an engineer must answer before starting a conduit run design. What are the environmental aspects of the area? How many conductors will the conduit contain? Is the conduit going to be installed above or below ground? What type of conduit does the customer prefer? Once these answers are available, the engineer can start the conduit design.

The first step in designing a conduit run is sizing the conduit. This may seem straightforward; however, there are several guidelines that the engineer must be aware of. First, calculating the conduit fill is not just calculating the inner area of the conduit. Second, the NEC and other client specific documentation may differ on how much the engineer can fill a conduit. Most facilities adhere to the $40 \%$ rule, meaning the useable conduit space is $40 \%$ of the total area of the cross section of the conduit. This guideline is in place mostly to facilitate the installation of conductors in the conduits. If an engineer were to completely fill a conduit the friction of the conductor upon the interior of the conduit would prevent the conductors from being pulled through.

Like conductor, conduit comes in a variety of sizes and materials; there is nonmetallic conduit, metallic conduit, and coated conduit. The sizes range from $1 / 4$ inch to an excess of 4 inches. The trade sizes usually are measured ever quarter inch of size. See Table 2.1 below. The measurement that the engineer will be most interested in for conduit sizing in this table is the inside diameter, this measurement will be used to determine the area inside the conduit. 
Table 2.1 - Electrical Metallic Tubing - Steel (Weights and Dimensions)[7]

\begin{tabular}{|c|c|c|c|c|c|c|c|c|c|c|}
\hline \multirow{2}{*}{ Code } & \multirow{2}{*}{$\begin{array}{c}\text { Trade } \\
\text { Size }\end{array}$} & \multirow{2}{*}{$\begin{array}{c}\text { Metric } \\
\text { Designator }\end{array}$} & \multicolumn{2}{|c|}{$\begin{array}{l}\text { Weights } \\
10 \text { Units Lengths }\end{array}$} & \multicolumn{2}{|c|}{$\begin{array}{c}\text { Outside } \\
\text { Diameter (1) }\end{array}$} & \multicolumn{2}{|c|}{$\begin{array}{c}\text { Inside } \\
\text { Diameter (2) }\end{array}$} & \multicolumn{2}{|c|}{ Wall Thickness } \\
\hline & & & lb. & kg. & in. & $\mathrm{mm}$. & in. & $\mathrm{mm}$. & in. & $\mathrm{mm}$. \\
\hline C-E00050 & $1 / 2^{\prime \prime}$ & 16 & 30 & 13.6 & 0.706 & 17.93 & 0.622 & 15.80 & 0.042 & 1.07 \\
\hline C-E00075 & $3 / 4^{\prime \prime}$ & 21 & 46 & 20.9 & 0.922 & 23.42 & 0.824 & 20.93 & 0.049 & 1.24 \\
\hline C-E00100 & $1^{\prime \prime}$ & 27 & 67 & 30.4 & 1.163 & 29.54 & 1.049 & 26.64 & 0.057 & 1.45 \\
\hline C-E00125 & $11 / 4^{\prime \prime}$ & 35 & 101 & 45.8 & 1.510 & 38.35 & 1.380 & 35.05 & 0.065 & 1.65 \\
\hline C-E00150 & $11 / 2 "$ & 41 & 116 & 52.6 & 1.740 & 44.20 & 1.610 & 40.89 & 0.065 & 1.65 \\
\hline C-E00200 & $2^{\prime \prime}$ & 53 & 148 & 67.1 & 2.197 & 55.80 & 2.067 & 52.50 & 0.065 & 1.65 \\
\hline C-E00250 & $21 / 2 "$ & 63 & 216 & 98.0 & 2.875 & 73.03 & 2.731 & 69.37 & 0.072 & 1.83 \\
\hline C-E00300 & $3 "$ & 78 & 263 & 119.3 & 3.500 & 88.90 & 3.356 & 85.24 & 0.072 & 1.83 \\
\hline C-E00350 & $31 / 2 "$ & 91 & 349 & 158.3 & 4.000 & 101.60 & 3.834 & 97.38 & 0.083 & 2.11 \\
\hline C-E00400 & $4 "$ & 103 & 393 & 178.3 & 4.500 & 114.30 & 4.334 & 110.08 & 0.083 & 2.11 \\
\hline
\end{tabular}

Using the previous example, from the conductor sizing module, calculate the conduit size. The circuit requires five $350 \mathrm{kcmil}$ conductors. The area of a $350 \mathrm{kcmil}$ conductor from Table 1.2 is .5202 square inches. The circuit requires that the engineer runs 5 of these conductors.

Total area of the current carrying conductors $=(5)(.5202)=2.601$ square inches.

The diameter of the largest conduit on the table is 4.334 inches, and so the inner area of this conduit must be:

$$
A=\pi r^{2}
$$

In the equation above $A$ is area, and $r$ is the radius of the circle.

$$
r=d / 2
$$

In the equation above $r$ is the radius of the circle and $d$ is the diameter of the circle.

$$
A=\pi\left(\frac{d}{2}\right)^{2}
$$


So, for this example:

$$
\begin{aligned}
& A=\pi\left(\frac{4.334}{2}\right)^{2} \\
& A=7.38 \text { inches }^{2}
\end{aligned}
$$

Also, remember that the engineer can only use $40 \%$ of the overall inner area of the conduit.

$$
\begin{array}{r}
A_{\text {Use }}=.4 \mathrm{~A} \\
A_{\text {Use }}=.4(7.38) \\
A_{\text {Use }}=2.952 \text { inches }^{2}
\end{array}
$$

As the engineer can see, above, to run the five $350 \mathrm{kcmil}$ conductors requires a four inch conduit.

There are several types of conduit utilized for different environmental conditions. These types can be separated into two main categories: metallic and non-metallic conduit. Metallic conduit can be even further broken down into ridged and bendable types. In addition, there are even coated conduits (as previously mentioned) for highly corrosive environments.

To make some of the advanced geometry that is needed to run some conduit there are several fittings that need to be incorporated. Some of these fittings will be introduced here. The simplest and one of the most commonly used, fitting is the "LB" (left bend) or "RB" (right bend). This fitting, shown below in Figure 2.1, turns the conduit to a right angle either to the left or the right depending on how the electrician installs the fitting. 
The LB in Figure 2.1 is a ridged metallic type fitting. These have to be specified with the seal and the plate.

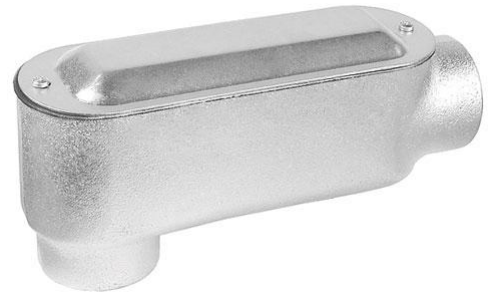

Figure 2.1 - LB conduit fitting [8]

Another type of fitting is an Expansion Joint; see Figure 2.2, which must be placed on very long straight sections of conduit to allow expansion and contraction of the length without damaging the conduit or conductor therein. [9]

Another conduit fitting crucial to any understanding of run construction is the conduit seal. Conduit seals must be placed at all area classification boundaries, see Figure 2.3.These fittings are also used when conduit enters an electrical enclosure in a classified area. [9] There are many more conduit fitting types that connect to make any shape that an engineer can design, however the mentioned are the most commonly used in the power and controls industry.

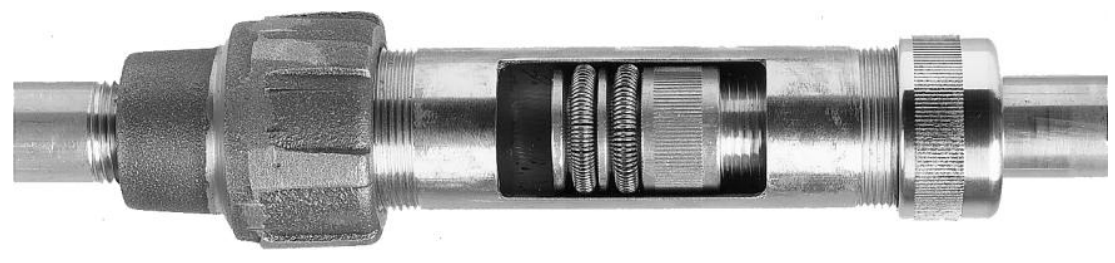

Figure 2.2 - Eaton's Patented Design Expansion Joint 


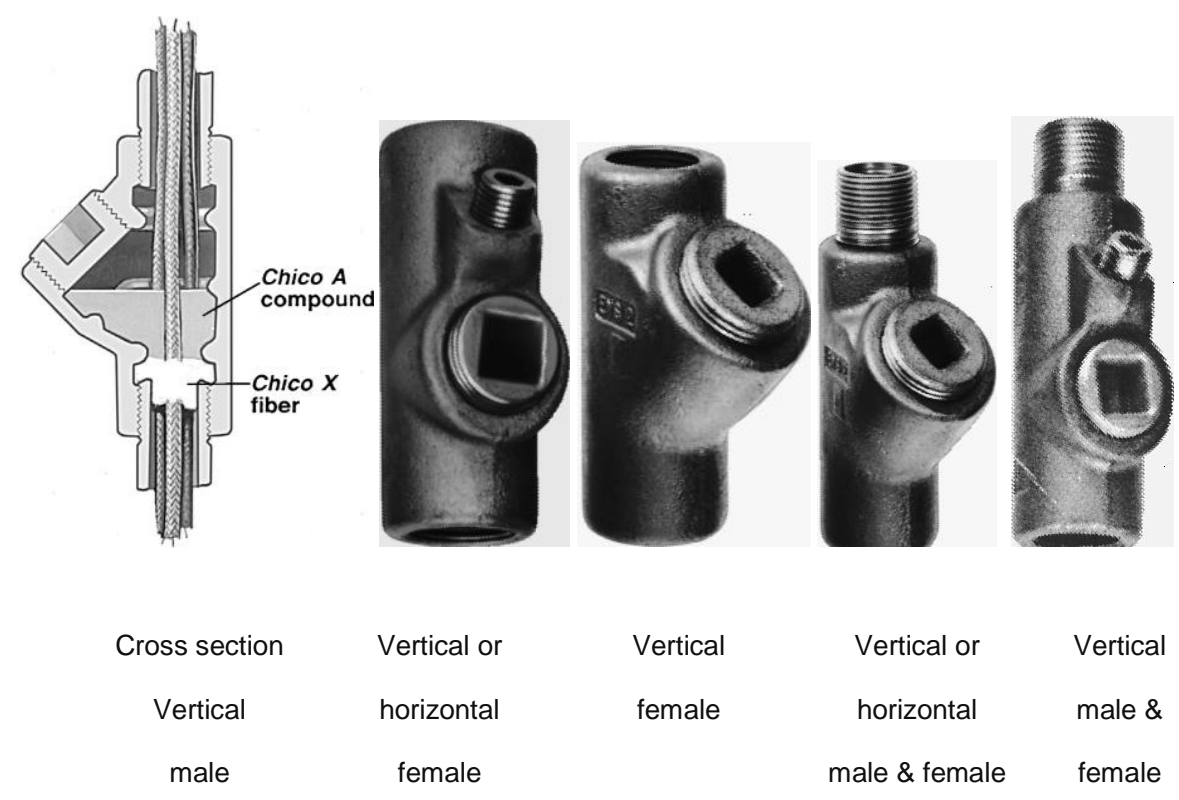

Figure 2.3 - Conduit Seal

Additionally, the engineer must remember when running conduit that there cannot be more than 180 degrees of bend in any run of conduit. This rule makes it possible for the electricians that have to install the conductor to pull it though the conduit with little trouble. Additionally, while the NEC states that the conductor pulled thought the conduit cannot fill more than forty percent of the area of the conduit, there are some facilities that will only allow the conduit fill to be 25 percent. The best way to run conduit is in the straightest and shortest way possible. This may seem obvious, but when the engineer must contend with equipment in place, structural limitations and customer requirements this is a design paradigm that can be easily forgotten. 


\section{Module 2 Design Project Conduit Design:}

Look at the piping drawing provided, what size conduit will be needed if run A must hold $2 \# 8$ and $3 \# 1$ conductors, run B must hold 6 \#12 conductors and run $\mathrm{C}$ must hold 2 \# 8 and 3 \#10 conductors? All of the conductors must withstand $165^{\circ} \mathrm{F}$. On the drawing plan the best route for the conduit. 


\section{Module III- Piping and Instrumentation Diagram}

\section{A. Student Learning Outcomes:}

The student with $70 \%$ or higher on the project will:

1. Choose the correct symbology utilizing the charts provided herein to answer the project question within the parameters given.

2. Originate a sketch of the measurement system by using the charts herein to answer the project question within the parameters stated.

3. Decipher the symbols presented by completing the oral in-class activity.

\section{B. Piping and Instrumentation Information:}

The first awareness that an engineer must have about piping and instrumentation

diagrams (P\&IDs) is that they are purely schematic. A pipe may not show any bends when going from one place to another on the drawing or diagram; but when it is traced in the field it may meander around the plant before reaching the destination.

Secondly, there is no set scale for a piping and instrumentation diagram. Two tanks could be shown the same size on the diagram and be very different volumes in the field. For electrical engineers the most important symbology is the representations for the instruments connected to the tanks and pipes. 
There are also different lines for different types of control fluids. For example, hydraulic control lines are represented with a dashed line. There are different frames around instruments to tell the engineer if the instrument is in a control room or actually on the pipe. Additionally, the shape of an instrument tells the engineer what type of instrument is shown. An example of some common symbols for P\&IDs can be seen in Figure 3.1.

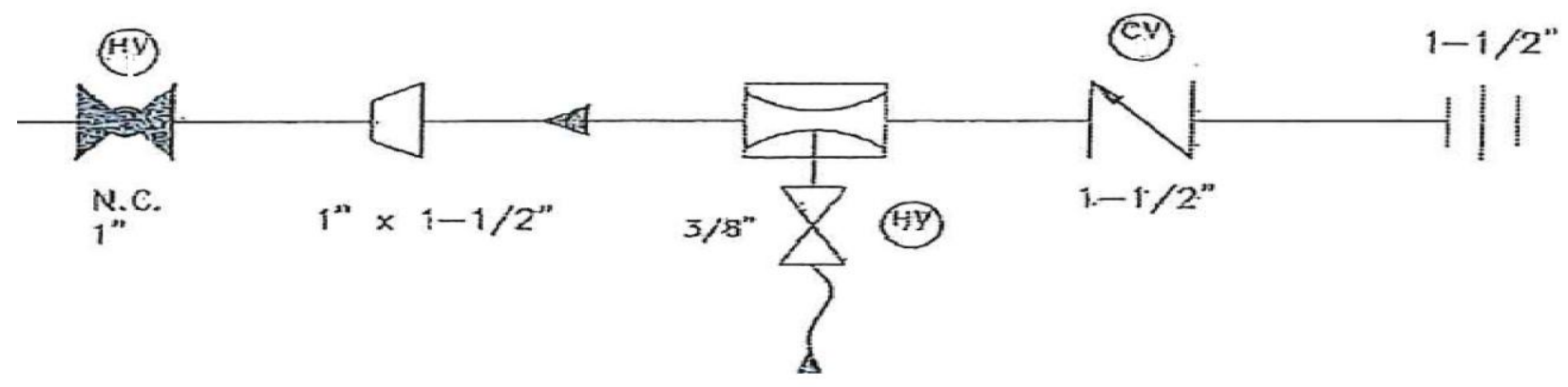

Figure 3.1- Sample P\&ID Section

The charts below show samples of the different symbols that can be encountered on a P\&ID. The first step to interpreting these symbols is comprehending how to use the standard lettering table. There are some letters that are reserved. These are seen in Table $3.1[10]$. 
Table 3.1- Reserved Letters for P\&ID Drawings[10]

\begin{tabular}{|c|c|c|c|c|c|}
\hline & \multicolumn{2}{|c|}{ First letters (1) } & \multicolumn{3}{|c|}{ Succeeding letters (15) } \\
\hline & Column 1 & Column 2 & Column 3 & Column 4 & Column 5 \\
\hline & $\begin{array}{c}\text { Measured/Initiating } \\
\text { Variable }\end{array}$ & $\begin{array}{l}\text { Variable } \\
\text { Modifier }\end{array}$ & $\begin{array}{l}\text { Readout/Passive } \\
\text { Function }\end{array}$ & $\begin{array}{l}\text { Output/Active } \\
\text { Function }\end{array}$ & $\begin{array}{l}\text { Function } \\
\text { Modifier }\end{array}$ \\
\hline A & Analysis & & Alam & & \\
\hline $\mathbf{B}$ & Eumer, Combustion & & User's Choice & User's Choice & User's Choice \\
\hline c & User's Choice & & & Contral & Close \\
\hline D & User's Choice & Diflerence, Diflerentis, & & & Deviafien \\
\hline $\mathbf{E}$ & Voltage & & Sensor, Pimary Element: & & \\
\hline$F$ & flow, Flow Rate & Rafio & & & \\
\hline$G$ & User's Choice & & $\begin{array}{l}\text { Gass, Gauge, Viewing } \\
\text { Device }\end{array}$ & & \\
\hline H & Hend & & & & High \\
\hline $\mathbf{1}$ & Current & & holicale & & \\
\hline$J$ & Power & & Sean & & \\
\hline K & Trme, Schedule & Time Rate of Change & & Contral Stafien & \\
\hline $\mathrm{L}$ & Level & & Light & & Low \\
\hline $\mathbf{M}$ & User's Choice & & & & Madde, Intermedists \\
\hline $\mathbf{N}$ & User's Choice & & User's Choice & User's Choice & User's Choice \\
\hline 0 & User's Choice & & Orifice, Restricjion & & Open \\
\hline $\mathbf{P}$ & Pressure & & Point (Test Connection) & & \\
\hline Q & Quantly & Integrate, Totalize & htegrate, Todalize & & \\
\hline $\mathbf{R}$ & Rasiation & & Record & & Run \\
\hline s & Speed, Frequency & Safety & & Switch & Slop \\
\hline $\mathbf{T}$ & Temperature & & & Transmit & \\
\hline $\mathbf{u}$ & Multivariacle & & Mittituncfion & Multituncion & \\
\hline $\mathbf{v}$ & \begin{tabular}{|l|} 
Vibration, Mechanical \\
Analysis \\
\end{tabular} & & & Valve, Damper, Louver & \\
\hline $\mathbf{w}$ & Weight, Foroe & & Well, Probe & & \\
\hline$x$ & Unclassified & X-axis & $\begin{array}{l}\begin{array}{l}\text { Accessory Devices } \\
\text { Undassfied }\end{array} \\
\end{array}$ & Undassfied & Undassfied \\
\hline$Y$ & Event State, Presence & $Y$-axis & & Auxilisy Devioes & \\
\hline$z$ & Postion, Dimension & \begin{tabular}{|l} 
Zaxis $\quad$ Safety \\
hstrumemed System
\end{tabular} & & $\begin{array}{l}\text { Driver, Actuator, Unclassified } \\
\text { fnal control element }\end{array}$ & \\
\hline
\end{tabular}


As an example of how to read this chart, if a P\&ID has a symbol on it that is annotated with "PI" it from column 1 "P" stands for pressure and from column 3 "I" stands for an indicator. So the symbol is representing a pressure indicator, this is probably not a glass gauge in the field but is more likely to be a digital readout. If the letters had been "PG" it would have definitely been a gauge in the field measuring pressure.

Now that the lettering on P\&ID drawings has been demonstrated, the next topic for discussion is the different types of "bubbles" that can be around the letters and their meanings. These symbols can be seen in Table 3.2. In row one the instrument is located in the field, usually near the process that it is measuring. In the next row the instrument is visible in a main central control screen usually separate from the instrument and process that it is measuring. In row three of this table the readout of the instrument is in a separate location from the instrument but it is also not in a position to be read normally by the operator. Row 4 of Table 3.2 this readout is visible by the operator but not on a primary panel. The last row denotes that the instrument readout is located in a field cabinet and is not readily visible. Looking now at the columns of Table 3.2, the first column (A) is the operators primary readout option. Column B is the alternate readout if the environment of the facility requires different safety options. Column $\mathrm{C}$ denotes that this readout is in software instead of a physical gauge. The discrete instrument bubble tells the reader that this instrument is not connected into the main control room; it is a standalone instrument. 
Table 3.2- Instrumentation Device and Function Symbols[10]

\begin{tabular}{|c|c|c|c|c|c|}
\hline \multirow[b]{3}{*}{ No. } & \multicolumn{2}{|c|}{$\begin{array}{l}\text { Shared display, } \\
\text { Shared control }\end{array}$} & \multirow[t]{2}{*}{ c } & \multirow[t]{2}{*}{ D } & \multirow[b]{3}{*}{ Location \& accessibility } \\
\hline & A & B & & & \\
\hline & $\begin{array}{c}\text { Primary } \\
\text { Choice } \\
\text { or } \\
\text { Basic } \\
\text { Process } \\
\text { Control } \\
\text { System }\end{array}$ & \begin{tabular}{|c|} 
Alternate \\
Choice \\
or \\
Safety \\
Instrumented \\
System
\end{tabular} & $\begin{array}{l}\text { Computer } \\
\text { Systems } \\
\text { and } \\
\text { Software }\end{array}$ & Discrete & \\
\hline 1 & & & & & $\begin{array}{l}\text { - Located in field. } \\
\text { - Not panel, cabinet, or console mounted. } \\
\text { - Normally operator acoessible. }\end{array}$ \\
\hline 2 & & & & & $\begin{array}{l}\text { - Localed in or on front of central or main panel or } \\
\text { console. } \\
\text { - Visible on front of panel or on video display. } \\
\text { Normally operator acoessible at panel front or console. }\end{array}$ \\
\hline 3 & & & & & $\begin{array}{l}\text { - Located in rear of central or main panel. } \\
\text { - Nocated in cabinet behind panel. } \\
\text { - Not visible on front of panel or on video display. }\end{array}$ \\
\hline 4 & & & & & $\begin{array}{l}\text { - Localed in or on front of secondary or local panel or } \\
\text { console. } \\
\text { - Visible on front of panel or on video display. }\end{array}$ \\
\hline 5 & & & & & $\begin{array}{l}\text { - Localed in rear of secondary or local panel. } \\
\text { - Nocated in field cabinet. } \\
\text { - Not normally operator accessible at panel or console. }\end{array}$ \\
\hline
\end{tabular}

Using the example from above (the "PI"), if this pressure indicator is located on the vessel that it is measuring, the symbol to use would have no lines through it. If it is a primary readout in the control room, it would have the symbol in column A, row 1 . If this indicator was read only in the field, it would be the symbol column D row 1. (See Figure 3.2) 


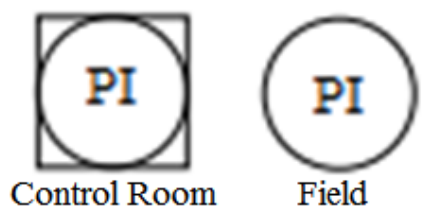

Figure 3.2-Divice and Function Symbol Examples

The next issue is how to connect the different instruments together. The first part of this process is in Table 3.3. This table shows how an engineer should interconnect different elements. Table 3.3 shows these interconnections using a generic bubble but that bubble can be replaced by any of the bubble types shown in Table 3.2. Rows one and two show the format of an element and transmitter, respectively. Next row 3 shows a close coupled transmitter and element combination, this means that the transmitter and element are physically attached to one another if not the same piece of equipment. Row four of Table 3.3 shows the interconnection between the element and a remote transmitter. These are the interconnections most used in the power and controls industry. Table 3.4 shows the types of connections available. These connections replace the solid line that Table 3.3 shows. The more common types of connections that are used are electric, hydraulic, and pneumatic. 
Table 3.3 - Instrument Interconnections[10]

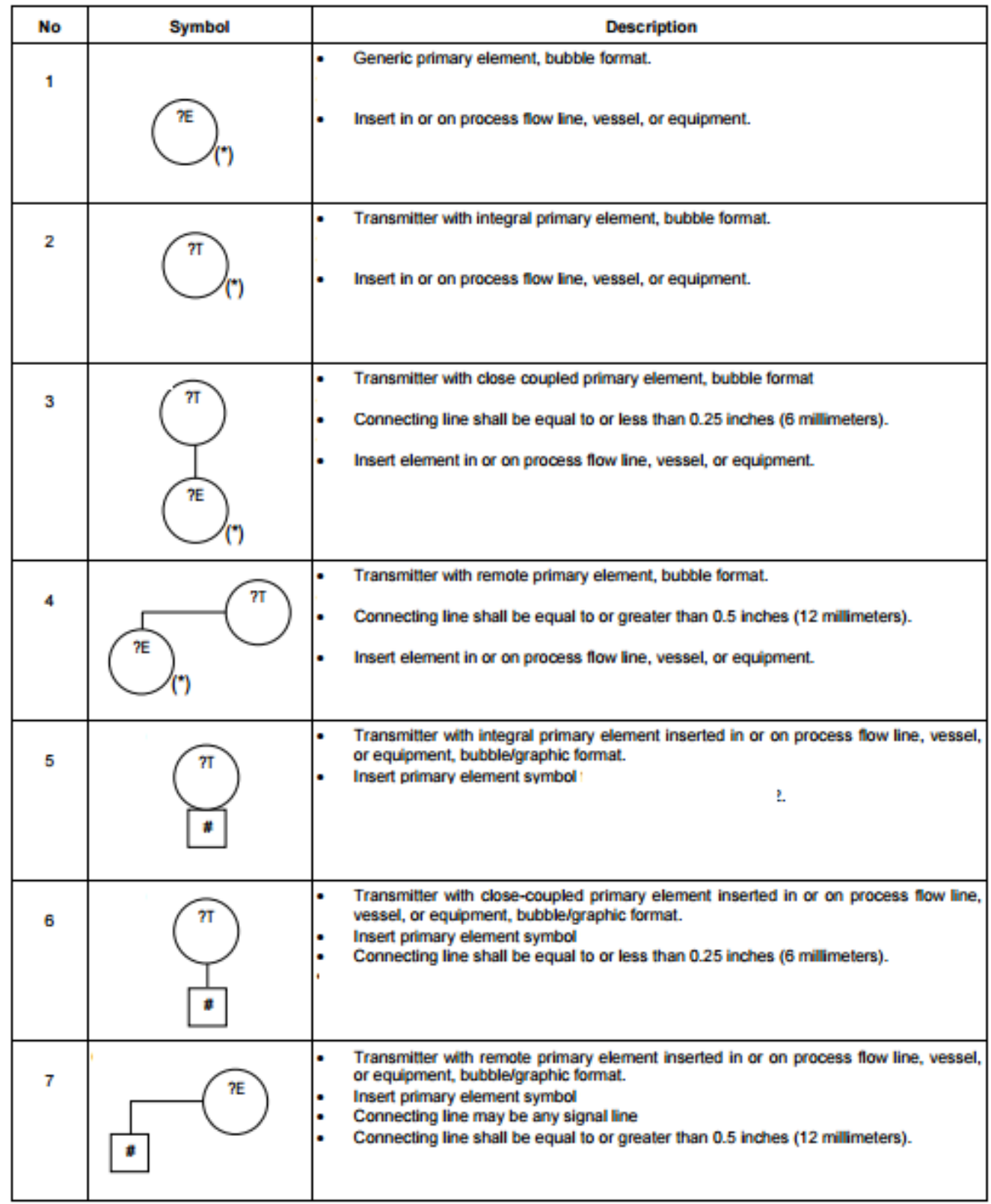


Table 3.4- Instrument to Instrument Connections[10]

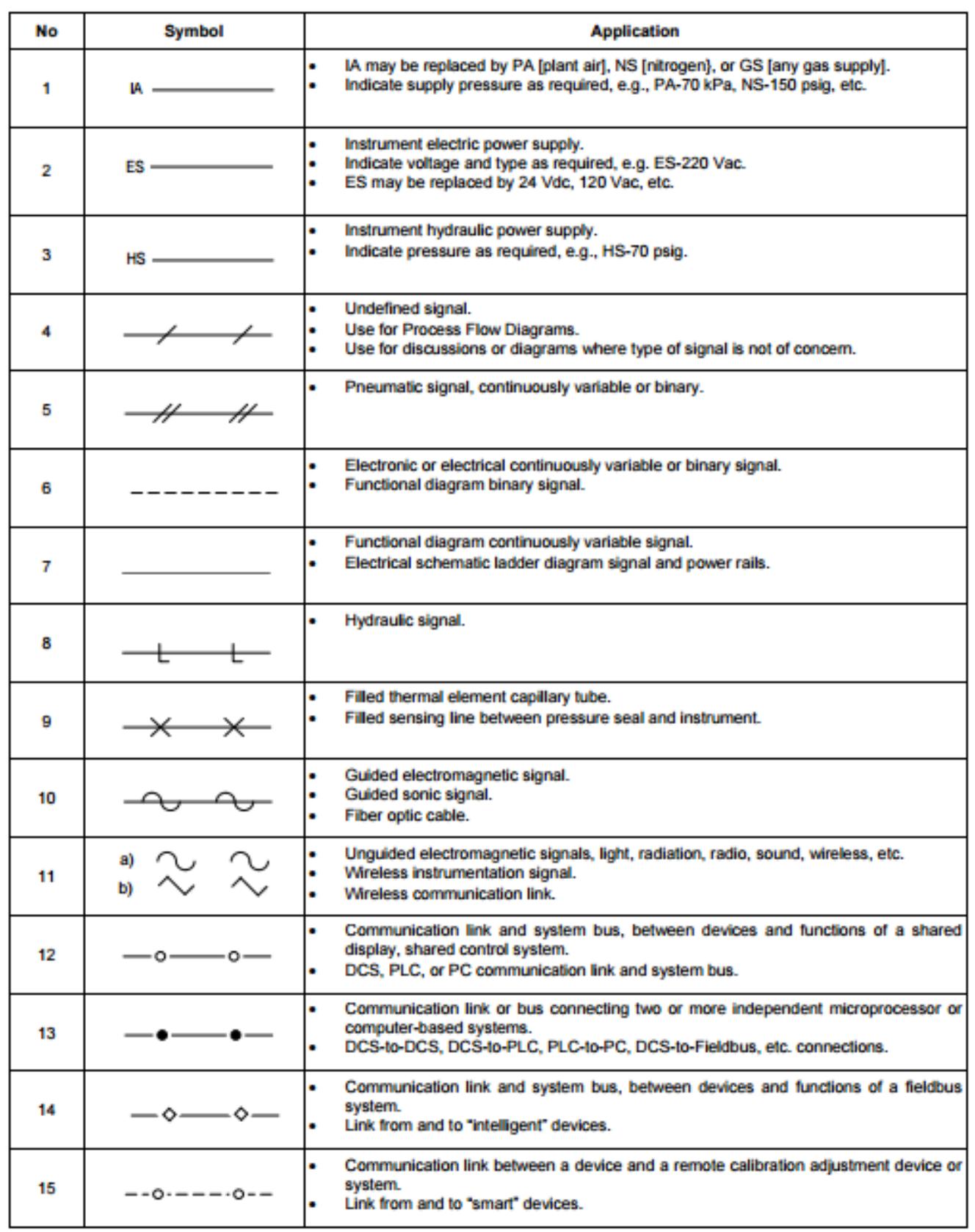


Instead of always using the solid line as shown in Table 3.3 the lines in Table 3.4 can be used to further explain how instrumentation is interconnected. For example, a temperature element connected to a temperature transmitter by an electrical connection would look like Figure 3.3.

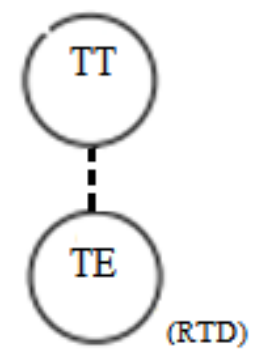

Figure 3.3-Temperature Element Connected to Temperature Transmitter

The (RTD) in the lower right corner of Figure 3.3 denotes the type of element this bubble represents. This tells the engineer that it is a "Resistance Temperature Detector". The element types can be found in Table 3.5. This table divides the different elements into process measurement such as flow level and pressure. Each section has various terms for elements associated with that particular process measurement. 
Table 3.5 -P\&ID Measurement Notations[10]

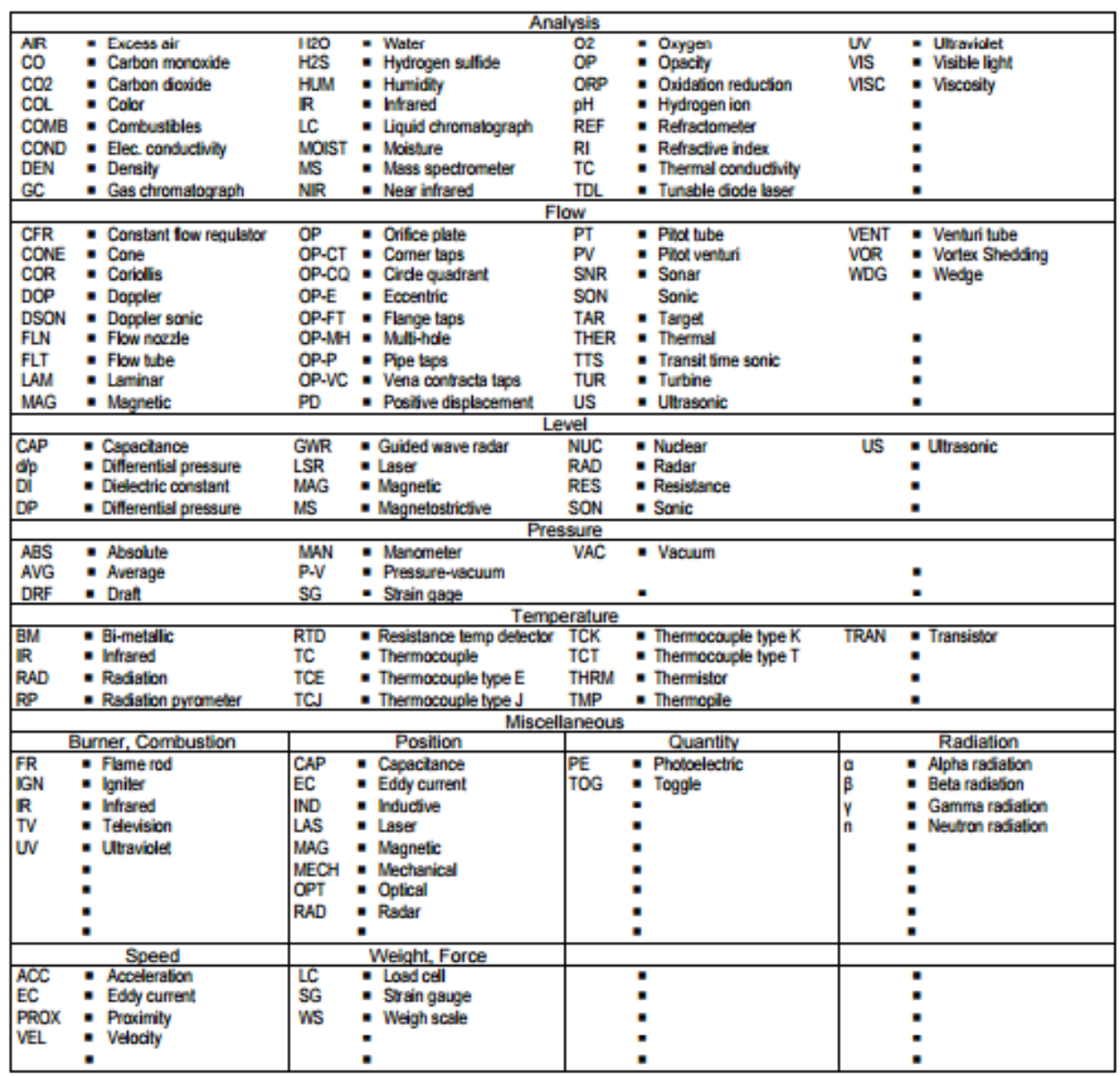

The last set of identifiers that an engineer needs to complete a P\&ID is the final control element symbols. These symbols can be found in Table 3.6. They are what the elements and transmitters control to stay in the programmed range. These can be as simple as a two way valve (row one) or as complex as a multi-way solenoid valve (row 19). 
Table 3.6 - Final Control Elements[10]

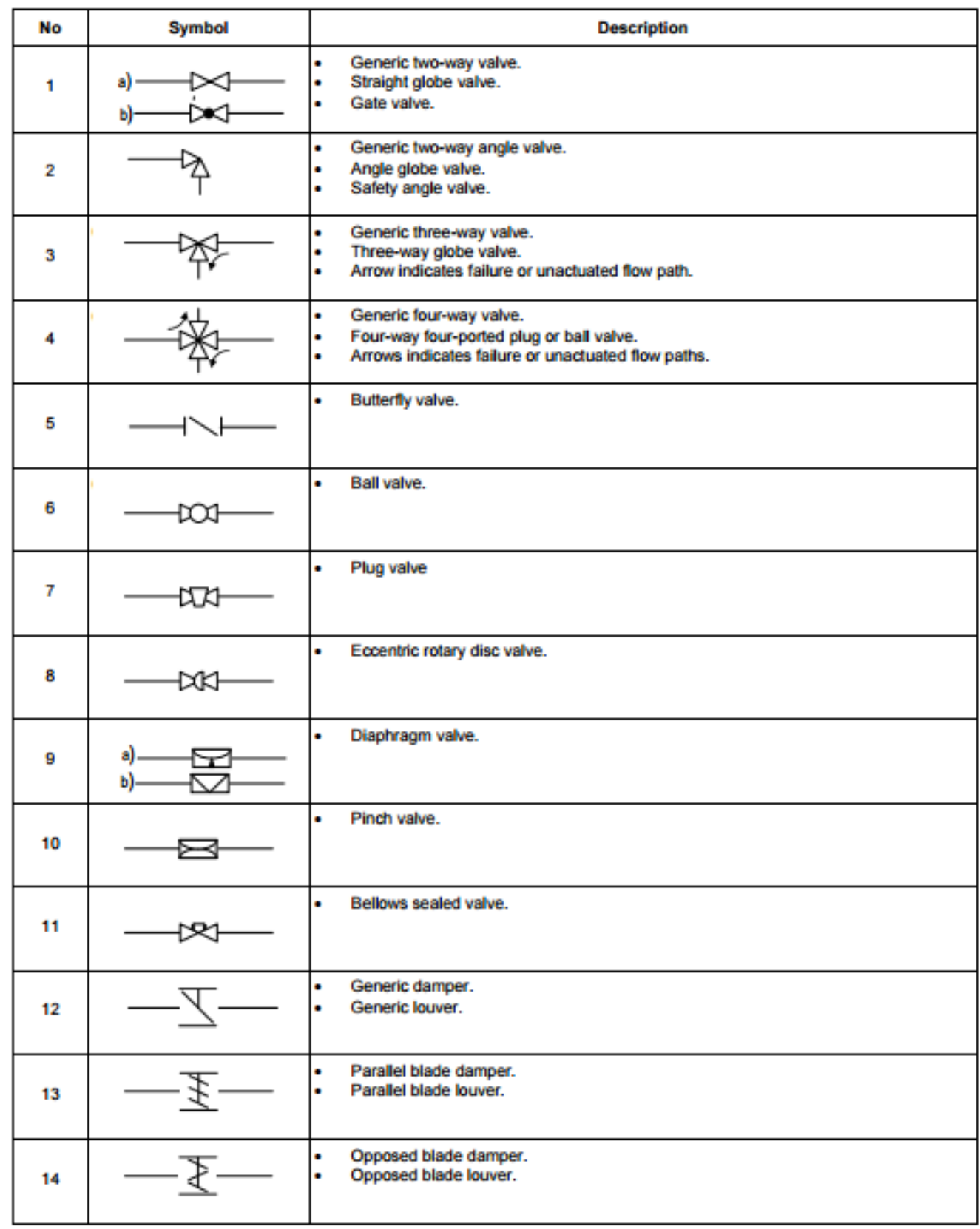


Table 3.6 - Final Control Elements Cont.[10]

\begin{tabular}{|c|c|c|}
\hline No & Symbol & Description \\
\hline & & Two-way on-off solenoid valve. \\
\hline 16 & & Angle on-off solenoid value. \\
\hline 17 & & $\begin{array}{l}\text { - Three-way on-off solenoid valve. } \\
\text { - } \quad \text { Arrow indicates de-energized flow path. }\end{array}$ \\
\hline 18 & & $\begin{array}{l}\text { - Four-way plug or ball on-off solenoid valve. } \\
\text { - Arrows indicales de-energized flow paths. }\end{array}$ \\
\hline 19 & & $\begin{array}{l}\text { - Four-way five-ported on-off solenoid valve. } \\
\text { - Arrows indicales de-energized flow paths. }\end{array}$ \\
\hline 20 & & - Permanent magnet variable speed coupling. \\
\hline 21 & & - Electric motor. \\
\hline
\end{tabular}

\section{Module 3 Design Project P\&ID:}

Design a system for a tank that includes pressure, temperature and level indicators that are read in the control room. This system should also have a redundant system of measurements on the tank. Sketch the P\&ID on the given worksheet; make sure to choose the correct symbology. 


\section{Module IV-Arc Flash Calculations}

\section{A. Student Learning Outcomes:}

1. The student with $70 \%$ or higher on the project will evaluate and assess the energy of an arc flash event by utilizing the formulas and tables herein and answering the question posed.

\section{B. Arc Flash Calculations:}

On October $8^{\text {th }}, 2015$, six employees of the Grant County Public Utility District were about to end their workdays at the Priest Rapids Dam outside of Richland, Washington. There was just one problem: Generator P08, one of ten located in the hydroelectric facility, was not functioning properly. In a hurry to get their duties finished, the employees decided to cut corners. Ultimately, the circuit breaker controlling P08 was "manually slow closed while energized with unit P08 in a stopped position". This caused an arc within the breaker, resulting in an explosion. [11]As a result of the explosion, two workers suffered severe burns and three others suffered lesser injuries. Arch flash is no different than a lightning strike. Before beginning to calculate arc flash hazards the engineer first has to understand what an arc flash actually is; "Arc flash is a dangerous condition associated with the unexpected release of tremendous amount of energy caused by an electric arc within electrical equipment. This release is in the form of intense light, heat, sound, and blast of arc products that may consist of vaporized components of enclosure material - copper, steel, or aluminum. Intense sound 
and pressure waves also emanate from the arc flash, which resembles a confined explosion.”[12]

There are two primary forms of failure which may result in an arc flash, breakdowns of insulation and maintenance personnel error. Insulation failure or breakdown may manifest in a variety of ways. The two foremost examples are surface tracking and age breakdown or treeing (see Figure 4.1). Maintenance personnel error such as working on a piece of electrical equipment without de-energizing it, or unracking a breaker while the breaker is closed and the lines are hot. It would surprise some engineers that on average one person is electrocuted at work every day in the United States.[12, 13]

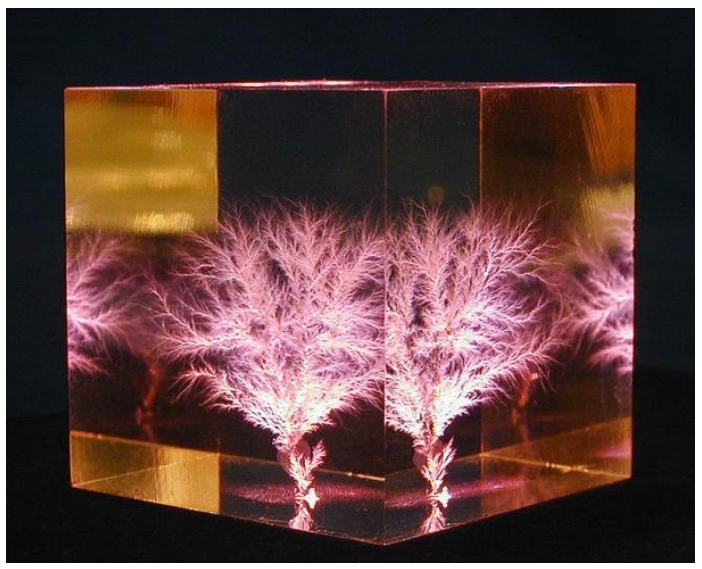

Figure 4.1 - Electrical Treeing in Polymethyl Methacrylate[14]

Arc burns are only one of the hazards of an arc flash event. Other hazards include: “electrical shock, molten metal projectiles, blast and pressure waves, intense light, intense sound, fire, effect of strong magnetic fields and plasma...toxic gases and vapors."[12] While a fault is happening, the terminals on the equipment can reach 
temperatures exceeding $35,000^{\circ} \mathrm{F}$. This literally vaporizes the metal, ionizing the air and creating the path for the arc. The amount of energy absorbed by the human body while exposed to non-alternating current is given by the following equation.

$$
S_{B}=\left(I_{B}\right)^{2} t_{s}
$$

In the equation above $S_{B}$ is the energy absorbed by the body $\left[\mathrm{A}^{2} \mathrm{~s}\right], I_{B}$ is the magnitude of the current [A], and $t_{s}$ is the time that the body is exposed to the current [s]. "It is recognized that to construct an accurate mathematical model of the arcing phenomena is rather impractical. This is because of the spasmodic nature of the fault caused by arc elongation blowout effects, physical flexing of cables and bus bars under short circuits, possible arc reignition [sic], turbulent flow of plasma, and high temperature Gradients (the temperature at the core being of the order of $25,000 \mathrm{~K}$, while at the arc boundary, of the order of $300-2000 \mathrm{~K})$.’'[12] However, there have been several attempts to get a close approximation of the arc flash current. First, Ralph Lee's and NFPA Equations, next IEEE 1584 Guide Equations, finally using a physics based circuit model.

Ralph Lee's and NFPA equations are the first to be discussed the first calculation is the maximum power in a three phase fault, given by the equation below.

$$
P=M V A_{b f}(0.707)^{2}
$$


In the above equation $P$ is power $[\mathrm{MW}]$ and $M V A_{b f}$ is the bolted fault mega volt ampere, a characteristic of the transformer. The next calculation that is made is the distance of the person from the fault without injury, in this case keeping the skin under $80^{\circ} \mathrm{C}$.

$$
D_{c}=\sqrt{2.65\left(M V A_{b f}\right) t}
$$

In the above equation $D_{c}$ is the distance from the arc [ft], and $t$ is the time exposed to the $\operatorname{arc}[\mathrm{s}]$. After this calculation the engineer can calculate the incident energy, see the equation below for greater than 600 volts.

$$
E=\frac{(793)(F)(V)\left(t_{A}\right)}{D^{2}}
$$

In the above equation $\mathrm{E}$ is the incident energy [kW], $\mathrm{F}$ is bolted fault short - circuit current $[\mathrm{kA}], \mathrm{V}$ is the system phase to phase voltage $[\mathrm{kV}], \mathrm{D}$ is the distance from the arc [inches], and $t_{A}$ is the time the arc exists. These equations are useful, but they do have some deficiencies. Notably, the calculations become more conservative the higher the voltage gets. Thus, the energy calculated may be greater than the actual incident energy. Another way of calculating arc flash incident energy is the IEEE 1584 Guide Equations.

The IEEE equations are applicable for electrical systems operating anywhere between 208 volts and 15 kilovolts, three phase, 50 or 60 hertz. The available range of short circuit current is 700 to106,000 amps, and conductor gap 13 to152 millimeters. The Ralph Lee's and NFPA equations above are for operating voltages under 1000 volts. 


$$
\begin{aligned}
\log \left(I_{a}\right)=K & +0.662 \log \left(I_{b f}\right)+0.0966 V+0.000526 G+0.5588 V \log \left(I_{b f}\right) \\
& -0.00304 G \log \left(I_{b f}\right)
\end{aligned}
$$

In the above equation $I_{a}$ is the arcing current $[\mathrm{kA}], \mathrm{K}$ is a constant -0.153 for open air arcs, -0.097 for arc in a box, $I_{b f}$ is the bolted three - phase fault rms symmetrical current [kA], $\mathrm{G}$ is the conductor gap [mm] value that can be found in Table 4.1, and $V$ is the system voltage $[\mathrm{kV}] .[12]$

Table 4.1 - Classes of Equipment and Typical Bus Gaps[12]

\begin{tabular}{lc}
\hline Classes of Equipment & Typical Bus Gaps (mm) \\
\hline 15-kV switchgear & 153 \\
5-kV switchgear & 104 \\
Low voltage switchgear & 32 \\
Low voltage MCCs and panel boards & 25 \\
Cable & 13 \\
Other & Not required \\
\hline
\end{tabular}

If the voltage of the system is greater than 1000 volts then the following equation is used.

$$
\log \left(I_{a}\right)=0.00402+0.983 \log \left(I_{b f}\right)
$$

This expression can be used in an open air arc calculation as well as a calculation in a box. Finally, the engineer can calculate the incident energy with the following equation based on an arc duration of .2 seconds. Thus one arrives at the following equation:

$$
\log \left(E_{n}\right)=K_{1}+K_{2}+1.081 \log \left(I_{a}\right)+0.0011 \mathrm{G}
$$


In the above equation $E_{n}$ is the normalized for distance and time incident energy $\left[\mathrm{J} / \mathrm{cm}^{2}\right]$, $K_{1}$ is a constant -0.792 for open air and -0.555 for arcs in a box, $K_{2}$ is also a constant 0 for ungrounded and high resistance grounded systems and -0.113 for grounded systems, $I_{a}$ is the arc current $[\mathrm{kA}]$, and $G$ is the conductor gap [mm]. Converting from normalized values gives the calculation below:

$$
E=4.184 C_{f} E_{n}\left(\frac{t}{0.2}\right)\left(\frac{610^{x}}{D^{x}}\right)
$$

In the equation above $E$ is the incident energy $\left[\mathrm{J} / \mathrm{cm}^{2}\right], C_{f}$ is a scaling factor 1.0 for voltages above $1 \mathrm{kV}$ and 1.5 for voltages at or below $1 \mathrm{kV}, \mathrm{t}$ is the time of the arc [s], $D$ is the distance from the arc to the human as seen in Table 4.2, $x$ is the distance exponent as given in Table 4.3. [12] 
Table 4.2 - Classes of Equipment and Typical Working Distances[12]

\begin{tabular}{lc}
\hline Classes of Equipment & Typical Working Distance (mm) \\
\hline $15 \mathrm{kV}$ switchgear & 910 \\
$5 \mathrm{kV}$ switchgear & 910 \\
Low voltage switchgear & 610 \\
Low voltage MCCs and panel boards & 455 \\
Cable & 455 \\
Other & To be determined in field \\
\hline
\end{tabular}

Table 4.3 - Factors for Equipment and Voltage Classes[12]

\begin{tabular}{llcc}
\hline System Voltage, $\mathrm{kV}$ & Equipment Type & $\begin{array}{c}\text { Typical Gap } \\
\text { between Conductors }\end{array}$ & Distance $\times$ Factor \\
\hline $0.208-1$ & Open air & $10-40$ & 2.000 \\
& Switchgear & 32 & 1.473 \\
& MCC and panels & 25 & 1.641 \\
& Cable & 13 & 2.000 \\
$>1-5$ & Open air & 102 & 2.000 \\
& Switchgear & $13-102$ & 0.973 \\
$>5-15$ & Cable & 13 & 2.000 \\
& Open air & $13-153$ & 2.000 \\
& Switchgear & 153 & 0.973 \\
& Cable & 13 & 2.000 \\
\hline
\end{tabular}

The final way to calculate arc flash that will be discussed is a mathematical model that uses a physics based approach. The circuit that will be used for these calculations is shown below in Figure 4.2.

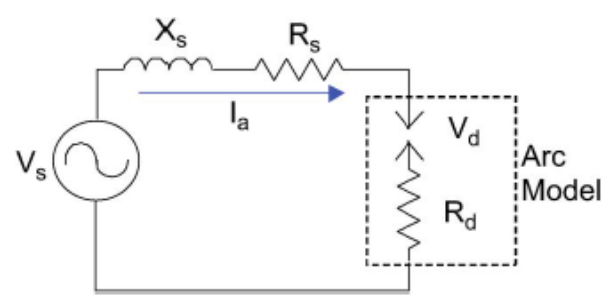

Figure 4.2 - Arc Flash circuit Model[15] 
Using Kirchhoff's laws the equation that the engineer finds is shown below.

$$
V_{s}=X_{s} I_{a}+R_{s} I_{a}+V_{d}+R_{d} I_{a}
$$

The $V_{d}+R_{d} * I_{a}$ part of this circuit is the arc voltage $V_{\mathrm{a}}$. The power in the arc is derived from the basic power equations. Two of these equations need to be added to get the total power of the arc flash. In the equations below $I$ is the current [amps], $P$ is the power [Watts], $V$ is the voltage [volts], and $R$ is the resistance [ohms]. [15]

$$
\begin{gathered}
P=V I \\
P=I^{2} R
\end{gathered}
$$

Applying these two equations the total power of the arc flash can be found by solving the following equation.

$$
P_{a}=I_{a}^{2} R_{d}+V_{d} I_{a}
$$

To find the energy in this method substitute $P_{a}$ into the IEEE 1584 Guide Equations, this gives the following equation.[15]

$$
E=C_{f} C_{e} t\left(I_{a}^{2} R_{d}+V_{d} I_{a}\right)\left(\frac{610^{x}}{D^{x}}\right)
$$

$$
\text { Where } C_{e}=0.000163 G^{2}-0.0246 G+5.835
$$

In the above equations $\mathrm{C}_{\mathrm{e}}$ is a function of the equipment gap.

In this module the student has read the importance of arc flash calculations, several ways to calculate the incident energy of an arc flash and now the student will test their knowledge while completing the following project. 


\section{Module 4 Project: Arc Flash}

Evaluate the arc flash calculations using one of the models above of $15 \mathrm{kV}$ switchgear.

The transformer is $80 \mathrm{kVA}$. The arc exists for 2 seconds and the short circuit current is 1500 A. Choose the resistance of a typical human body for the $R_{d}$. The total impedance of the line is $1.5+\mathrm{j} 0.3 \Omega$. 


\section{Module V-Area Classification}

\section{A. Student Learning Outcomes:}

The student with $70 \%$ or higher on the project will:

1. Originate a sketch of the classified area by utilizing the charts and formulas in the API 500 to answer the project question within the parameters stated.

2. Determine the size of the classified area by calculating the hazard radius utilizing correct formulas and tables herein to answer the project question.

3. Determine the class and division of the classified area by utilizing the correct charts herein to answer the project question.

\section{B. Area Classification Information:}

Engineers are often relied upon to calculate the risks involved in a particular industrial process or worksite. When these risks are miscalculated or ignored, the potential for a large scale disaster is increased immensely.

Take for example the incident that occurred at the Imperial Sugar refinery in Port Wentworth, Georgia on. The "Dixie Crystals" facility had been processing granulated sugar from raw cane sugar since 1917, when it was originally constructed by Savannah Foods and Industries, Inc. At around 7:15 pm that evening, an explosion occurred in the processing plant's conveyor belts. Due to incredibly high levels of sugar dust that had accumulated in the facility over decades of production, multiple secondary detonations 
devastated the entire complex. Fourteen people died; eight at the scene and six more from injuries sustained in the accident. Thirty six others suffered wounds significant enough to require hospitalization, ranging from burns to crippling injuries. [16]

The ultimate cause of the event was eventually found to have been relatively new steel enclosure plates that had been installed on some of the plant's conveyor belts. These enclosures lacked the necessary ventilation to allow dust to escape from the belts, which in turn allowed enough particulate matter to accumulate exceeding the minimum explosible concentration (MEC). After that concentration was achieved, it is believed that one of the bearings on the conveyors overheated, providing an ignition point for the initial explosion.[16]

The US Chemical Safety Board's final report identified that Imperial Sugar lacked a Corporate Safety Officer. This individual would have been tasked with identifying the hazards in the plant and had that person followed area classification standards, it is likely that the risks would have been properly identified and the facility would have been correctly ventilated, thus avoiding the tragedy. Imperial Sugar was ultimately fined four million dollars for their failures to properly address safety concerns at the facility. In addition, at least forty four civil suits were filed against the company by the injured workers.[16]

Area classifications are important because of this described potential for catastrophic events. Most areas have two of the three elements needed for combustion. As an example, the three components needed for an explosion are oxygen, a spark, and flammable material. Oxygen is (obviously) in almost all facilities, an electrical system 
can definitely provide the spark, and the flammable material is the fiber, dust or vapor present because of the manufacture or transfer of the product. (See Figure 5.1) Using the example of a gas pump, there is oxygen present, any fuel nozzle will have flammable vapors present if it has been used at all, and if a person has a cellular phone, a cigarette, or too much static electricity, they could provide the spark that would create an explosive environment.

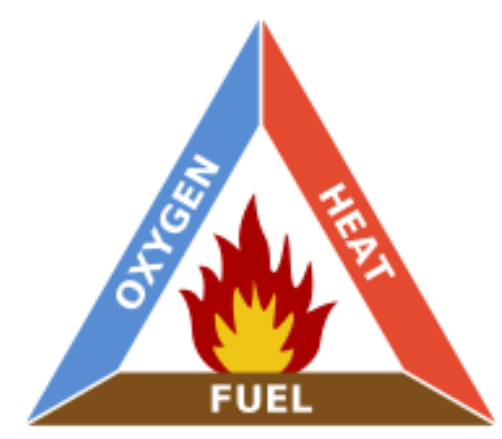

Figure 5.1 - Explosion Triangle[17]

First, one must understand the different types of areas and the different classification types. In classifying areas there are three classes and two divisions. The divisions signify when the area would be dangerous. The classes tell the engineer what type of hazard. A class one area is an area which may have flammable gasses or vapors present. This type of area can be found in everyday life such as the example of the aforementioned gasoline pump.

A class two area may have combustible dust or powder. This type of area can be found in places like flour mills, grain elevators, firework manufactories, and pharmaceutical plants. Coal fired power plants are also vulnerable to this classification. Due to high levels of particulate matter that can cause chain reactions these areas are 
generally recommended to be codified based on the particulate or gasses' autoignition flashpoint.

A class three area may have suspended flammable fibers or particles. A common scenario where this type of area may be found would be in a fabric mill. The division describes when the hazard may be present. In a division one area the hazard is present under normal operating conditions. In a division two area the hazard is only present if there is a malfunction of the system. For example a gasoline pump is a class one division two zone, meaning there could be flammable vapors present if there is a malfunction. See

Table 5.1.[18]

Table 5.1- Area Classification Table[18]

The table below summarizes the various hazardous (classified) locations.

\begin{tabular}{|c|c|c|c|}
\hline \multicolumn{4}{|c|}{ Summary of Class I, II, III Hazardous Locations } \\
\hline \multirow[t]{2}{*}{ CLASSES } & \multirow[t]{2}{*}{ GROUPS } & \multicolumn{2}{|c|}{ DIVISIONS } \\
\hline & & 1 & 2 \\
\hline $\begin{array}{c}\text { I } \\
\text { Gases, } \\
\text { vapors } \\
\text { and } \\
\text { liquids }\end{array}$ & \begin{tabular}{|l} 
A: Acetylene. \\
B: Hydrogen, etc. \\
C: Ether, etc. \\
D: Hydrocarbons, fuels, solvents, \\
etc.
\end{tabular} & $\begin{array}{l}\text { Normally explosive and } \\
\text { hazardous. }\end{array}$ & \begin{tabular}{|l} 
Not normally present in \\
an explosive \\
concentration (but may \\
accidentally exist).
\end{tabular} \\
\hline$\underset{\text { Dusts }}{\text { II }}$ & $\begin{array}{l}\text { E: Metal dusts (conductive, and } \\
\text { explosive) * } \\
\text { F: Carbon dusts (some are } \\
\text { conductive, and all are } \\
\text { explosive) * } \\
\text { G: Flour, starch, grain, } \\
\text { combustible plastic or chemical } \\
\text { dust (explosive). }\end{array}$ & $\begin{array}{l}\text { Ignitable quantities of } \\
\text { dust normally are or } \\
\text { may be in suspension, } \\
\text { or conductive dust may } \\
\text { be present. }\end{array}$ & $\begin{array}{l}\text { Dust not normally } \\
\text { suspended in an ignitable } \\
\text { concentration (but may } \\
\text { accidentally exist). Dust } \\
\text { layers are present. }\end{array}$ \\
\hline $\begin{array}{l}\text { III } \\
\text { Fibers } \\
\text { and } \\
\text { flyings. }\end{array}$ & $\begin{array}{l}\text { Textiles, wood-working, etc. } \\
\text { (easily ignitable, but not likely to } \\
\text { be explosive). }\end{array}$ & $\begin{array}{l}\text { Handled or used in } \\
\text { manufacturing. }\end{array}$ & \begin{tabular}{|l}
$\begin{array}{l}\text { Stored or handled in } \\
\text { storage (exclusive of } \\
\text { manufacturing). }\end{array}$ \\
\end{tabular} \\
\hline
\end{tabular}


There are also some other classification definitions that must be explained before the process of classification can begin. First, Class I Liquids are usually handled above flashpoint and can produce a large quantity of vapor. Crude oil is always counted as a Class I liquid. Class II Liquids are usually handled below flashpoint and produce very little vapor. Class III Liquids do not produce sufficient amounts of vapors to be considered for electrical classification. What an engineer wants to know is how large is the hazard radius. This measurement depends on two factors, release rate and the volatility of the vapor. [19]

The first step to classifying an area is determining if the area must be classified. The following question helps determine if the area should be classified. Is flammable material used, handled, or stored? If the answer to this question is yes then the area must be classified. The next step to classifying a zone is determining the volatility of the material being processed using descriptions and charts from API 500.; see Figure 5.2. 


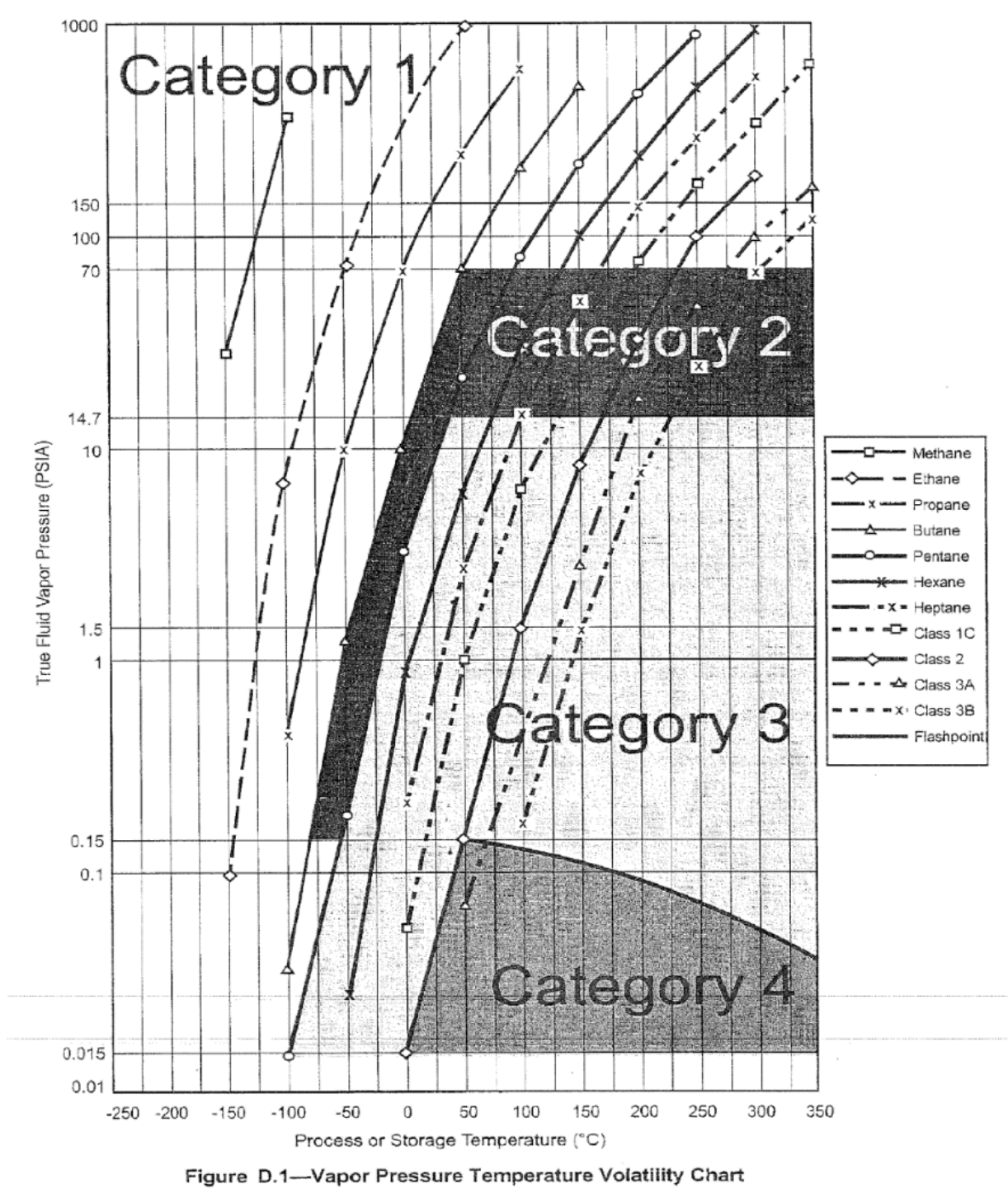

Figure 5.2 - Figure D.1 from API 500[19]

The next step to the classification process is to determine the type of source. The source could be a pump, an exhaust vent, a relief valve or another piece of equipment. Once this information is gathered the engineer must then determine the hazard radius using figures from the API 500 Appendix D. It is shown below in Table D.1 and Figure D.3- Adequately Ventilated Process Area with heavier-than-air Gas or Vapor Source Located near or above grade.[19] 
Table D.1-Pumps Handling Heavier-than-air Gases or Vapors Located in Non-enclosed Adequately Ventilated Process Areas

\begin{tabular}{|c|c|c|c|c|c|c|c|c|c|c|c|}
\hline Pumps & Category & \multicolumn{3}{|c|}{$\begin{array}{l}\text { Low Flow } \\
<100 \mathrm{gpm}\end{array}$} & \multicolumn{3}{|c|}{$\begin{array}{l}\text { Medium Flow } \\
100 \text { to } 500 \mathrm{gpm}\end{array}$} & \multicolumn{3}{|c|}{$\begin{array}{l}\text { High Flow } \\
>500 \mathrm{gpm}\end{array}$} & \multirow{2}{*}{$\leftarrow$ Pump Flow Rate } \\
\hline $\begin{array}{r}\text { Low }=<100 \mathrm{psig} \\
\text { Medium = } 100 \text { to } 500 \mathrm{psig} \\
\text { High }>500 \mathrm{psig}\end{array}$ & $\rightarrow$ & 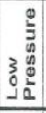 & 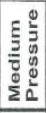 & 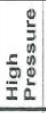 & 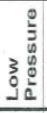 & 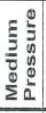 & 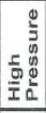 & 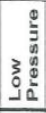 & 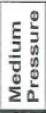 & 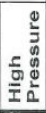 & \\
\hline \multirow{3}{*}{ Standard Pump } & 1 & 15 & 25 & 20 & 25 & 50 & 100 & 25 & 50 & 100 & \multirow{6}{*}{ Hazard Radius ft } \\
\hline & 2 & 10 & 15 & 25 & 10 & 25 & 50 & 15 & 25 & 50 & \\
\hline & 3 & 3 & 10 & 15 & 5 & 10 & 25 & 15 & 15 & 25 & \\
\hline High Technology & 1 & 5 & 10 & 15 & 5 & 10 & 25 & 10 & 10 & 25 & \\
\hline Low Seal Emissions & 2 & 3 & 5 & 10 & 3 & 5 & 10 & 5 & 10 & 10 & \\
\hline Pump & 3 & 3 & 3 & 5 & 3 & 3 & 5 & 5 & 5 & 10 & \\
\hline
\end{tabular}

\begin{tabular}{|c|c|c|c|c|c|c|}
\hline $\begin{array}{c}\text { Hazard } \\
\text { Radius } \\
(\mathrm{ft})\end{array}$ & $\begin{array}{c}\mathrm{D}_{1} \\
(\mathrm{ft})\end{array}$ & $\begin{array}{c}\mathrm{H}_{1} \\
(\mathrm{ft})\end{array}$ & $\begin{array}{c}\mathrm{D}_{2} \\
(\mathrm{ft})\end{array}$ & $\begin{array}{c}\mathrm{H}_{2} \\
(\mathrm{ft})\end{array}$ & $\begin{array}{c}\mathrm{D}_{3} \\
(\mathrm{ft})\end{array}$ & $\begin{array}{c}\mathrm{H}_{3} \\
(\mathrm{ft})\end{array}$ \\
\hline 3 & 3 & 3 & 0 & NA & 7 & 1.5 \\
5 & 5 & 5 & 0 & NA & 10 & 1.5 \\
10 & 10 & 10 & 0 & NA & 10 & 2 \\
15 & 15 & 15 & 0 & NA & 10 & 2 \\
25 & 20 & 20 & 5 & 10 & 20 & 2 \\
50 & 25 & 25 & 25 & 25 & 25 & 2 \\
100 & 25 & 25 & 25 & 25 & 50 & 2 \\
\hline
\end{tabular}

Figure 5.3- Figure D.3 from API 500 Adequately Ventilated Process Area with heavier-thanair Gas or Vapor Source Located near or above grade[19]

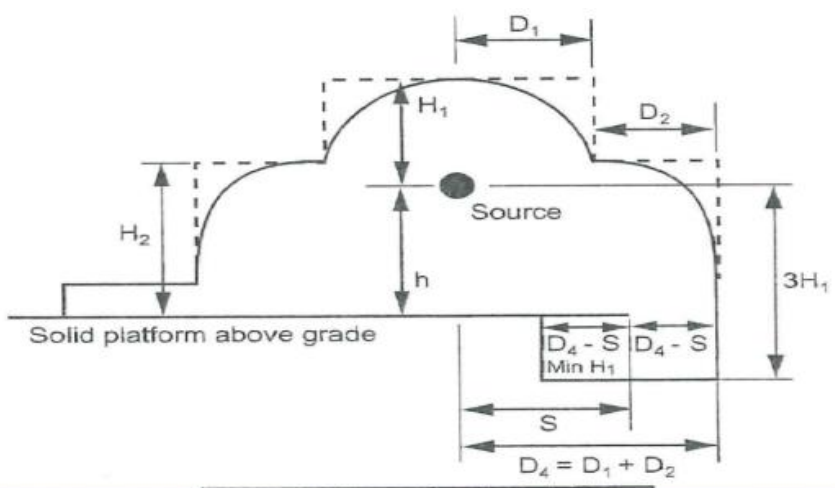

Source above elevated platform 


\section{Figure 5.4 - Figure D.3 Accompanied Diagram[19]}

The hazard radius shown in Figure D. 3 from the API 500 is given in feet but, that is not the area to be classified. The engineer has to then look at Figure 5.3 to determine the classified area. For example, how large is the classified area if the area that an engineer needed to put a power panel was close to a pump that pumps $125^{\circ} \mathrm{C}$ hexane at a pressure of 65 PSIA at a rate $1200 \mathrm{gpm}$ ? In what class and division should this be classified ? First the engineer needs to look at Figure 5.2 to determine the class of the chemical. In this case it is a category II liquid. Then the engineer would consult table D.1 from the API 500. In this case the flow rate is above $500 \mathrm{gpm}$. The hazard radius is determined to be 5ft. This is not the final area radius. The engineer then must consult Figures D.3 and 5.3 to find the dimensions of the classified area.

Once an area is classified, the design of electrical equipment in that area either has to meet the classification standards or in some cases the equipment to be installed can be moved out of the classified area. An engineer has several options in determining area classification. There are preset diagrams, (see appendix V), for a lot of the situations that may be encountered.[19] However, not all situations will be covered. Sometimes the classified area could be smaller. If the classified area is smaller, it may be possible to move the electrical components out of the classification area. There are also several mathematical models for area classification: the McMillian's Model, Cox's Modified Model and The IEC 60079-10-1 model. [20] 
First, the McMillian's model needs several calculations. The first of these calculations is the mass flow of the gas. Then one must calculate the distance of the classified area. Using the equation below calculates the gas mass flow.

$$
G=0.006 A * P_{o}\left[\left(\frac{M}{T_{1}}\right)\right]^{0.5}
$$

In the equation above $G$ is the mass released per unit time $[\mathrm{kg} / \mathrm{s}], \mathrm{A}$ is the cross sectional area of the nozzle $\left[\mathrm{m}^{2}\right], P_{o}$ is the upstream pressure $\left[\mathrm{N} / \mathrm{m}^{2}\right], \mathrm{M}$ is the molar mass of the gas $[\mathrm{kg} / \mathrm{kmol}], T_{1}$ is the absolute temperature of release $[\mathrm{K}]$. After the engineer has calculated $\mathrm{G}$ then one must calculate the radius of the classified area using the following equation.

$$
X=2.1 X 10^{3} \sqrt{\frac{G}{L E L^{2} M^{1.5} T^{0.5}}}
$$

In the equation above the $L E L$ is the lower explosive limit [\% vol], $X$ is the distance from the source of release until the $L E L$ is reached [m], $M$ is the molar mass of the gas $[\mathrm{kg} / \mathrm{kmol}]$, and $T$ is the ambient temperature $[\mathrm{K}]$. This model is only valid if the flow of the escaping gas is greater than the ambient air speed. If the flow of the leaking gas is lower than the ambient air speed the leaking gas will not build up causing the explosive atmosphere that is the problem.

Second, the modified Cox's model is shown in the equation below. 


$$
x=\frac{5 C_{o} d_{o}}{0.2 * L E L}\left(\frac{\rho_{x}}{\rho_{o}}\right)^{0.5} k_{\rho o} k_{p r_{0}}
$$

In the equation above $L E L$ is the lower explosive limit [\% vol], $C_{\mathrm{o}}$ is the concentration at the outlet [\% vol], $d_{o}$ is the outlet diameter [m], $\mathrm{x}$ is the distance from the source of release until $20 \%$ LEL is reached $[\mathrm{m}], \rho_{x}$ is the ambient density $[\mathrm{kg} / \mathrm{m} 3], \rho_{0}$ is the gas density at outlet $[\mathrm{kg} / \mathrm{m} 3], k_{\rho o}$ is the density adjustment factor, and $k_{p r_{0}}$ is the pressure adjustment factor.[20]

Finally, the IEC 60079-10-1 model does not just talk about procedural area classification, it also illustrates equipment choices, and how that choice affects the area classification. "In areas where dangerous quantities and concentrations of flammable gas or vapor may arise, protective measures are to be applied in order to reduce the risk of explosions" [21] The area classification formula for this model is shown below.

$$
V_{z}=f V_{k}=\frac{f(D V / D t)_{\min }}{C}
$$

In the equation above $f$ is the efficiency of the ventilation, $V_{\mathrm{k}}$ is the relationship between the calculated value $(D V / D t)_{\min }$ and the actual ventilation rate within the volume under consideration in the vicinity of the release, $(D V / D t)_{\min }$ is the minimum volumetric flow rate of fresh air [m3/s] and $C$ Is the number of fresh air changes per unit time [s-1].

As shown above, the engineer has several different ways to calculate the hazard radius of a piece of equipment. The method is the engineer's choice. If the engineer cannot move the electrical components out of the classified area, then explosion proof 
components must be specified. These components are designed to contain the explosions that take place in the case of an incident.

\section{Module 5 project: Area Classification}

A pump will pump $50^{\circ} \mathrm{C}$ Pentane at a pressure of 15 PSIA at a rate $400 \mathrm{gpm}$. How large is the classified area? What hazardous category is the Pentane? What class and division should this area be? Sketch the area classification diagram complete with dimensions. 


\section{Conclusion}

\section{A. Electrical Engineer Responsibilities}

Although some industries will vary, the preceding documents and others are part of the responsibility of the electrical engineering department. The electrical engineering department must have a hand in creating the P\&ID, and area classification drawing. These two documents are usually a product of the process engineering department working with the electrical engineering department. Although, other department's documents may be used to create a conduit routing plan, including the conductor and conduit sizes, the drawing is the sole responsibility of the electrical engineering department. There should always be care taken when creating and checking these drawings, because an incorrect drawing makes not only the drafter and engineer look incompetent but it also reflects poorly on the company that the engineer works for.

\section{B. Final Thoughts}

In conclusion, this thesis fills some of the gaps in an engineer's education. After completing the design projects, the engineer should replicate the processes in each module to design systems for clients in the field. Project checkers should also check the engineer's calculations more easily after completing the projects. The five topics the author presented are conductor sizing, conduit running, standard piping and instrumentation diagram symbology, arc flash energy calculations, and finally area classification. 
The first of these modules covers the basics of conductor sizing. This module will discuss the importance of specifying the correct size of conductor, the standard sizes of conductor, the types of conductor insulation, and finally detail the calculations of conductor sizing and voltage drop.

The second module includes the basics of designing conduit runs. This module will also introduce the student to different fittings and seals needed in the running of conduit. This module will inform the student on the conduit sizing process, including standard conduit sizes, then detail several types of conduit fittings that are frequently used in industry.

The third module introduces the standard symbols needed to read and understand a piping and instrumentation diagram. Reserved letters are the first topic discussed in this module, then the types of "bubbles" and connection lines, finally the types of end equipment.

The fourth module discusses arc flash. This module will include several ways to calculate the energy of an arc flash, as well as the safe working distance for a piece of electrical equipment.

Finally, the fifth module introduces the topic of area classification, and the importance of designing with this classification in mind. This module will discuss four different ways of calculating a hazard radius for equipment both indoors and outdoors. Due to the changes in technology and changes in The National Electric Code some of these modules may have to be updated to keep current with evolving standards (around every four years). 


\section{References}

[1] L. B. Nilson, Teaching at Its Best A Research Based Resource for College Instructors, 4 ed. San Francisco, CA: Jossey-Bass, 2016.

[2] C. Furse, B. Farhang-Boroujeny, S. Richardson, R. Verma, A. Kedrowicz, and B. Stenquist, "Integrated System Level Design In Electrical Engineering," presented at the ASEE Conferences, Chicago, Illinois, 2006.

[3] M. Ciletti and G. Plett, "Piloting A Balanced Curriculum In Electrical Engineering Introduction To Robotics," presented at the ASEE Conferences, Portland, Oregon, 2005.

[4] R. Bowman, " Electrical Engineering Freshmen Practicum," presented at the ASEE Conferences, Chicago, IL, 2003.

[5] J. M. Mendel and H. H. Kuehl, "The New Electrical Engineering Curriculum At The University Of Southern California," presented at the ASEE Conferences, Milwaukee, WI, 1997.

[6] J. a. B. Learning, Ugly's Electrical References 2014 Edition. Burlington, MA, 2014.

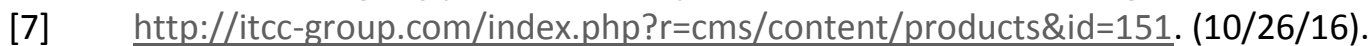

[8] http://www.garvinindustries.com/conduit-fittings-supports/aluminum-and-malleableiron-conduit-bodies/malleable-iron-lb.

[9] Eaton, "Full Line Product Catalog Crouse-Hinds," ed, 2013.

[10] J. T.-T. A. Inc., P. B.-H. Inc., M. C.-A. Inc., E. C.-T. D. C. Company, B. D.-S. Electric, D. D.-A. S. Co., et al., AMERICAN NATIONAL STANDARD ANSI/ISA-5.1-2009 Instrumentation Symbols and Identification Research Triangle Park, NC, 2009.

[11] C. Lorentson. (2016, 11/19). What Caused the Priest Rapids Dam Arc Flash Explosion? Available: http://www.powerstudies.com/blog/what-caused-priest-rapids-dam-arcflash-explosion

[12] J. C. Das, "Arc Flash Hazards and their Analyses," in ARC Flash Hazard Analysis and Mitigation, ed: Wiley-IEEE Press, 2012, pp. 1-39.

[13] D. R. Doan, J. K. Slivka, and C. J. Bohrer, "A Summary of Arc Flash Hazard Assessments and Safety Improvements," IEEE Transactions on Industry Applications, vol. 45, pp. 12101216, 2009.

[14] Wikipedia. (10/28/16). File:ElectricalTree1.jpg. Available: https://en.wikipedia.org/wiki/Electrical_treeing\#/media/File:ElectricalTree1.jpg

[15] T. Papallo, "Arc Flash Calculations Using a Physics-Based Circuit Model," IEEE Transactions on Industry Applications, vol. 48, pp. 1230-1236, 2012.

[16] U. S. C. S. A. H. I. BOARD, "INVESTIGATION REPORT SUGAR DUST EXPLOSION AND FIRE (14 Killed, 36 Injured)," U.S. CHEMICAL SAFETY AND HAZARD INVESTIGATION BOARD PORT WENTWORTH, GEORGIASeptember 2009.

[17] https://commons.wikimedia.org/wiki/File:Fire_triangle.svg.

[18] nordenergi.org. Hazardous Area Classification NEC.

[19] API, "API RP-500," in Recommended practice for classification of areas for electrical installations in petroleum refineries classified as Class I, Division 1 and Division 2ed. USA, 1997.

[20] E. Rangel, A. M. Luiz, and H. L. d. P. M. Filho, "Area classification is not a copy and paste process," in 2014 IEEE Petroleum and Chemical Industry Technical Conference (PCIC), 2014, pp. 381-388. 
[21] IEC, "EC 60079-10-1, Explosive atmospheres - Part 10-1:Classification of areas Explosive gas atmospheres.," ed. Switzerland, 2008. 


\section{Appendices}

\section{Appendix 1: Project Solutions}

\section{Module 1 Design Project Conductor Sizing:}

The customer has a system that is composed of a three phase space heater $(75 \mathrm{~A})$ and a single phase lighting circuit (50A). If the customer specifications state everything in the plant must be able to endure temperatures that exceed $150^{\circ} \mathrm{F}$. The power panel is 250 feet from the loads, and the single conduit must be run overhead. What type of conductor would you need to use? How big must the conductor be? What is the voltage drop over the length of the conductor? Explain your choices.

\section{Solution:}

Type of conductor: RHW, THHW, THW, THWN, XHHW, USE, or ZW are all valid answers. This information is found in Ugly's Electrical References page 73. The student should use the operating temperature to find the list above. In this solution the author has chosen to use XHHW.

Size of conductor: From the same table used above the student will find that the conductor sizes needed are \#4 for the three phase circuit and a \#6 for the single phase circuit. However when the voltage drop is calculated the student should find that the voltage drop is too large.

Voltage drop: Using the formulas given in this module and the tables referenced in the module the student must find the area of the conductor chosen. 
Starting with the \#4 conductor for the three phase circuit:

$$
\begin{gathered}
V d=\frac{1.73 * 12.9 * 250 * 75}{\frac{.0814}{.001^{2}}} \\
V d=5.14 \%
\end{gathered}
$$

Next try \#1 conductor for the three phase circuit:

$$
\begin{gathered}
V d=\frac{1.73 * 12.9 * 250 * 75}{\frac{.1534}{.001^{2}}} \\
V d=2.7 \%
\end{gathered}
$$

This shows that the actual size of the conductor for the three phase circuit is a \#1.

Starting with the \#6 conductor for the single phase circuit:

$$
\begin{gathered}
V d=\frac{2 * 12.9 * 250 * 50}{\frac{.0590}{.001^{2}}} \\
V d=7.5 \%
\end{gathered}
$$

Next try \#2 conductor for the single phase circuit:

$$
\begin{gathered}
V d=\frac{2 * 12.9 * 250 * 50}{\frac{.1146}{.001^{2}}} \\
V d=2.8 \%
\end{gathered}
$$

This shows that the actual size of the conductor for the single phase circuit is a $\# 2$. 


\section{Module 2 Design Project Conduit Design:}

Look at the piping drawing provided, what size conduit will be needed if run A

must hold 2 \#8 and 3 \#1 conductors, run B must hold 6 \#12 conductors and run C must hold 2 \# 8 and 3 \#10 conductors? All of the conductors must withstand $165^{\circ} \mathrm{F}$. On the drawing plan the best route for the conduit.

Piping Drawing 


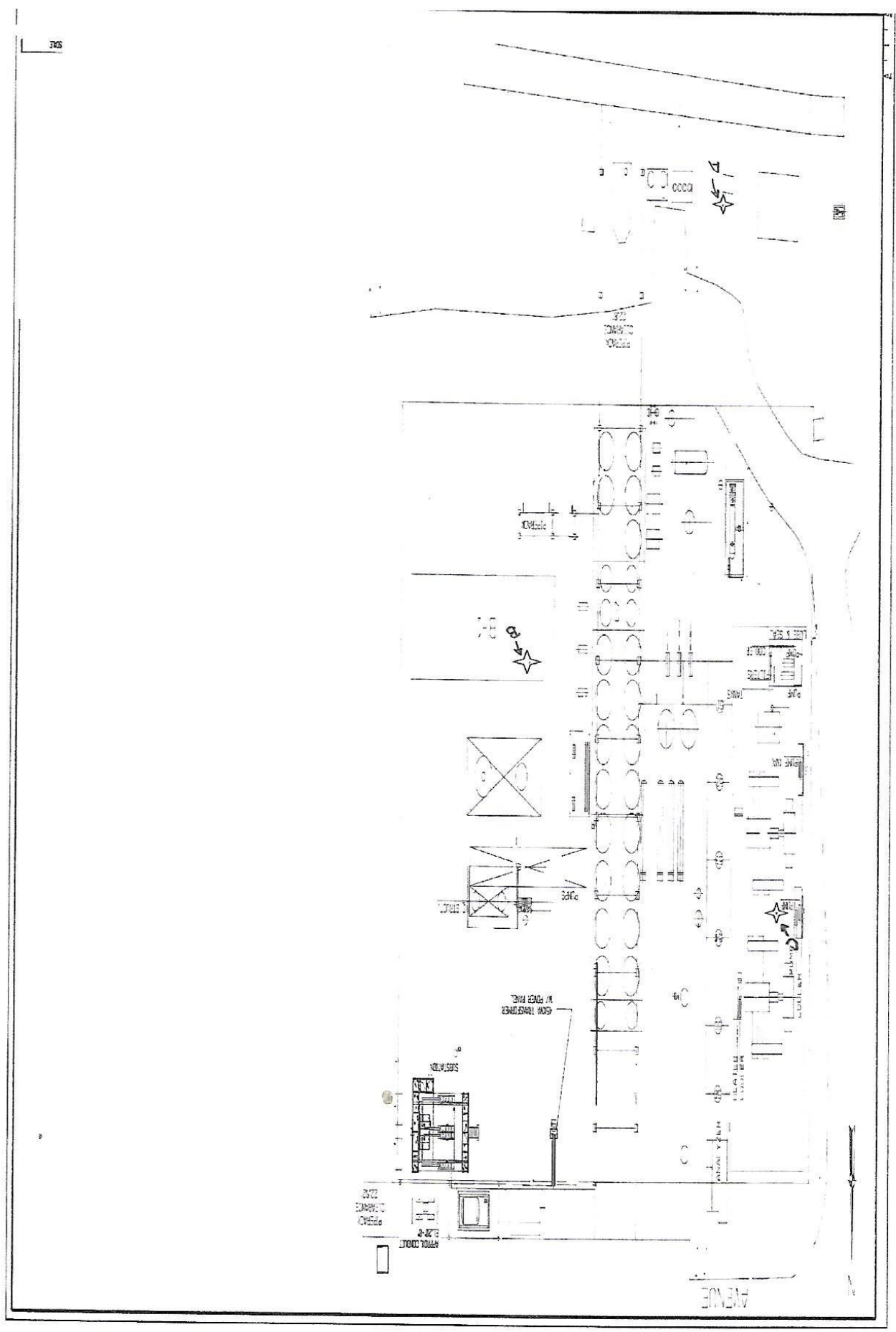


Solution: 


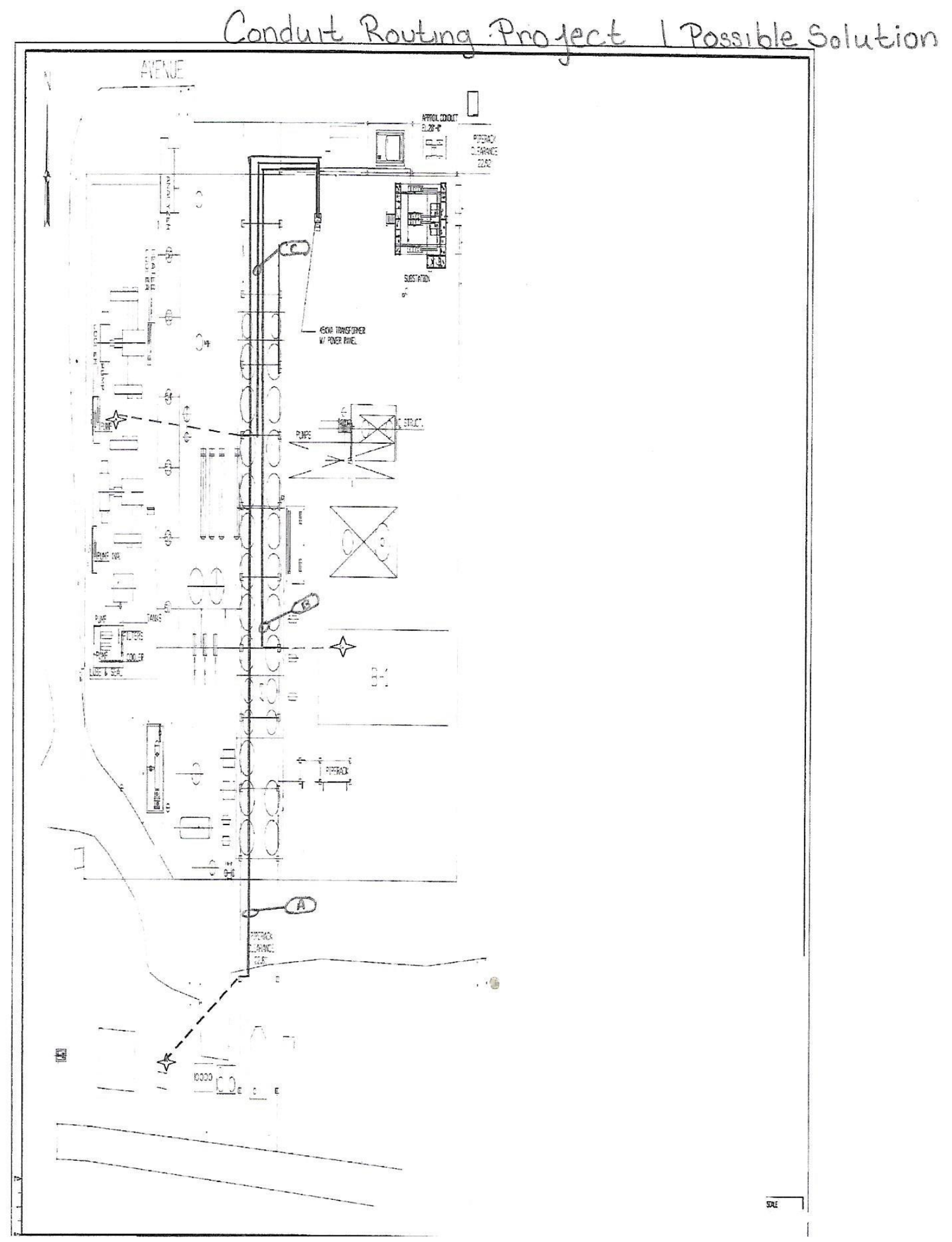




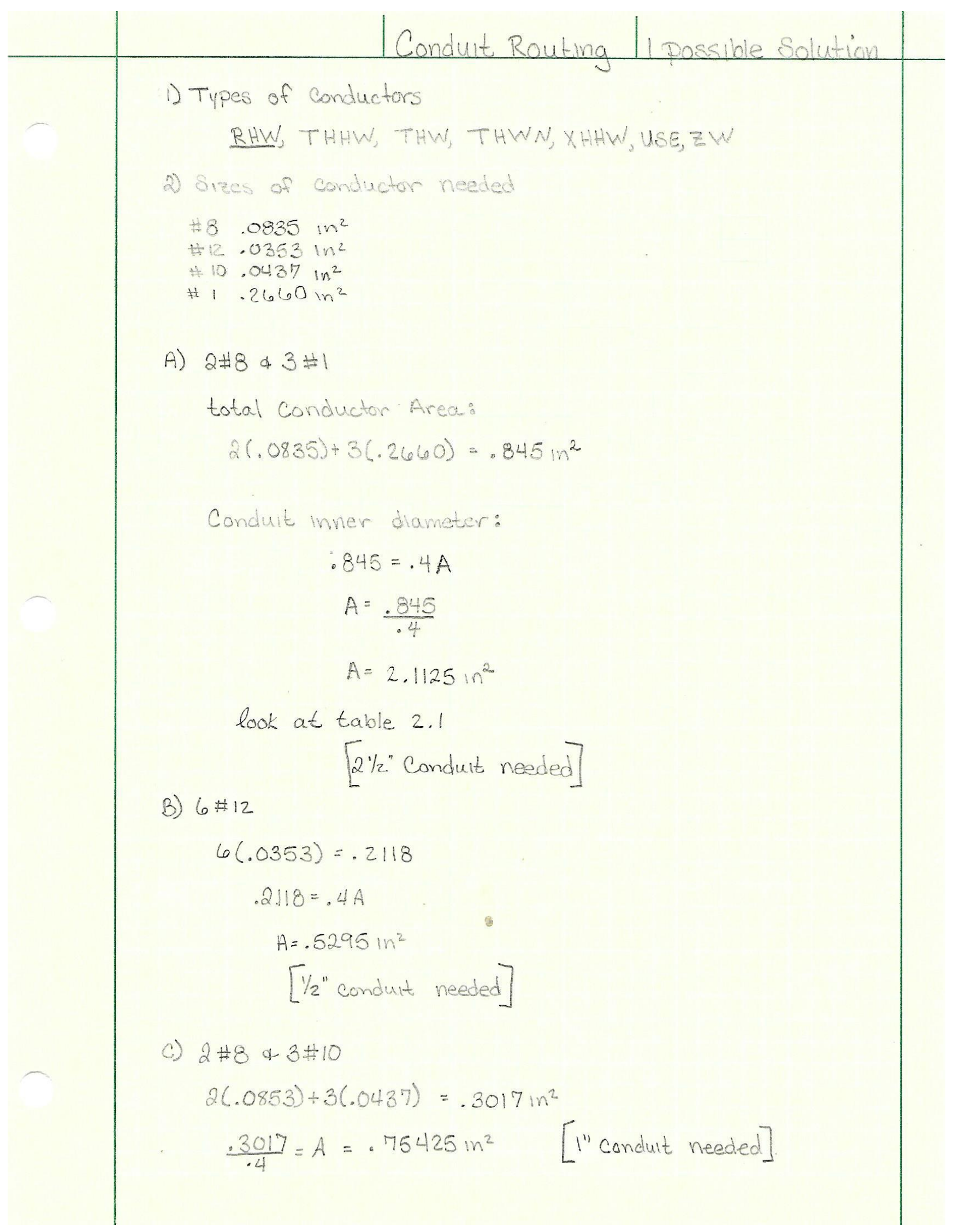




\section{Module 3 Design Project P\&ID:}

Design a system for a tank that includes pressure, temperature and level indicators that are read in the control room. This system should also have a redundant system of measurements on the tank. Sketch the P\&ID; make sure to choose the correct symbology.

P\&ID Project Worksheet:

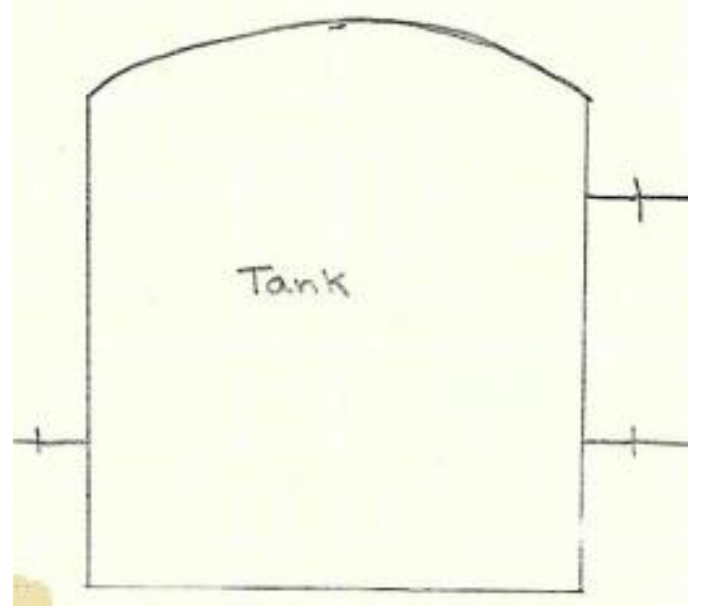

Solution: 


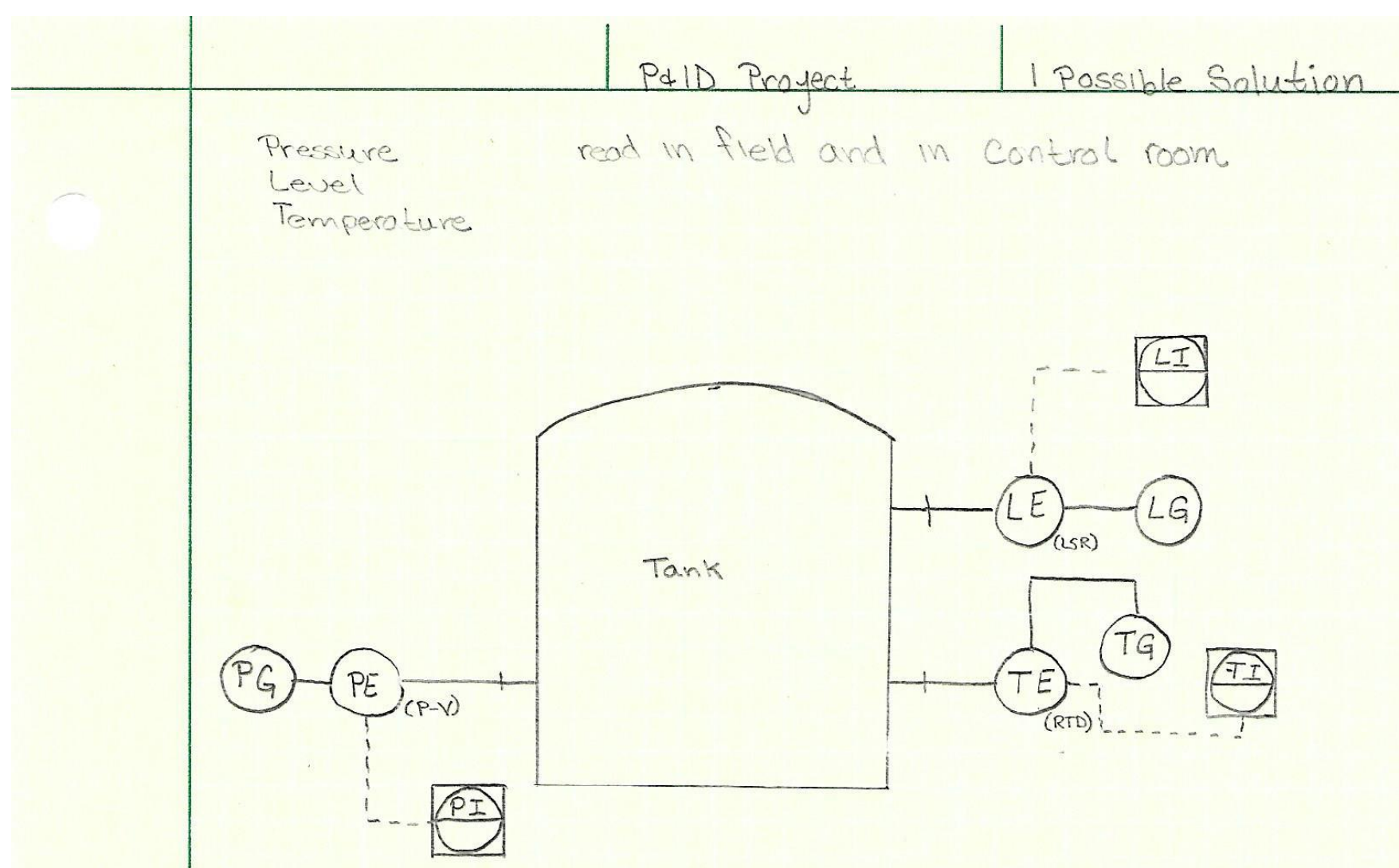




\section{Module 4 Project: Arc Flash}

Evaluate the arc flash calculations using one of the models above of $15 \mathrm{kV}$

switchgear. The transformer is $80 \mathrm{kVA}$. The arc exists for 2 seconds and the short circuit

current is $1500 \mathrm{~A}$. Choose the resistance of a typical human body for the $R_{d}$. The total impedance of the line is $1.5+\mathrm{j} 0.3$.

Solution: 


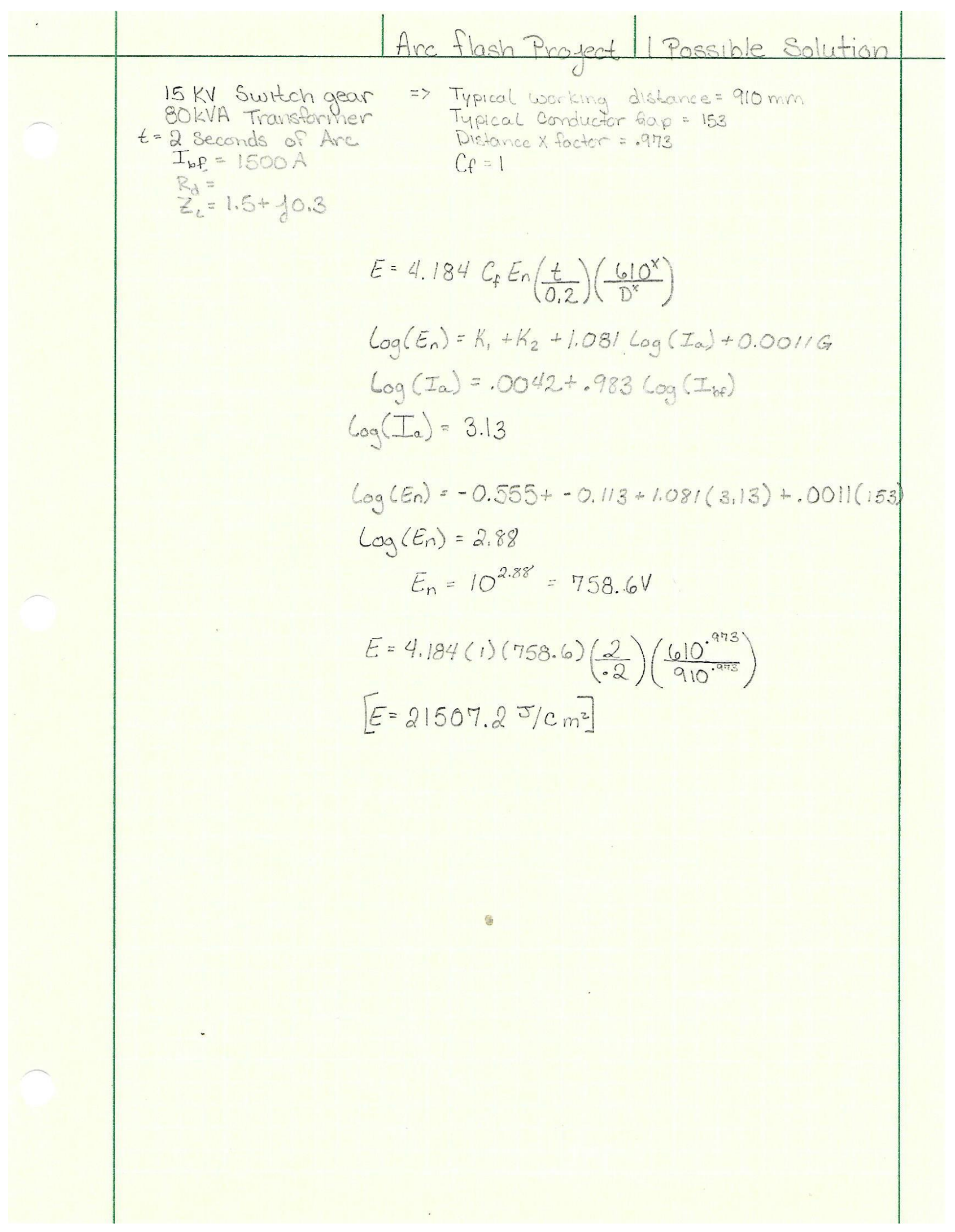




\section{Module 5 project: Area Classification}

A pump will pump $50^{\circ} \mathrm{C}$ Pentane at a pressure of 15 PSIA at a rate $400 \mathrm{gpm}$. How

large is the classified area? What hazardous category is the Pentane? What class and

division should this area be? Sketch the area classification diagram complete with dimensions.

Solution: 


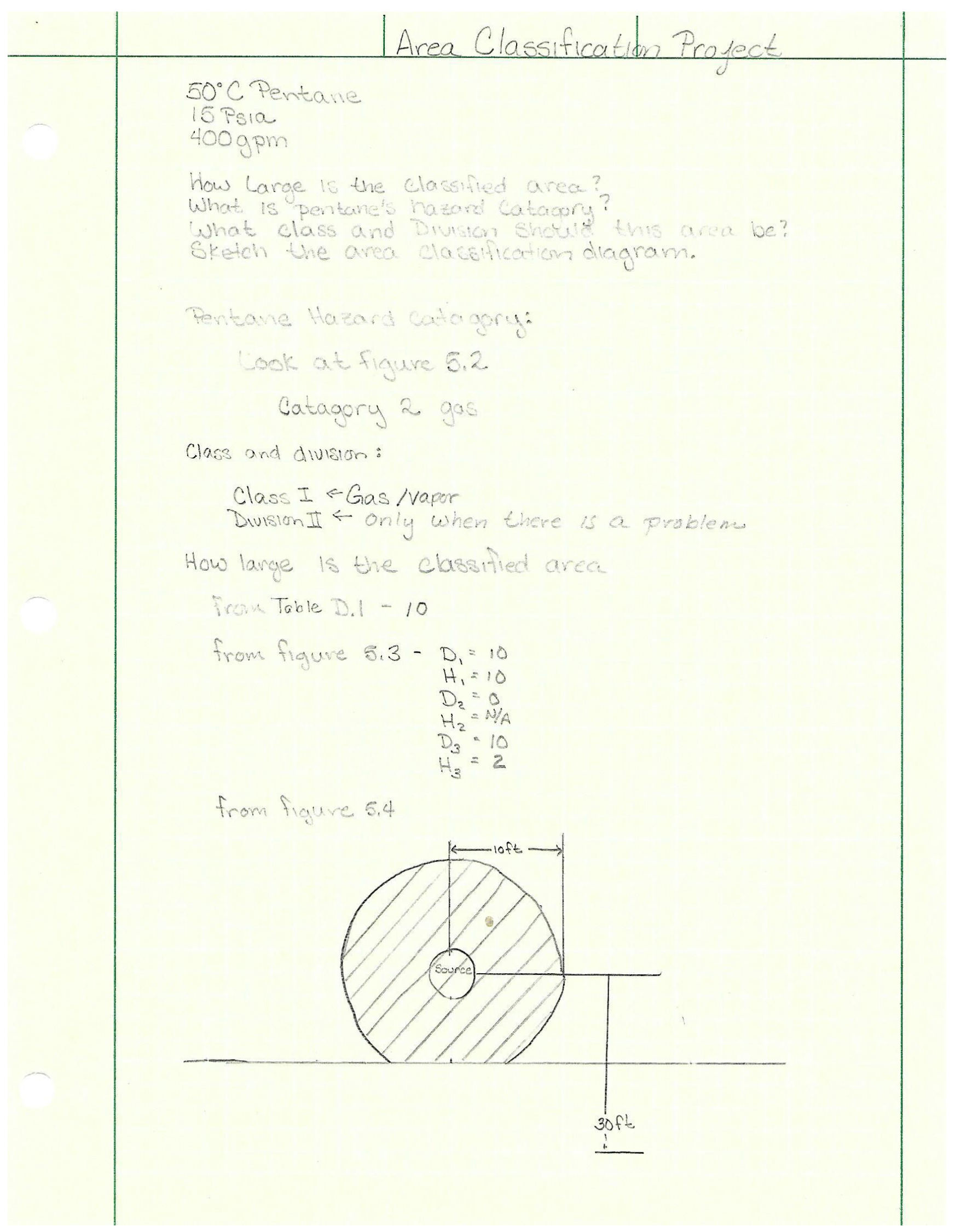




\section{Appendix 2: Power Point Presentations:}

Module I

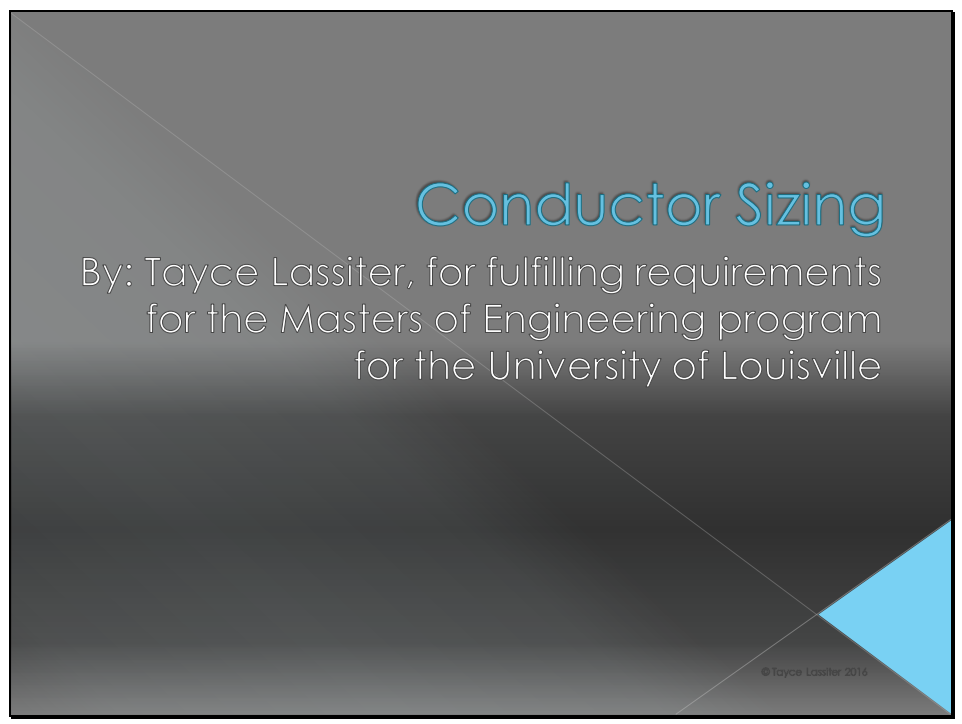




\section{Conductor Sizing}

This module has been created for students that wish to know how to size conductors for the power and control industry. The following slides will convey the importance of conductor sizing as well as the process of conductor sizing. This module will also cover the concept of voltage drop. The reason voltage drop occurs and how to calculate voltage drop.

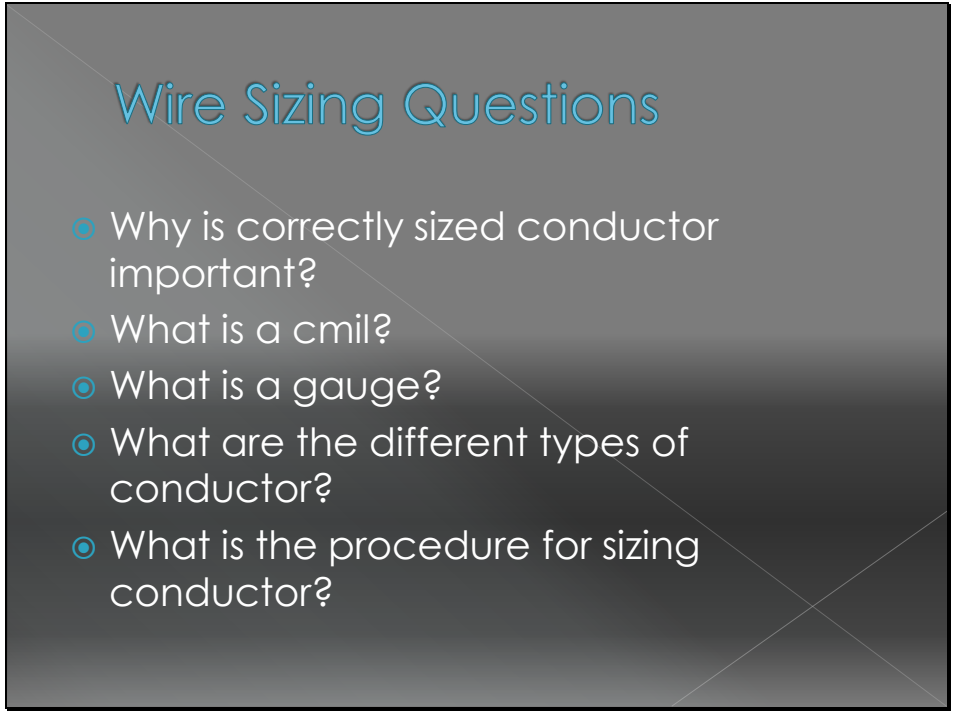




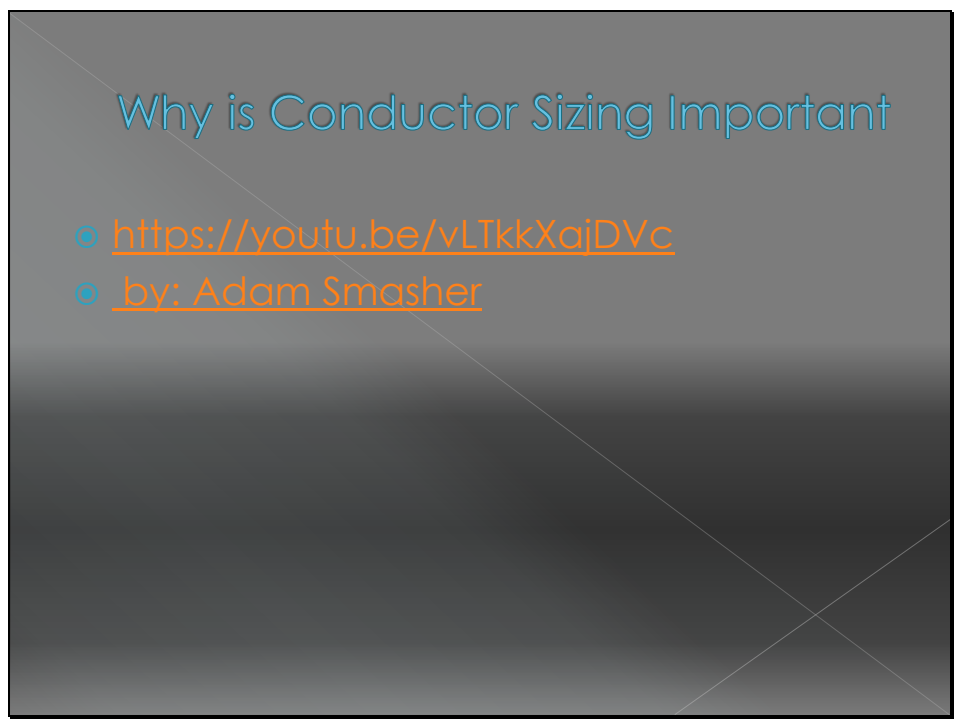

Why is Conductor Sizing Important

As the video shows when too much current is run through a conductor the insulation will burn off and the conductor will melt.

o The video shows a very small wire. Think about the conductors you have seen around town, what if one of those conductors failed in the same way? 

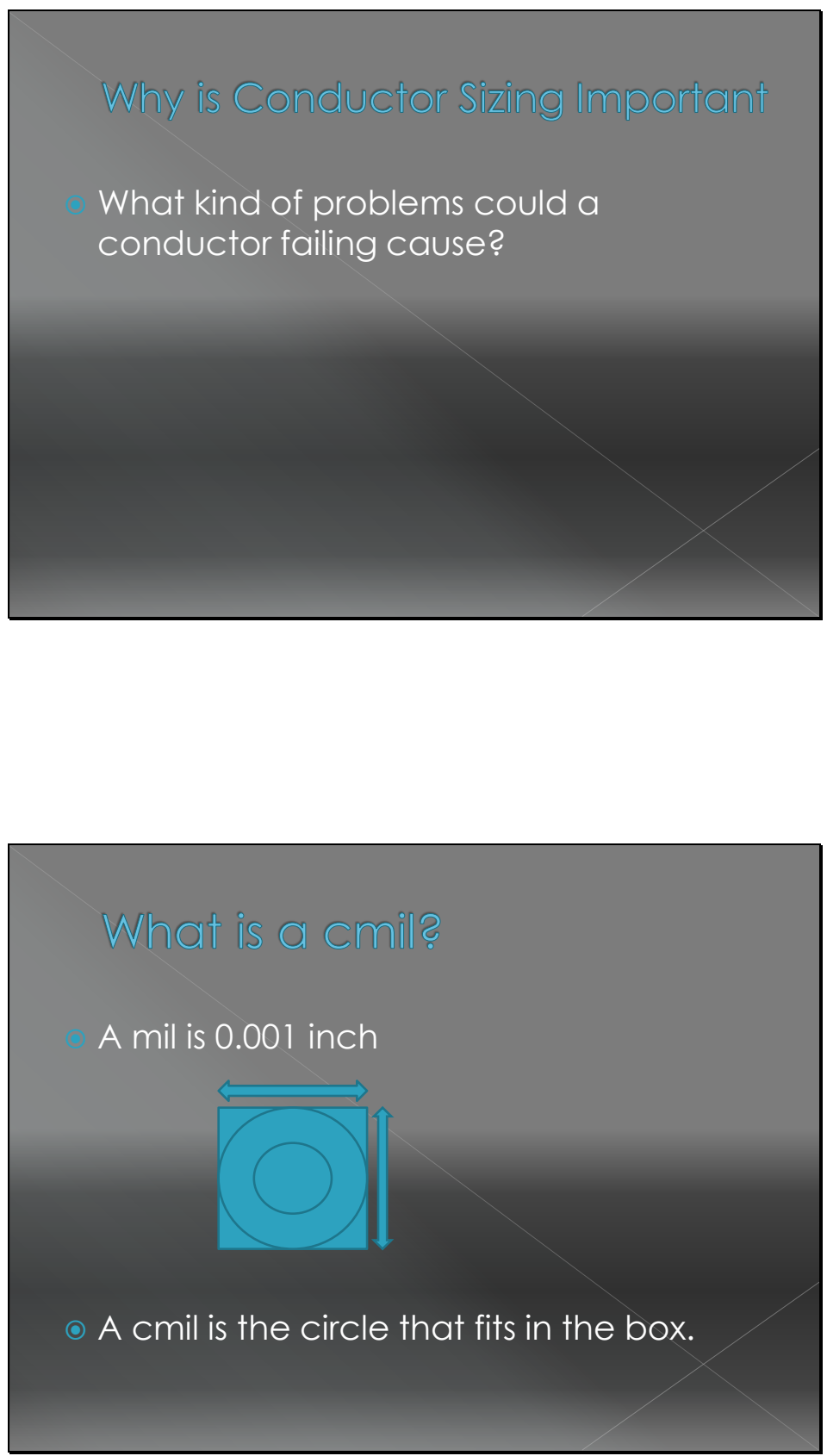


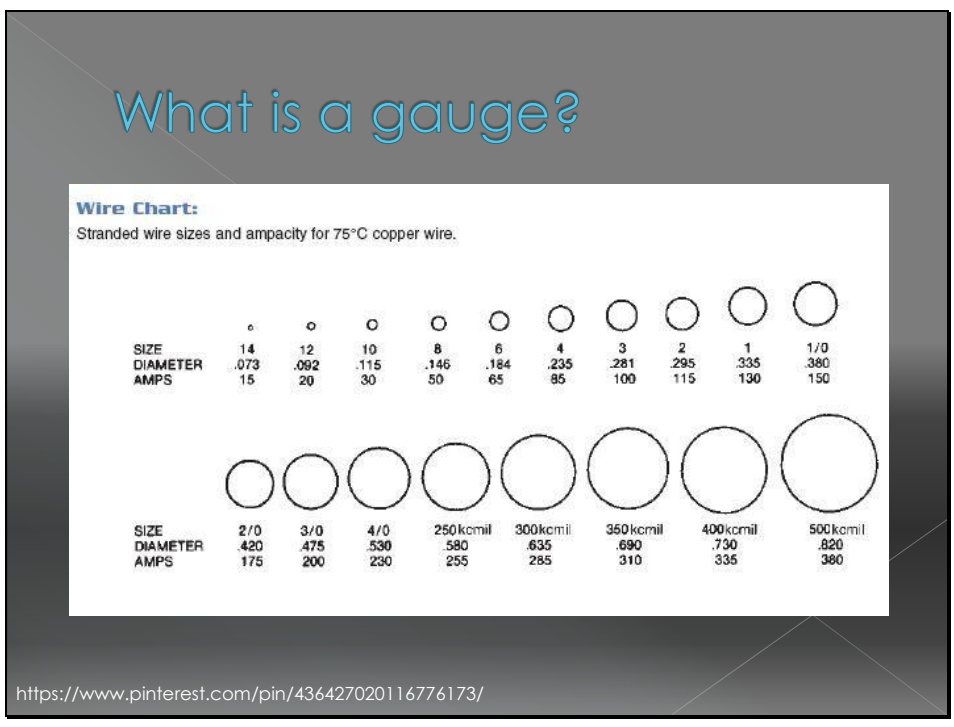




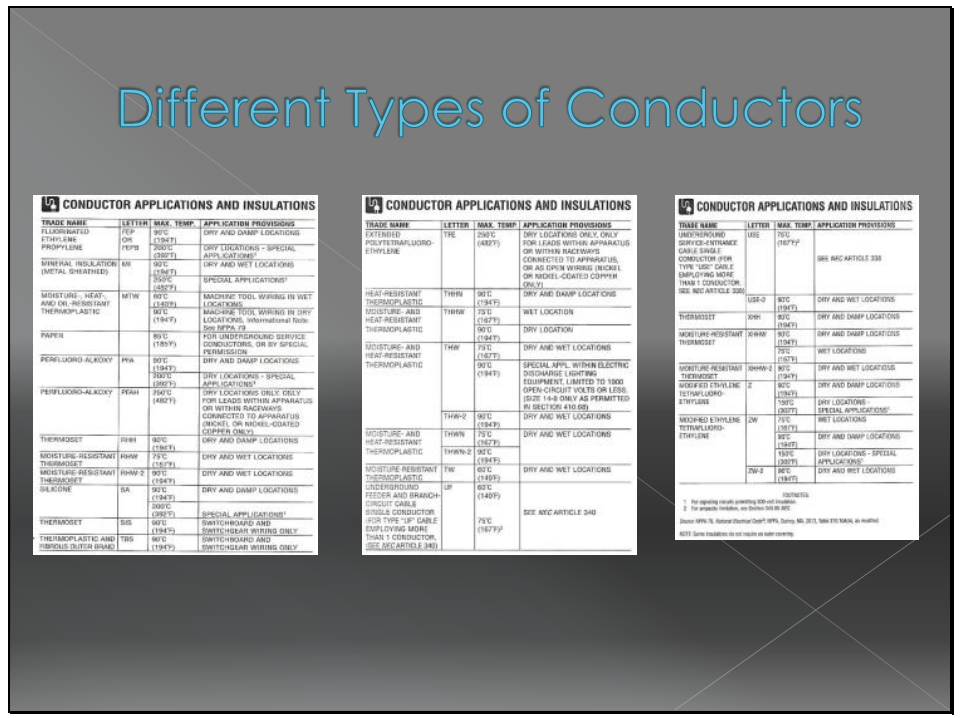

Conductor Sizing Procedure

1) Gather the following information Expected environmental temperature Type of wire needed Material of the wire

Amps needed for the circuit

> Voltage of the circuit

> Medium the wire will be installed in Length of the conductor run 


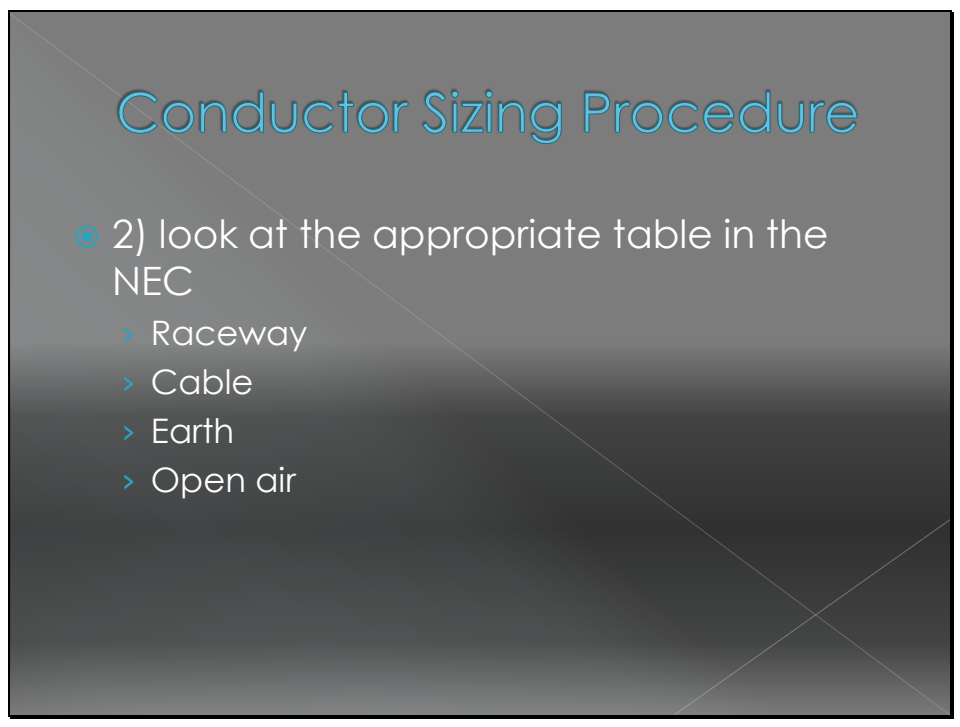

Conductor sizing Procedure

3) Find the correct conductor type See above tables

4) Find the ampacity needed for the circuit

○ 5) Look to the left column for the correct size

○ Are we finished? 


\section{Conductor Sizing Procedure}

\section{Nope!}

6) Do we need to de-rate the wire? How may wires are going to be run together?

U⿴囗十 ADJUSTMENT FACTORS

For More Than Three Current-Carrying Conductors
in a Raceway or Cable

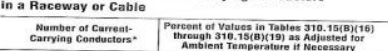

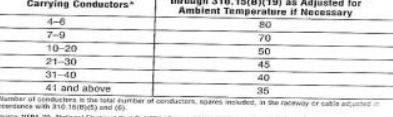

Conductor Sizing Procedure

7) Do voltage drop calculations

This calculation needs to be under $3 \%$

For single phase circuits:

$$
V d=\frac{2 K L I}{C m}
$$

o For three phase circuits:

$$
V d=\frac{1.73 K L I}{C m}
$$

- Now are we finished? 


\section{Conductor Sizing Procedure}

Vd is voltage drop a percentage

I is current in amps

$L$ is length of the run in feet

- $\mathrm{Cm}$ is the cross sectional area of the wire in circular mils

o $\mathrm{K}$ is the resistance in ohms of 1 circular mil foot of the conductor. For $167^{\circ} \mathrm{F} \mathrm{K}=12.9$ for copper and $K=21.2$ for aluminum.

Conductor Sizing Procedure

Yes!

Is the wire bigger than the NEC table said it had to be? 


\section{Example}

The customer wants to power a three phase heater circuit, they have provided you with the following information:

The circuit needs 40A, $240 \mathrm{~V}$. The conductor will be run though conduit, they prefer copper wire and that you design for $90^{\circ} \mathrm{C}$. The shortest run possible is 300 feet.

\section{Example}

What type of conductor is needed? How many wires need to be run? Do we need to de-rate the wire?

d) What wire size does the NEC say?

e) What is the voltage drop?

f) What is the final size of the conductor? 


\section{Example}

a) What type of conductor is needed? Known:

1) conductor will be run though conduit 2) they prefer copper wire

3) design for $90^{\circ} \mathrm{C}$.

4) See above charts

I choose THHN-2 Moisture and heat resistant can be used in wet or dry conditions

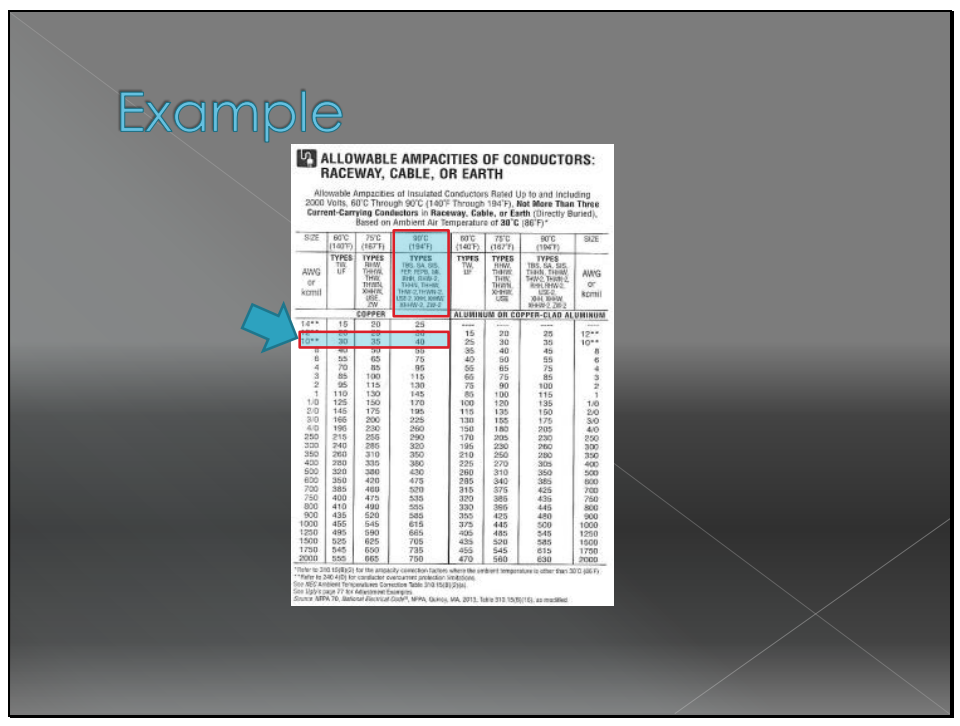




\section{Example}

b) Known:

1)Three phase heater circuit

Therefore we need to run three current carrying conductors

c) Known:

Only need to de-rate when there are more than 3 current carrying conductors in a conduit.

No

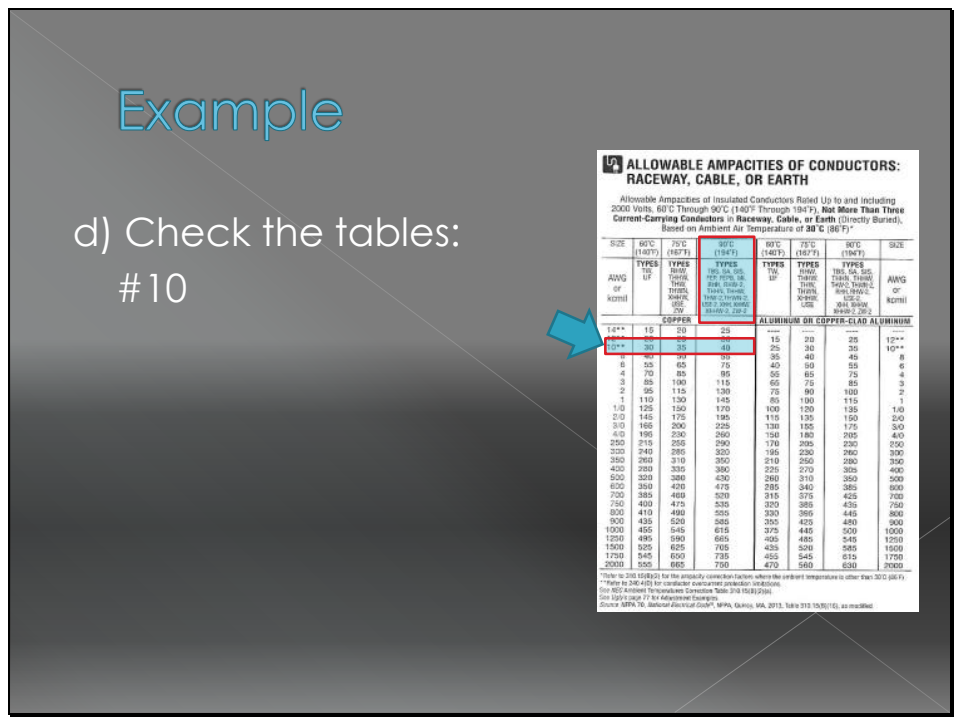




\section{Example}

e) Voltage drop Known:

1) run is 300 feet

2) copper wire

3) current

4) cross sectional area of the wire

5) resistivity $K=12.9$

6) three phase circuit

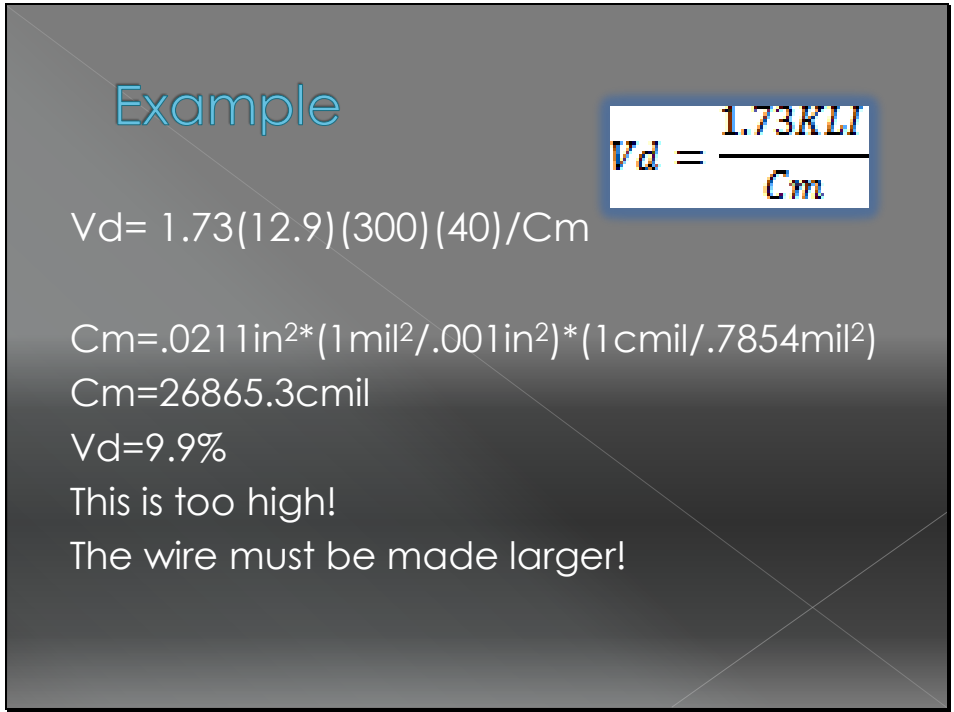




\section{Example}

$V d=1.73(12.9)(300)(40) / C m \Rightarrow 267804 / C m$

Try a \# 1

$\mathrm{Cm}=.1562 \mathrm{in}^{2 *}\left(1 \mathrm{mil}^{2} / .001 \mathrm{in}^{2}\right)^{*}\left(1 \mathrm{cmil} / .7854 \mathrm{mil}^{2}\right)$

$\mathrm{Cm}=198879.6 \mathrm{cmil}$

$\mathrm{Vd}=1.3 \%$

This is acceptable but can we use a smaller wire?

\section{Example}

$\mathrm{Vd}=267804 / \mathrm{Cm}$

Try a \#3

$\mathrm{Cm}=.0973 \mathrm{in}^{2} *\left(1 \mathrm{mil}^{2} / .001 \mathrm{in}^{2}\right) *(1 \mathrm{cmil} / .7854$ $\mathrm{mil}^{2}$ )

$\mathrm{Cm}=123885.9 \mathrm{cmil}$

$\mathrm{Vd}=2.1 \%$

f) Use a \#3 


\section{Quiz!}

The customer wants to power a single phase lighting circuit, they have provided you with the following information:

The circuit needs 18A, $120 \mathrm{~V}$. The conductor will be run though conduit in wet conditions, they prefer aluminum wire and that you design for $90^{\circ} \mathrm{C}$. The shortest run possible is 275 feet

\section{Quiz!}

What type of conductor is needed? How many wires need to be run? Do we need to de-rate the wire?

d) What wire size does the NEC say?

e) What is the voltage drop?

f) What is the final size of the conductor? 
Module II

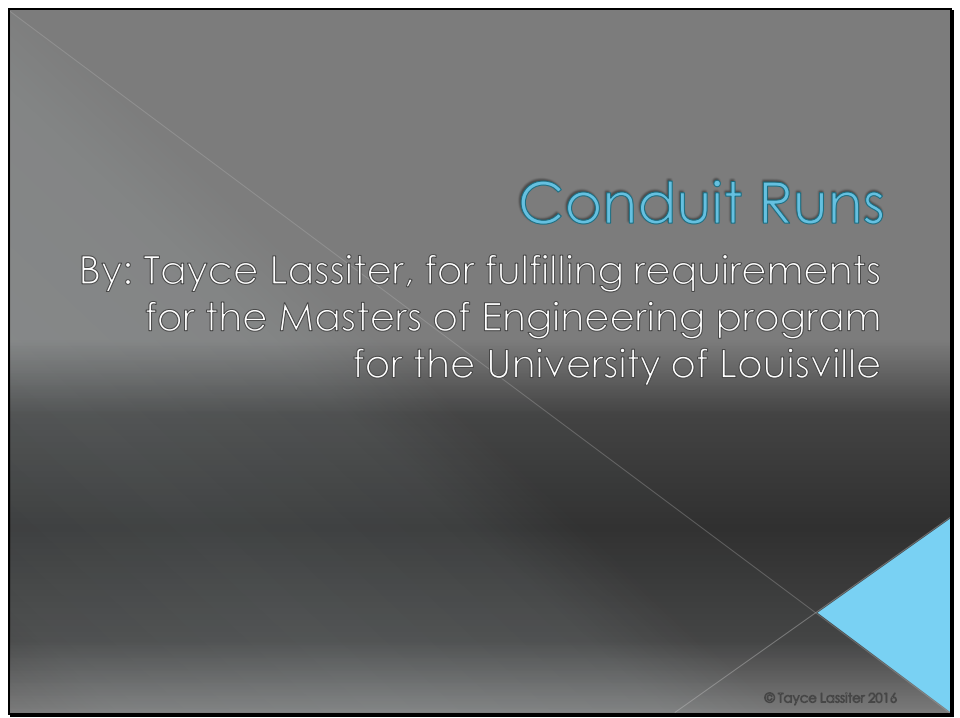

Conduit Runs

This module has been created for students that wish to know how to size and route conduit for the power and control industry. The following slides will convey the importance of conduit sizing as well as the process of conduit sizing. This module will also cover the some of the more common conduit fittings. 

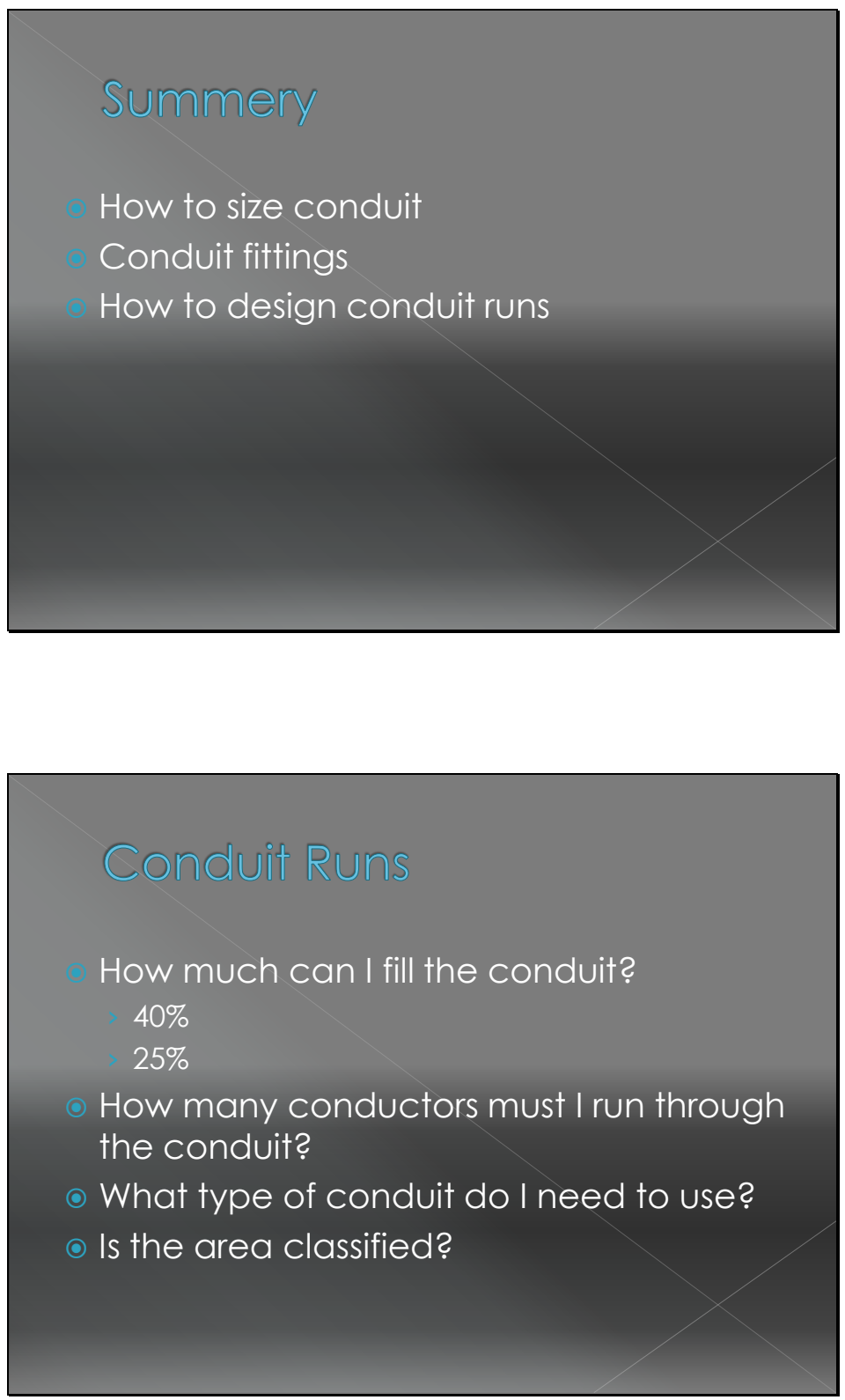


\section{Sizing the Conduit}

How large are the wires that need to be run through the conduit?

- How many of these conductors must be run through the conduit?

\section{Sizing the Conduit}

The first step of sizing a conduit is to size the conductor to be run though the conduit.

- For example:

The circuit needs 3 \#2 conductors and a \#8 ground wire.

First we need to know how large the conductor areas are 


\section{Sizing the Conduit}

As see in the previous module the size of the conductor depends on the type of conductor used. And the size of the conductor. In this example we will use XHHW-2 type wire.

Sizing the Conduit

XHHW-2 cross sectional area:

$\# 2=.1146$ square inches

$\# 8=.0437$ square inches

- Total area

$>.1146 *(3)+.0437 *(1)=.3875$ square inches

o What size conduit will hold this wire? 


\begin{tabular}{|c|c|c|c|c|c|c|c|c|c|c|}
\hline \multirow{2}{*}{ Code } & \multirow{2}{*}{$\begin{array}{c}\text { Trade } \\
\text { Size }\end{array}$} & \multirow{2}{*}{$\begin{array}{c}\text { Metric } \\
\text { Designator }\end{array}$} & \multicolumn{2}{|c|}{$\begin{array}{l}\text { Weights } \\
10 \text { Units Lengths }\end{array}$} & \multicolumn{2}{|c|}{$\begin{array}{c}\text { Outside } \\
\text { Diameter (1) }\end{array}$} & \multicolumn{2}{|c|}{$\begin{array}{c}\text { Inside } \\
\text { Diameter (2) }\end{array}$} & \multicolumn{2}{|c|}{ Wall Thickness } \\
\hline & & & lb. & kg. & in. & $\mathrm{mm}$. & in. & $\mathrm{mm}$. & in. & $\mathrm{mm}$. \\
\hline C-E00050 & $1 / 2^{\prime \prime}$ & 16 & 30 & 13.6 & 0.706 & 17.93 & 0.622 & 15.80 & 0.042 & 1.07 \\
\hline C-E00075 & $3 / 4 "$ & 21 & 46 & 20.9 & 0.922 & 23.42 & 0.824 & 20.93 & 0.049 & 1.24 \\
\hline C-E00100 & $1^{\prime \prime}$ & 27 & 67 & 30.4 & 1.163 & 29.54 & 1.049 & 26.64 & 0.057 & 1.45 \\
\hline C-E00125 & $1 y_{4}^{\prime \prime}$ & 35 & 101 & 45.8 & 1.510 & 38.35 & 1.380 & 35.05 & 0.065 & 1.65 \\
\hline C-E00150 & $1 y_{2}^{\prime \prime}$ & 41 & 116 & 52.6 & 1.740 & 44.20 & 1.610 & 40.89 & 0.065 & 1.65 \\
\hline C-E00200 & $2^{\prime \prime}$ & 53 & 148 & 67.1 & 2.197 & 55.80 & 2.067 & 52.50 & 0.065 & 1.65 \\
\hline C-E00250 & $21 / 2 "$ & 63 & 216 & 98.0 & 2.875 & 73.03 & 2.731 & 69.37 & 0.072 & 1.83 \\
\hline C-E00300 & $3 "$ & 78 & 263 & 119.3 & 3.500 & 88.90 & 3.356 & 85.24 & 0.072 & 1.83 \\
\hline C-E00350 & $31 / 2 "$ & 91 & 349 & 158.3 & 4.000 & 101.60 & 3.834 & 97.38 & 0.083 & 2.11 \\
\hline C-E00400 & $4 "$ & 103 & 393 & 178.3 & 4.500 & 114.30 & 4.334 & 110.08 & 0.083 & 2.11 \\
\hline
\end{tabular}

\section{Sizing the conduit}

Lets look at a $1 / 2$ inch conduit:

Inside diameter $=.622$ inches

Area $=\pi(d / 2)^{2}$

Area $=\pi(.622 / 2)^{2}$

Area $=.304$ square inches

o This will not fit the wire we need to run 


\section{Sizing the Conduit}

Lets look at a 2 inch conduit:

Inside diameter $=2.067$ inches

Area $=\pi(d / 2)^{2}$

Area $=\pi(2.067 / 2)^{2}$

Area $=3.355$ square inches

o Lets check the $40 \%$ rule: $40 \% * 3.355=1.34$ square inches this will more than accommodate our conductors, but is if too large?

Sizing the Conduit

Lets look at a 1 inch conduit: Inside diameter $=1.049$ inches

Area $=\pi(d / 2)^{2}$

Area $=\pi(1.049 / 2)^{2}$

Area $=.86$ square inches

( Lets check the $40 \%$ rule: $40 \% * .86=.346$ Will not work 


\section{Sizing the Conduit}

Lets look at a 1 1/2 inch conduit: Inside diameter $=1.610$ inches

Area $=\pi(d / 2)^{2}$

Area $=\pi(1.610 / 2)^{2}$

Area $=2.04$ square inches

( ) Lets check the $40 \%$ rule: $40 \% * 2.04=.816$ square inches This will work!

\section{Conduit Fittings}

There are many types of conduit fittings the three main ones that we will talk about are the conduit seal, the expansion joint and the left bend "LB" 


\section{Conduit Fittings}

\section{The "LB"}

This fitting turns the conduit at a $90^{\circ}$ angle Depending on how this fitting is installed it can also be a "RB" or right bend alternatively it can be a front or rear bend This conduit fitting can be very versatile
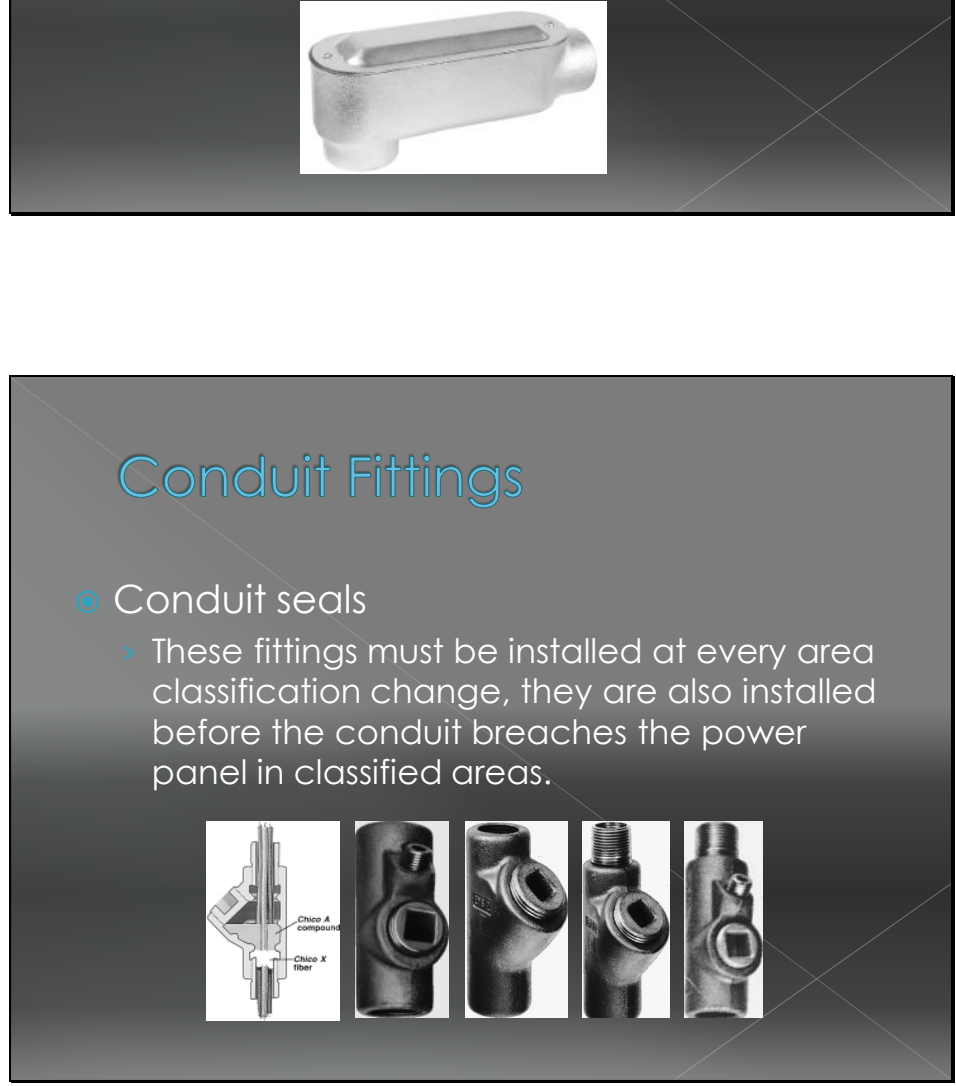


\section{Conduit Fittings}

The Expansion Joint:

This fitting is used when the conduit run is more than 100 feet long without any bends. It relieves the stress of expansion and contraction, in the changing seasons, without damaging the conduit or the conductor therein.

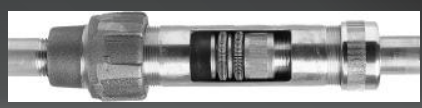

\section{Conduit Runs}

Now that we know how large the conduit is and how fittings need to be used. We can run the conduit.

- Conduit should be run the in the straightest route possible, there cannot be more than $180^{\circ}$ of turn in an underground conduit run. 
Module III

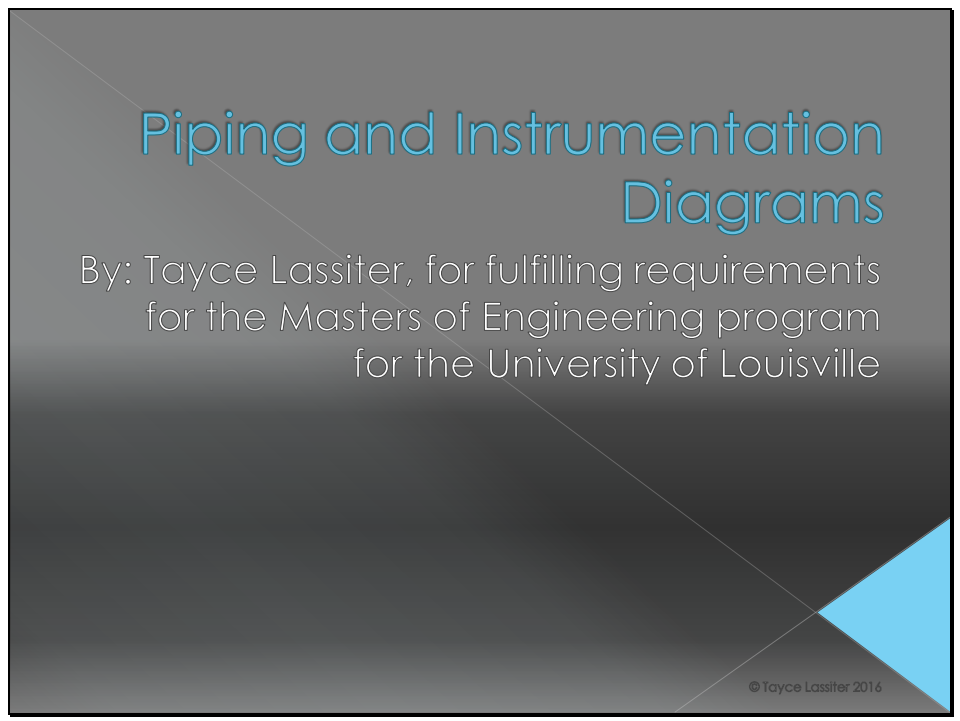

Piping and Instrumentation Diagrams

This module has been created for students that wish to know about piping and instrumentation diagrams for the power and control industry. The following slides will convey the process of reading a piping and instrumentation diagram as well as how to choose the correct symbols for a diagram. 


\section{Summery}

What is a P\&ID?

Reserved letters

Instrument symbology

- What does this look like?

\section{What is a P\&ID}

A drawing that shows the connections for piping, tanks and instruments

These drawings have no scale and they do not have to be physically accurate

A pipe may be drawn straight from a tank to another tank, but in reality it snakes around several pieces of equipment 


\section{What is a P \&}

These drawings are one of the

engineering control drawings, this is

where you would look for information

about flow through a pipe, sizes of pipes

and valves, and what instrumentation is

located on these pipes and tanks

\section{Reserved Letters}

To make it easier for a lot of engineers to read and design these drawings there is a standard that dictates what tags mean

- No matter who makes the P\&ID these letters represent the same thing! 


\section{Reserved Letters}

If there is a "LG"

anywhere on any

P\&ID then you know

that what is

represented by that

bubble is a level

gauge!
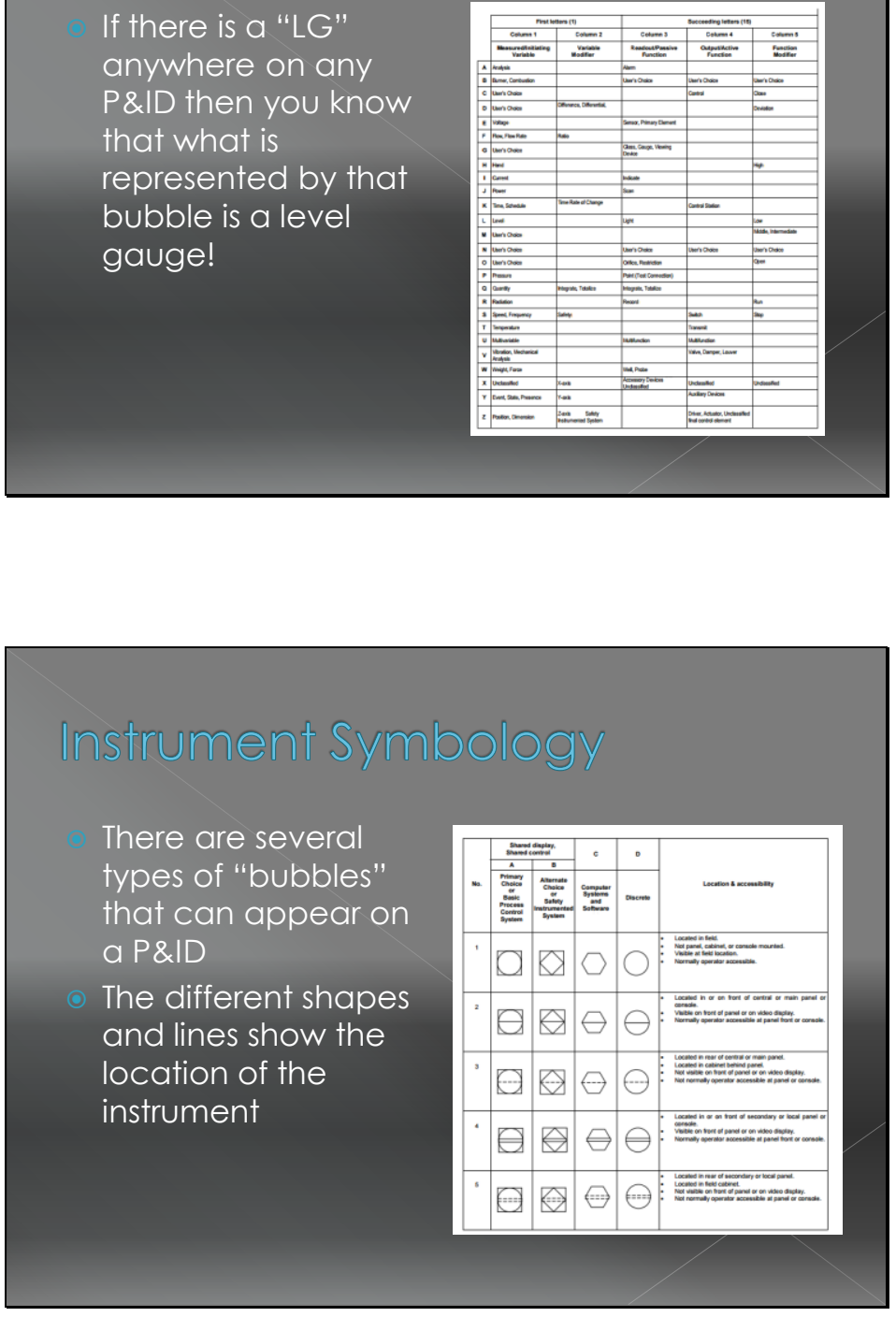

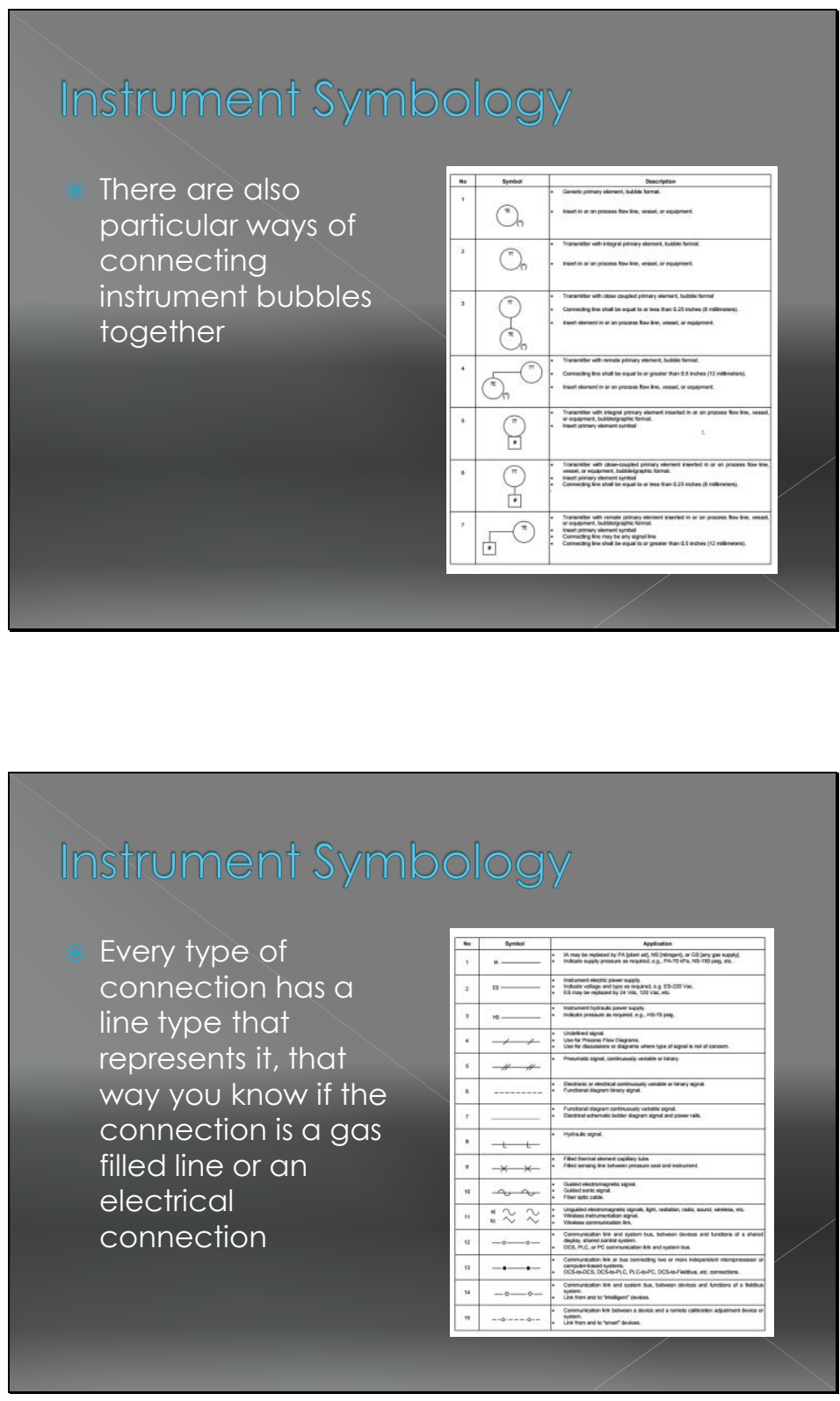

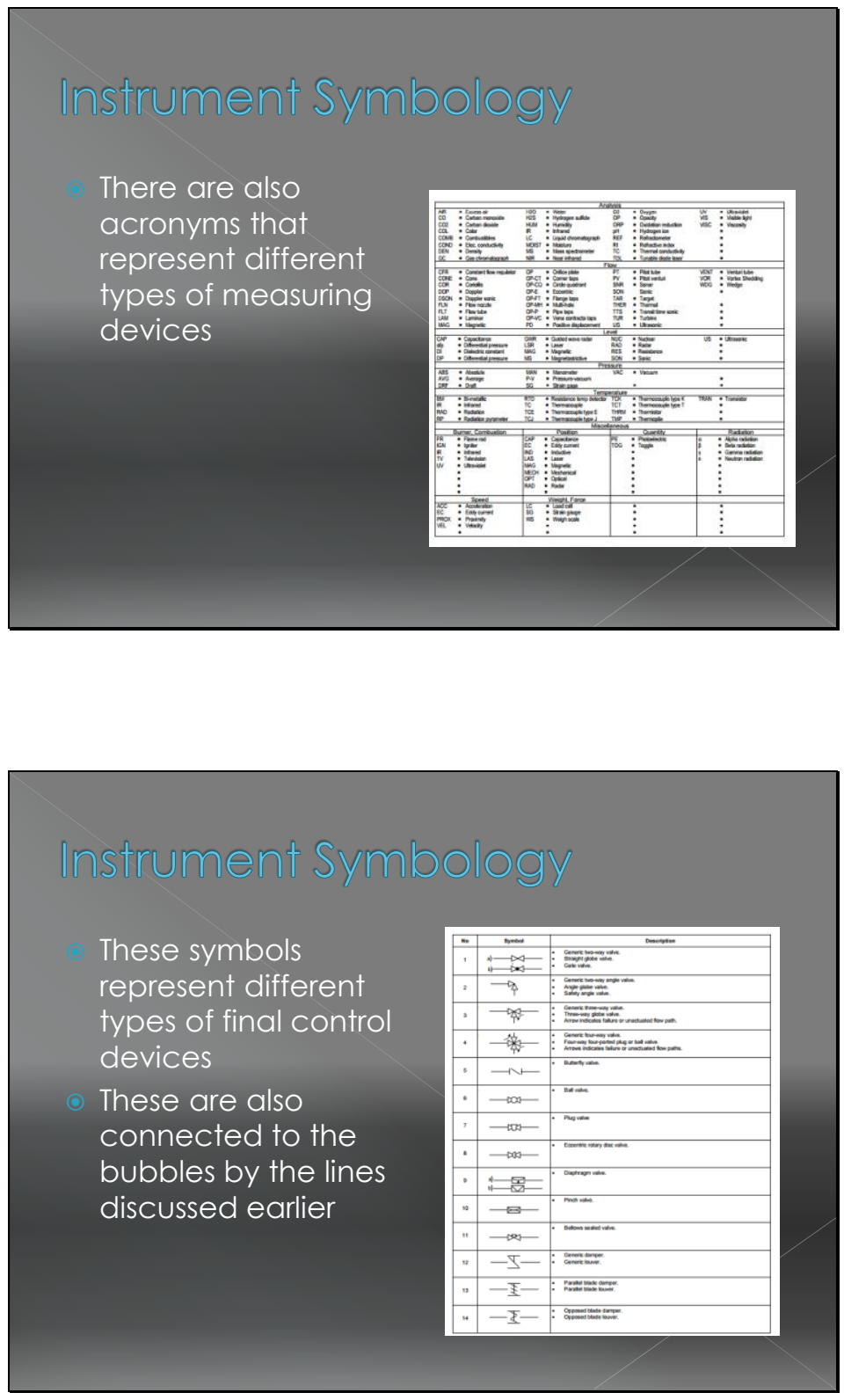


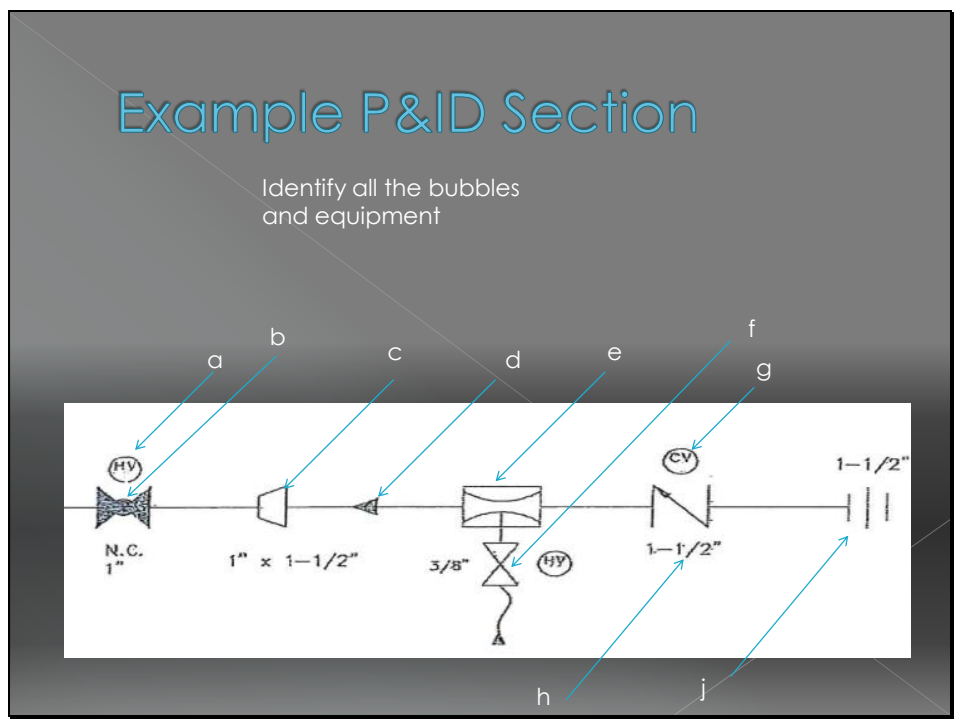

Module IV

\section{Arc Flash Calculations}

By: Tayce Lassiter, for fulfilling requirements for the Masters of Engineering program for the University of Louisville 


\section{Arc Flash Calculations}

This module has been created for students that wish to know how to calculate arc flash energy for the power and control industry. The following slides will convey the importance of arc flash calculations as well as the process of calculating arc flash energy. This module will show the student several different ways to calculate arc flash energy.

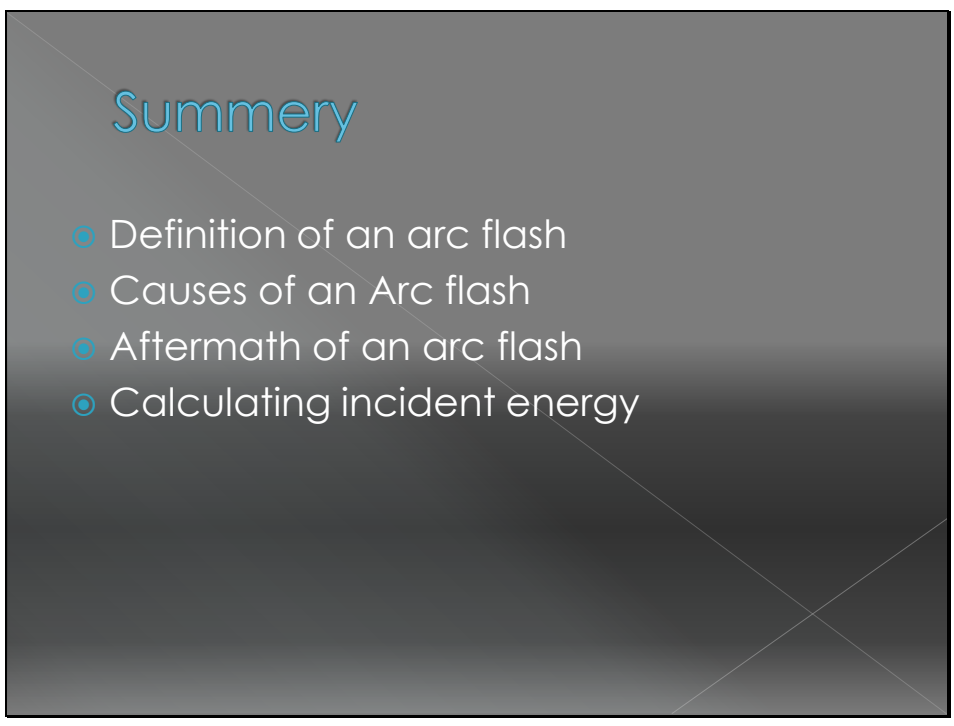




\section{What is an Arc Flash}

An unsafe environment where there is an unplanned path for current to travel

When current uses the moisture in the air and/or a person's body to create a path to ground

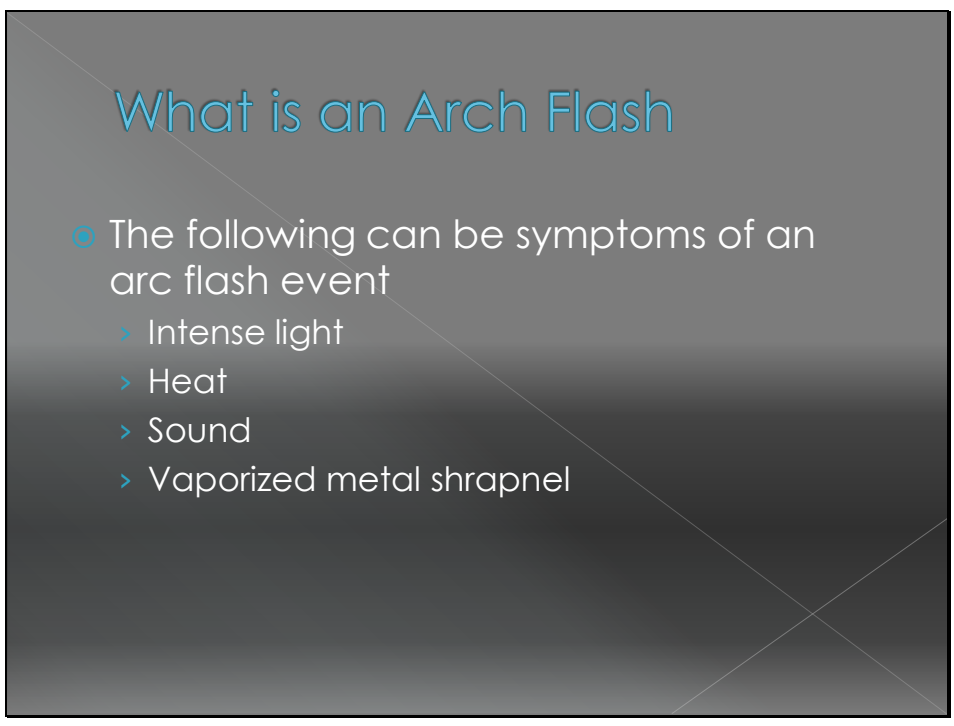




\section{What Couses Arc Flash}

Two main causes:

1. Treeing or wearing of the insulation around a conductor

2. Maintenance personnel error - This is the most common cause for arc flash
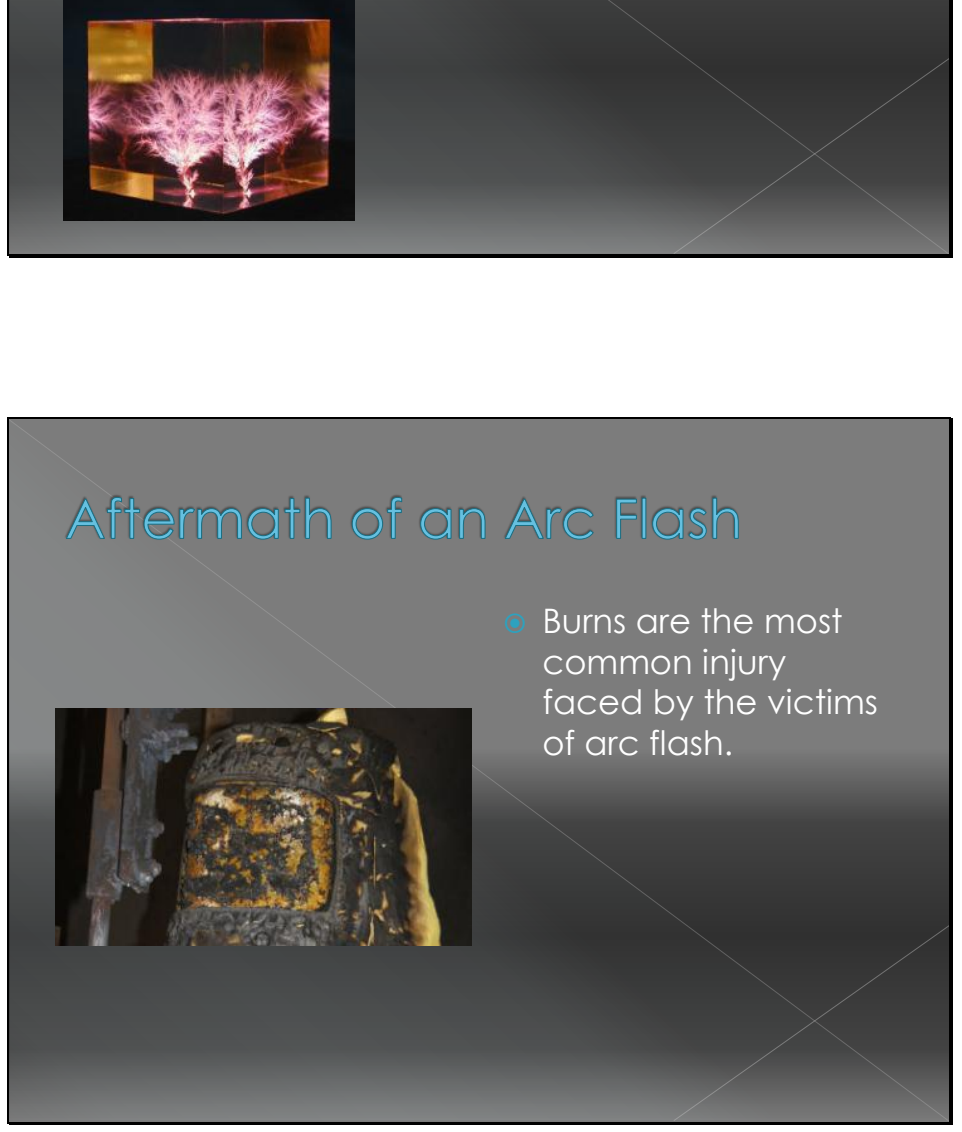

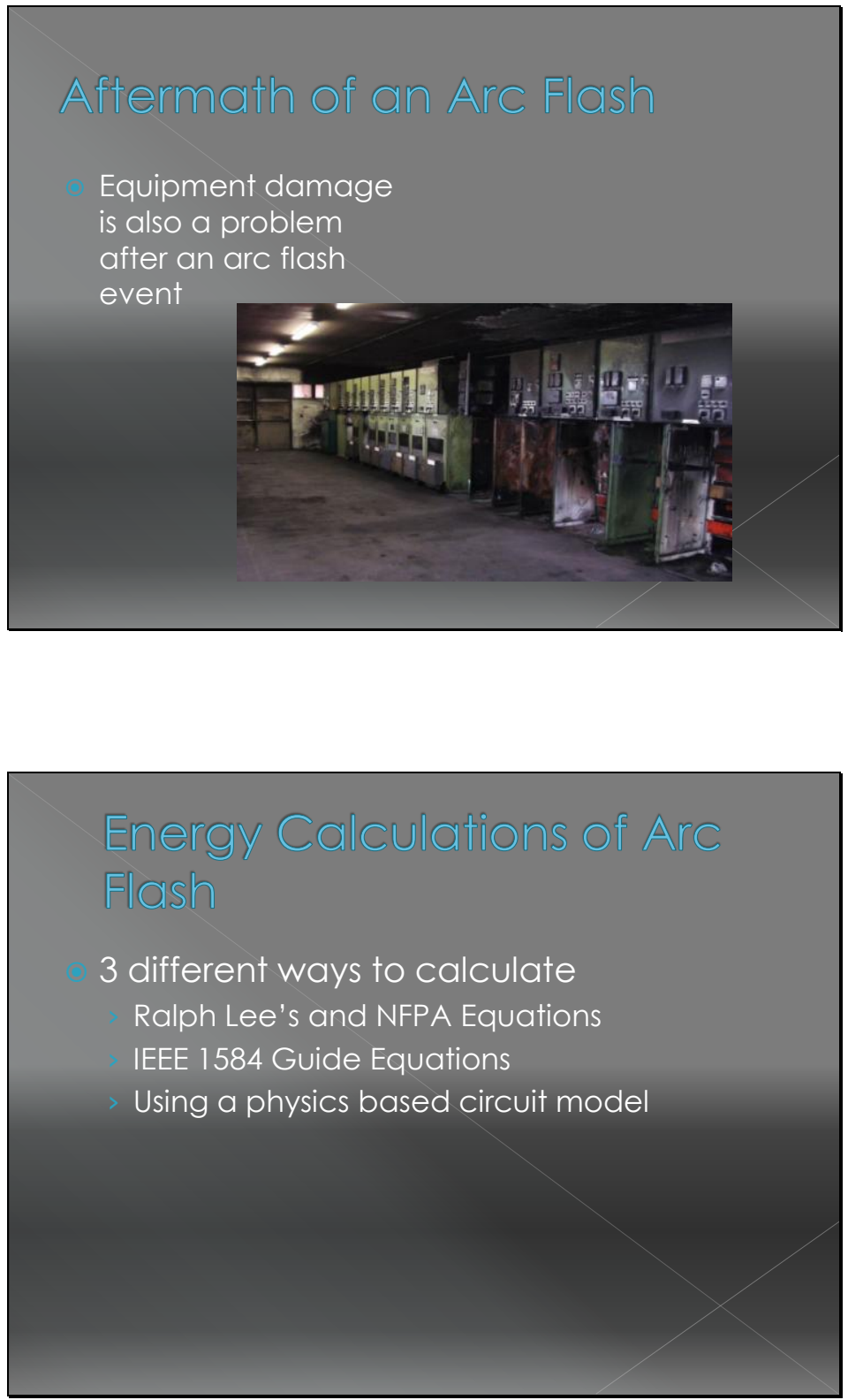


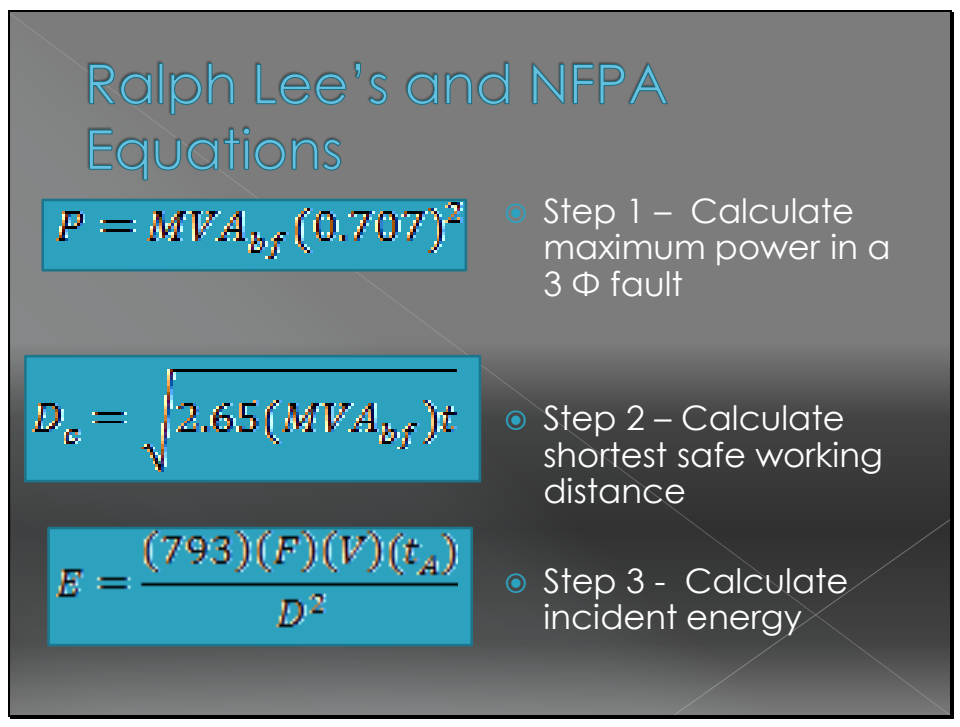

Example

Evaluate the arc flash energy $15 \mathrm{kV}$ switchgear. The transformer is $45 \mathrm{MVA}_{\mathrm{bf}}$. The arc exists for 4 seconds and incent current is $8700 \mathrm{~A}$. The worker is working $910 \mathrm{~mm}$ away from the component.

(c) $\mathrm{P}=45(0.707)^{2}=22.5 \mathrm{MW}$

(ㅇ) $D_{C}=(2.65(45)(4))^{1 / 2}=21.84 \mathrm{ft}$

(ㅇ $\mathrm{E}=((793)(8.7)(15)(4)) /(3.6)=114,985 \mathrm{~kW}$ 

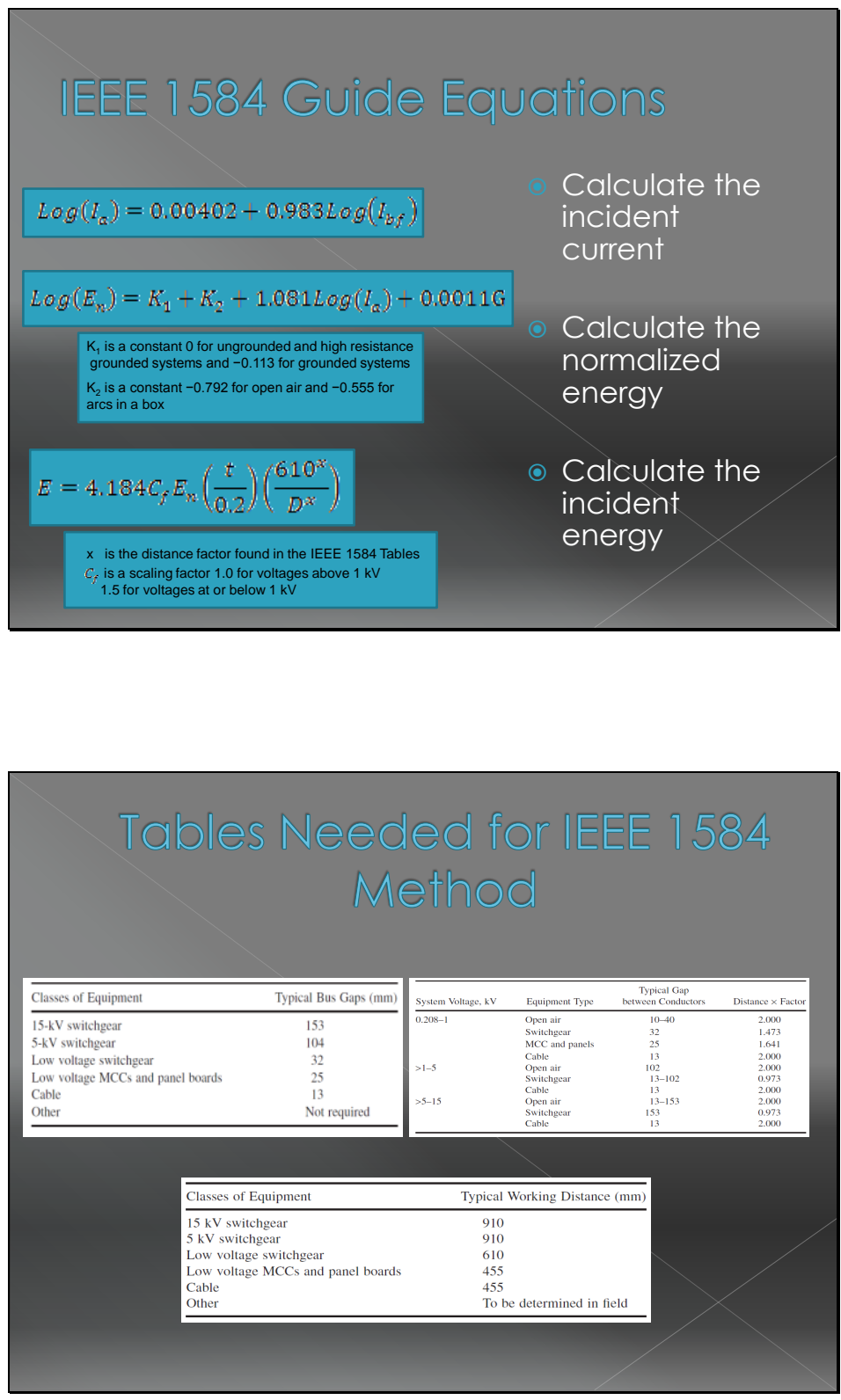


\section{Example}

Evaluate the arc flash energy $15 \mathrm{kV}$ switchgear. The transformer is $45 \mathrm{MVA}_{\mathrm{bf}}$. The arc exists for 4 seconds and incent current is $8700 \mathrm{~A}$. The worker is working $910 \mathrm{~mm}$ away from the component.

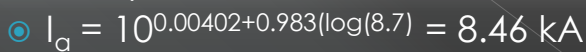

o $\mathrm{E}_{\mathrm{N}}=10^{1.081(\log (8.46))-0.113-0.555+0.0011(153)}$

$$
=3.18 \mathrm{~J} / \mathrm{cm}^{2}
$$

○ $E=4.184(1.5)(3.18)(4 / .2)(610.973 / 910.973)$

$$
=73.6 \mathrm{~J} / \mathrm{cm}^{2}
$$

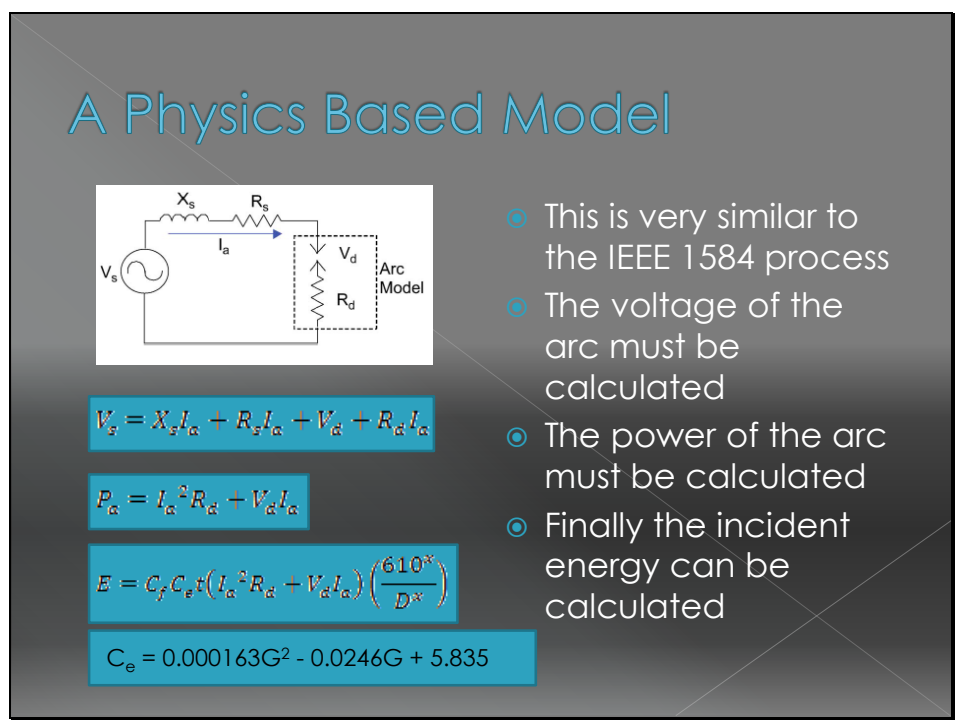




\section{Example}

Evaluate the arc flash energy $15 \mathrm{kV}$ switchgear. The transformer is $45 \mathrm{MVA}_{\mathrm{bf}}$. The arc exists for 4 seconds and incent current is $8700 \mathrm{~A}$. The worker is working $910 \mathrm{~mm}$ away from the component. Total impedance of the system is $20+7 \mathrm{j}$

(0) $V_{d}=15-8.7(20+7 j)-(100,000)(8.7)$

$$
=-870159-60.9 \mathrm{j} \mathrm{kV}
$$

\section{Example}

$P_{a}=8.7^{2}(100,000)+(-870159-60.9 j)(8.7)$ $=6.6 \times 10^{6}-529.83 \mathrm{j} \mathrm{kW}$

$\circ C_{e}=0.000163(910)^{2}-0.0246(910)+5.835$ $=118.43$

○ $E=(1.5)(118.43)(4)\left(6.6 \times 10^{6}-529.83 j\right)(610.973 / 910.973)$ $=4.76 \times 10^{9}-359.017 \mathrm{j}=4.76 \times 10^{9}<-.000004^{\circ} \mathrm{W}$ 
Module V

\section{Arc Flash Calculations}

By: Tayce Lassiter, for fulfilling requirements

for the Masters of Engineering program for the University of Lovisville

\section{Arc Flash Calculations}

This module has been created for students that wish to know how to calculate arc flash energy for the power and control industry. The following slides will convey the importance of arc flash calculations as well as the process of calculating arc flash energy. This module will show the student several different ways to calculate arc flash energy. 

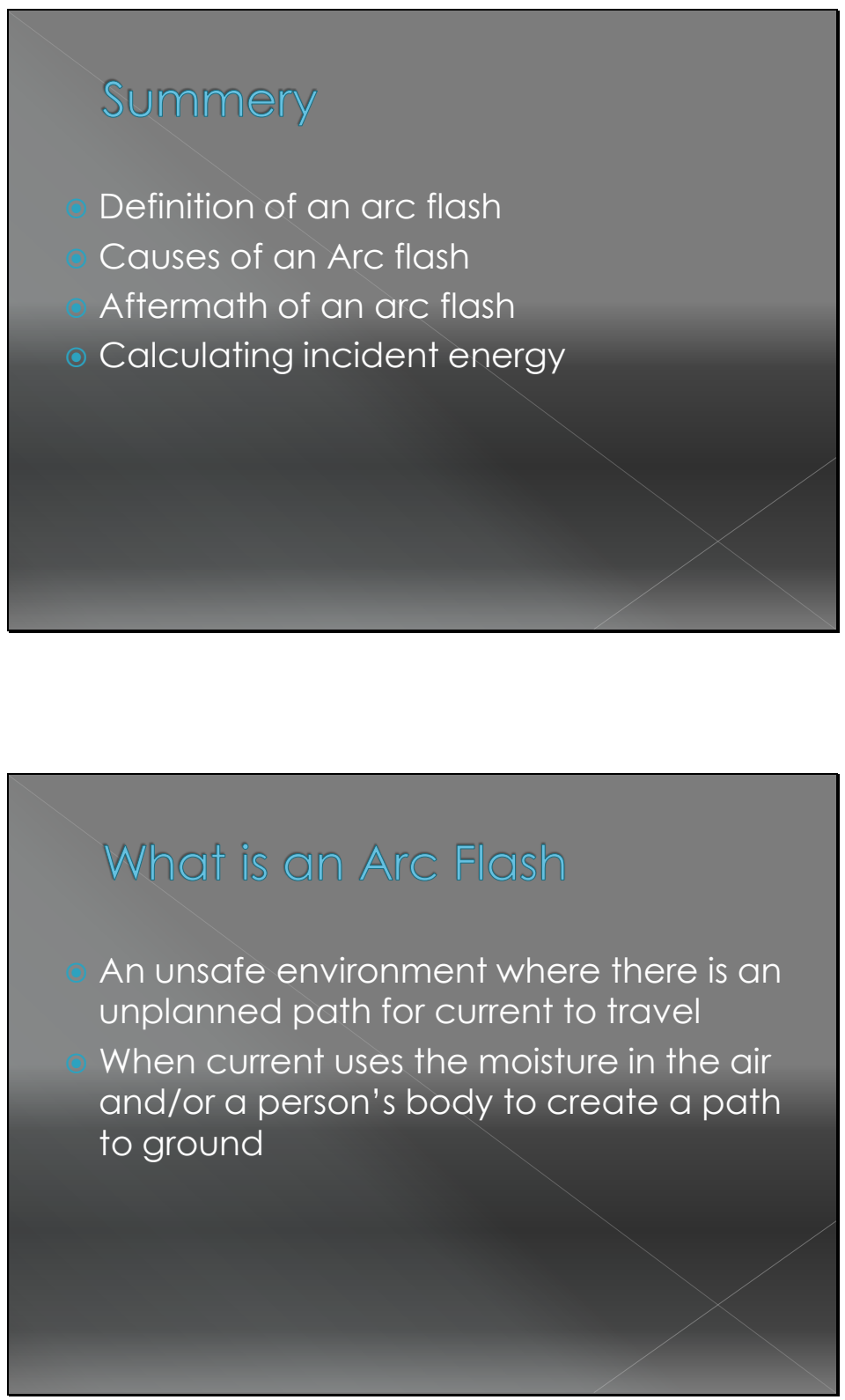


\section{What is an Arch Flash}

The following can be symptoms of an arc flash event

Intense light

Heat

Sound

> Vaporized metal shrapnel

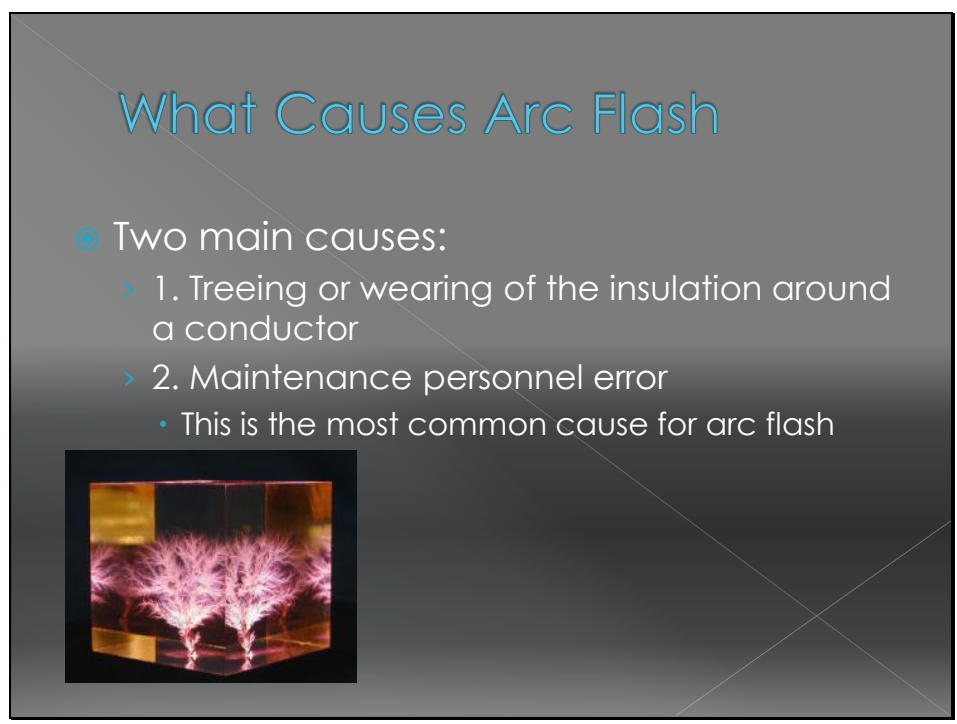



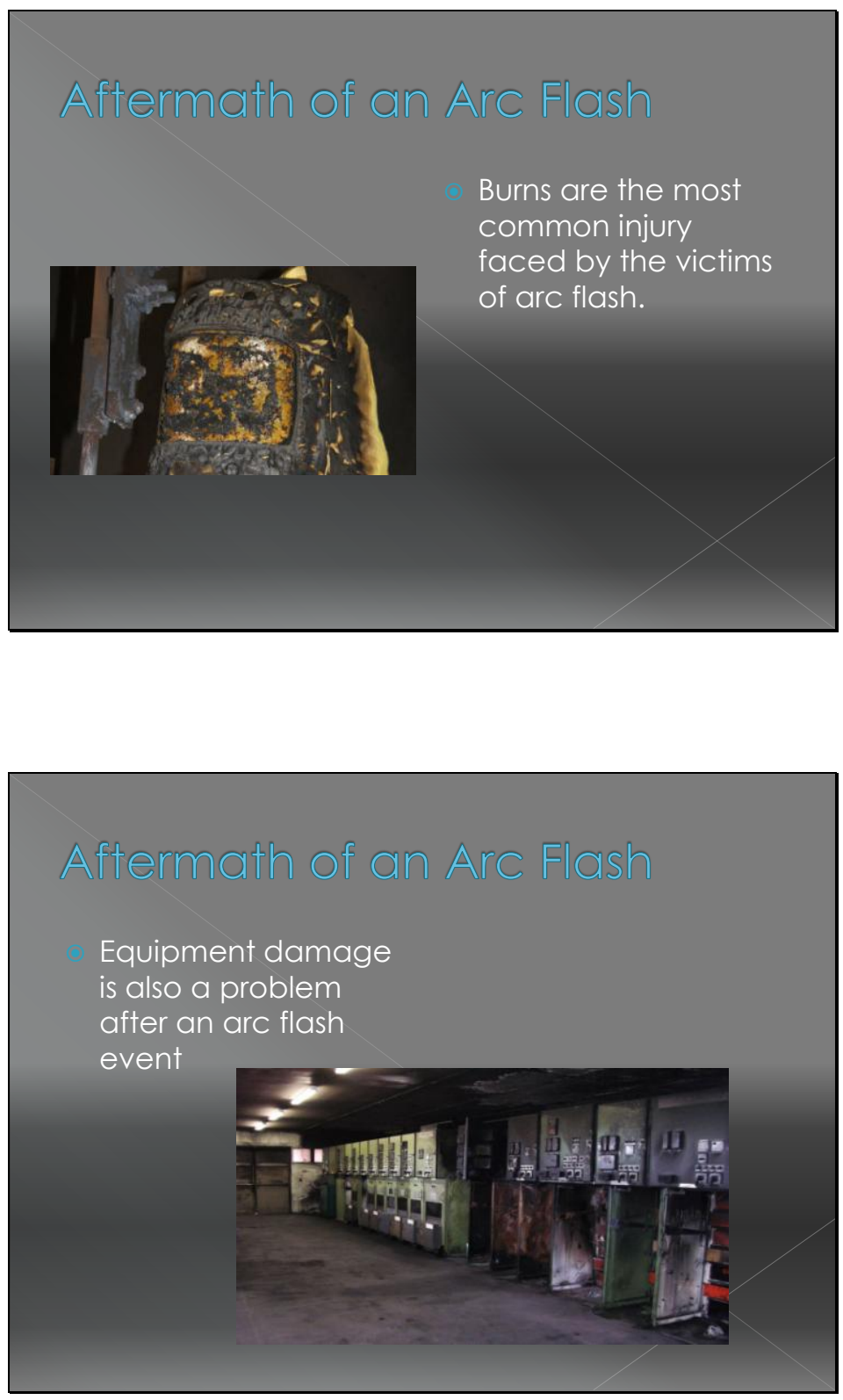

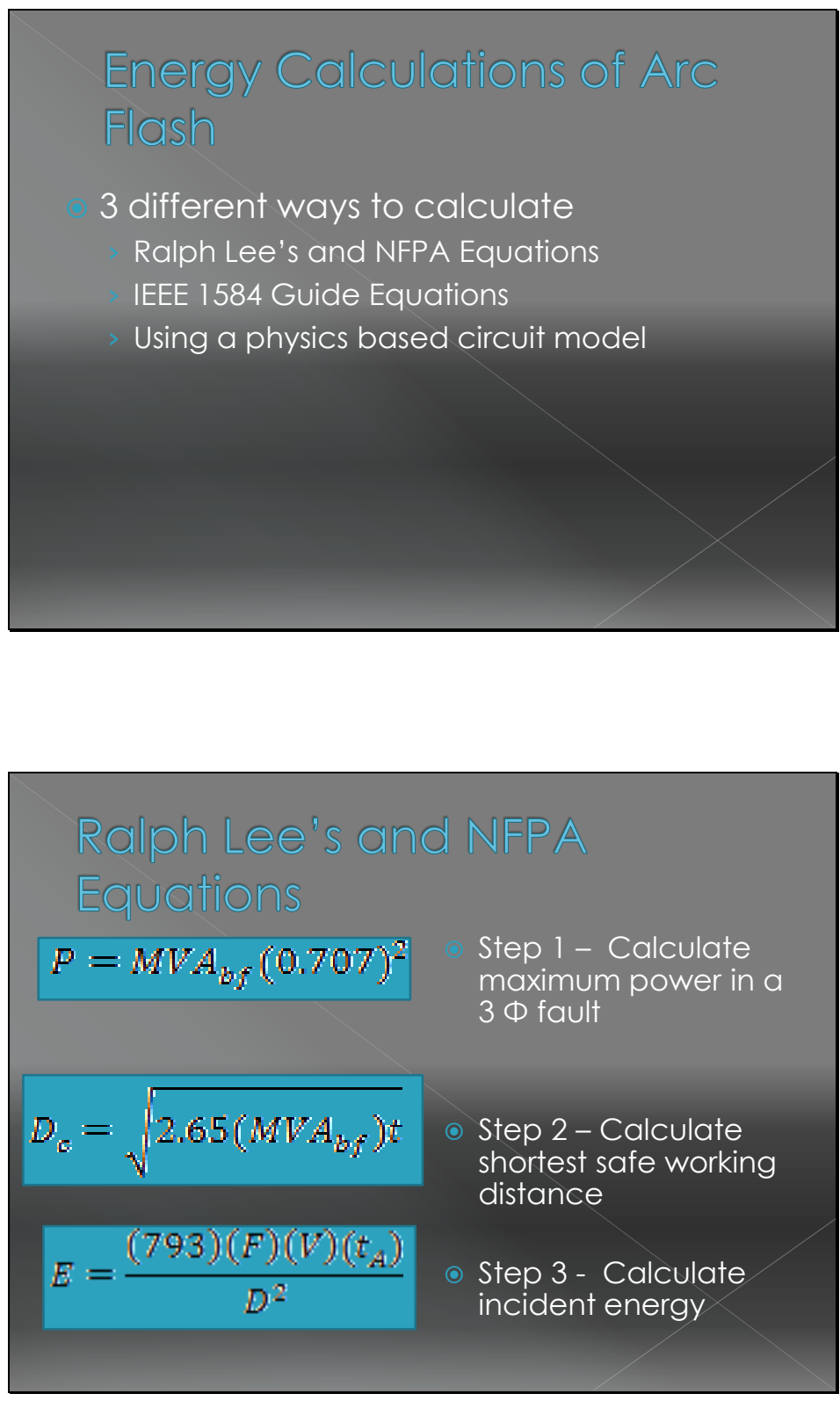


\section{Example}

Evaluate the arc flash energy $15 \mathrm{kV}$ switchgear. The transformer is $45 \mathrm{MVA}_{\mathrm{bf}}$. The arc exists for 4 seconds and incent current is $8700 \mathrm{~A}$. The worker is working $910 \mathrm{~mm}$ away from the component.

() $\mathrm{P}=45(0.707)^{2}=22.5 \mathrm{MW}$

○ $D_{C}=(2.65(45)(4))^{1 / 2}=21.84 \mathrm{ft}$

(ㅇ) $\mathrm{E}=((793)(8.7)(15)(4)) /(3.6)=114,985 \mathrm{~kW}$

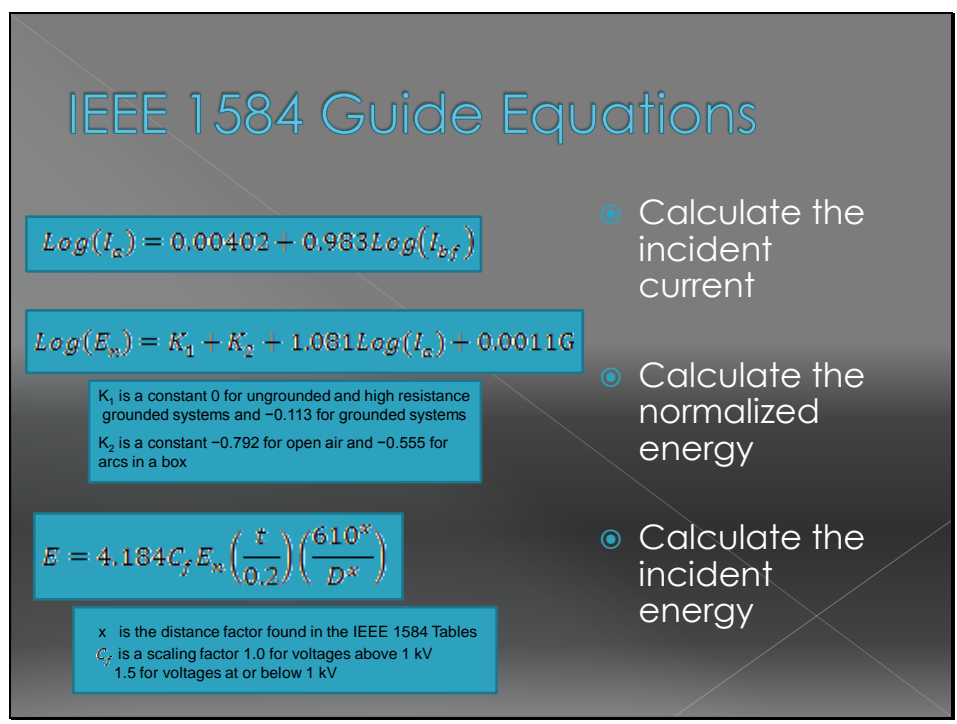




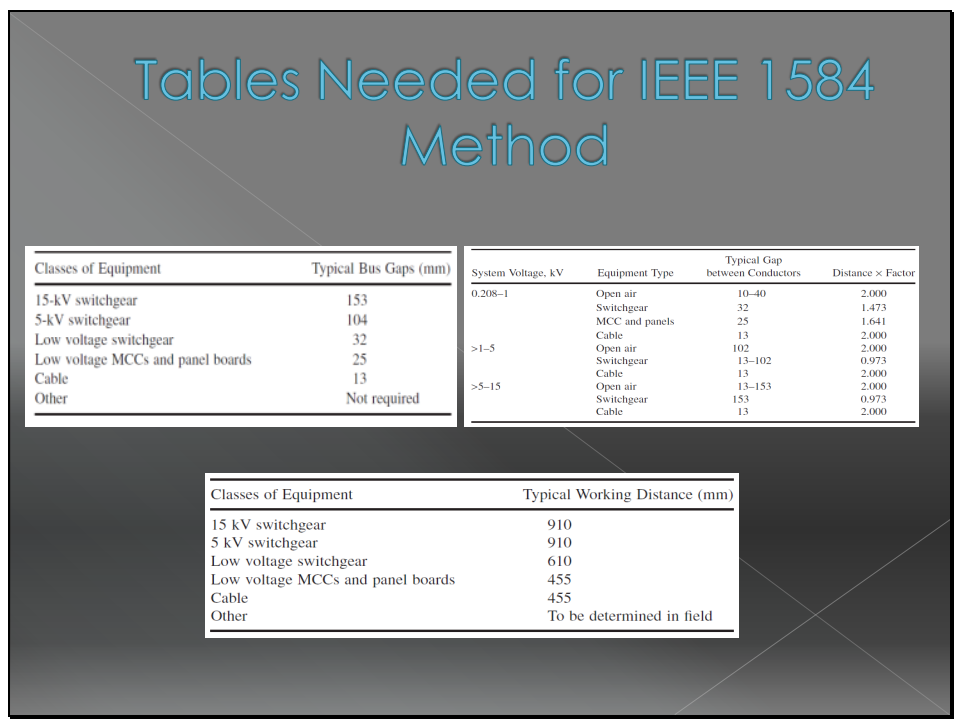

Example

Evaluate the arc flash energy $15 \mathrm{kV}$ switchgear. The transformer is $45 \mathrm{MVA}_{\mathrm{bf}}$. The arc exists for 4 seconds and incent current is $8700 \mathrm{~A}$. The worker is working $910 \mathrm{~mm}$ away from the component.

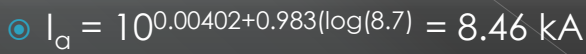

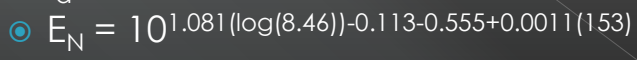
$=3.18 \mathrm{~J} / \mathrm{cm}^{2}$

○ $E=4.184(1.5)(3.18)(4 / .2)(610.973 / 910.973)$

$=73.6 \mathrm{~J} / \mathrm{cm}^{2}$ 


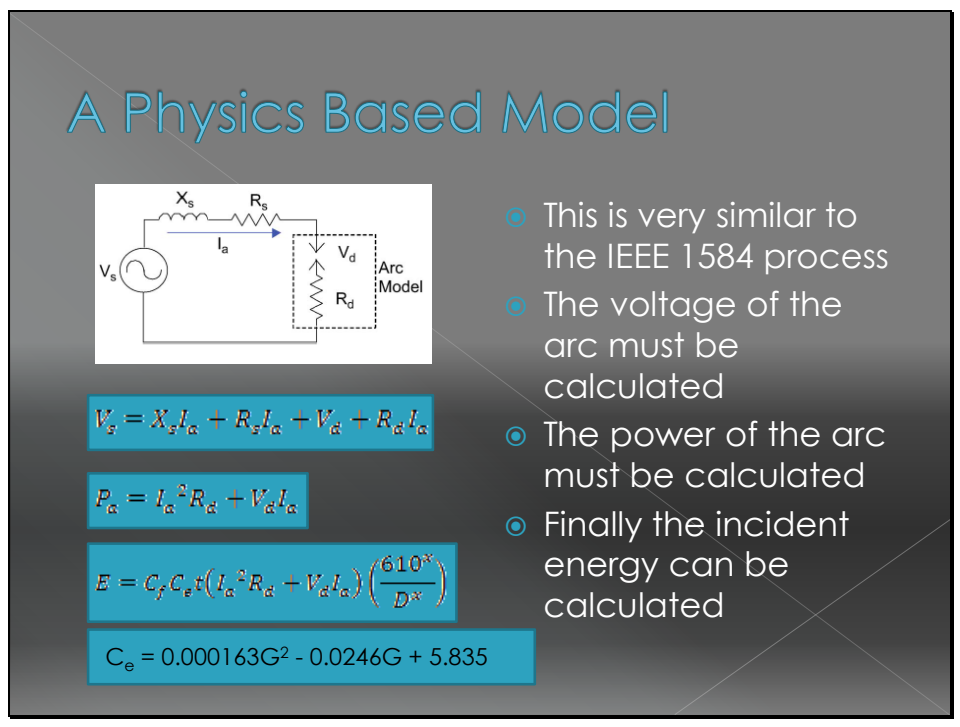

Example

Evaluate the arc flash energy $15 \mathrm{kV}$ switchgear. The transformer is $45 \mathrm{MVA}_{\mathrm{bf}}$. The arc exists for 4 seconds and incent current is $8700 \mathrm{~A}$. The worker is working $910 \mathrm{~mm}$ away from the component. Total impedance of the system is $20+7 \mathrm{j}$

(o $\mathrm{V}_{\mathrm{d}}=15-8.7(20+7 \mathrm{j})-(100,000)(8.7)$

$$
=-870159-60.9 \mathrm{j} \mathrm{kV}
$$



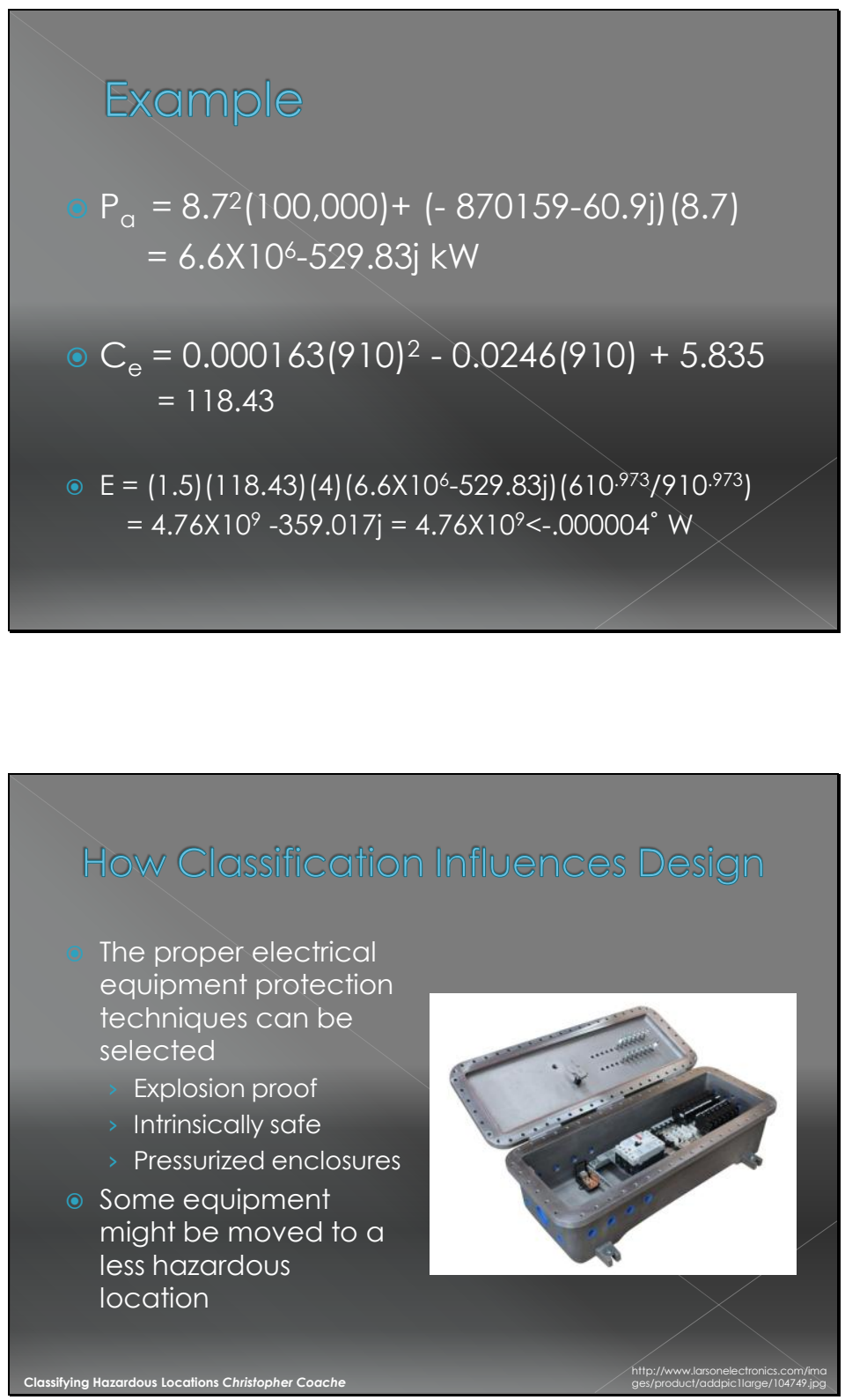

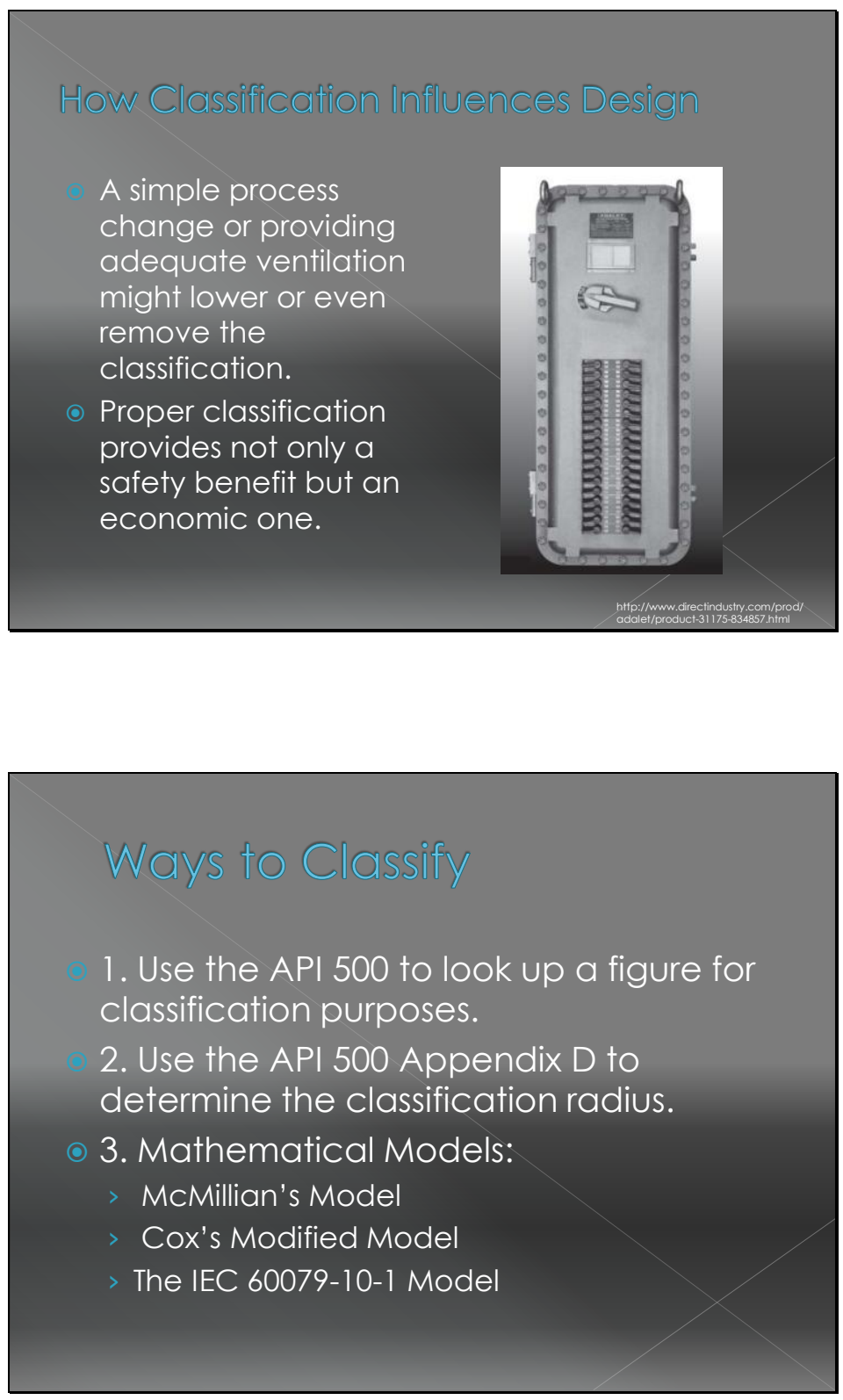


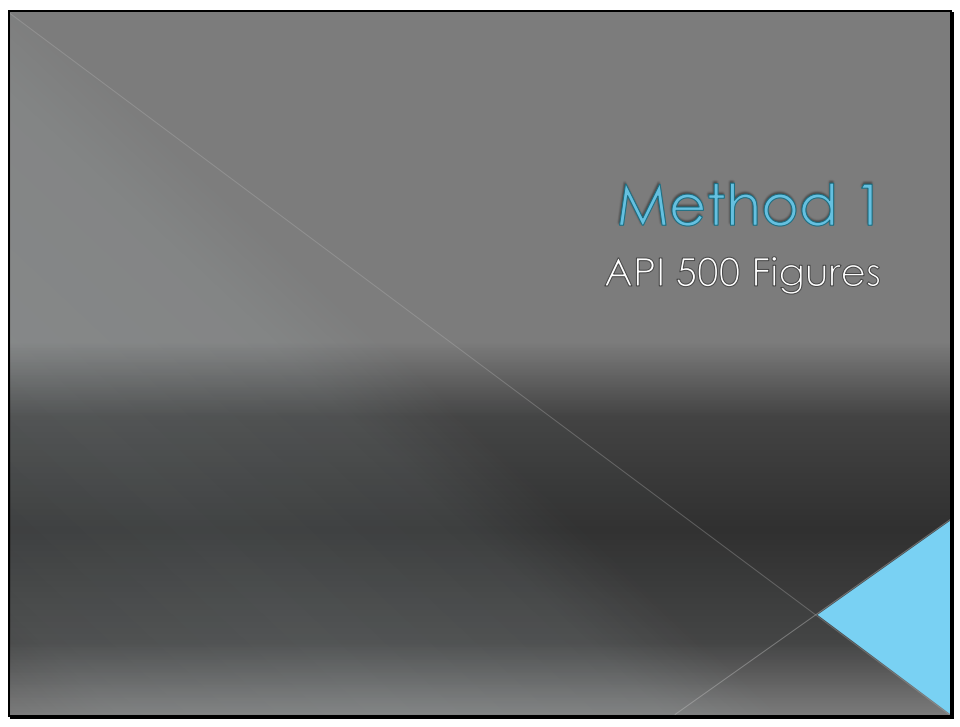

Pumps and Compressors
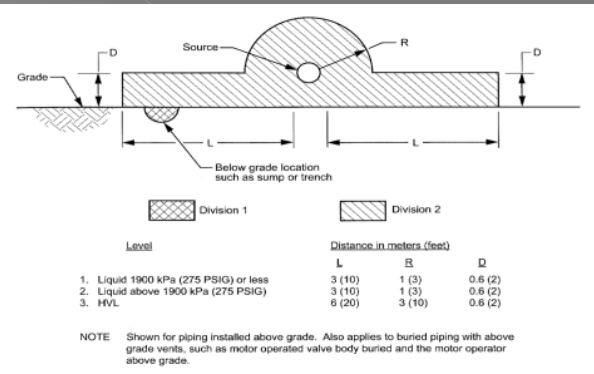

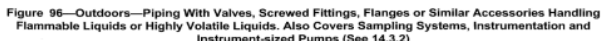




\section{Pumps and Compressors}

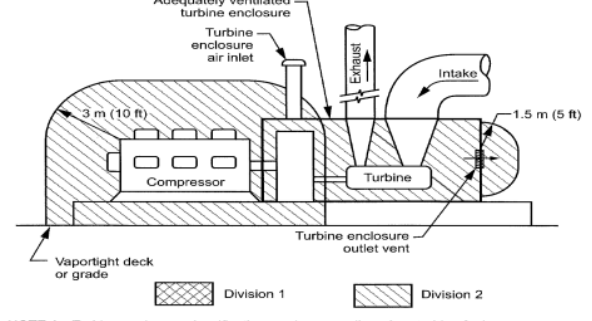

NOTE 1 Turbine enclosure classification as shown applies when turbine fuel gas pressure
exceoeds $861.8 \mathrm{kPa}($ (125 PSi) and enclosure is adequately ventilated. See Section 8.2 .5 for additional requirements.
NOTE 2 Turbine enclosure is unclassined when adequately ventilated and turbine fuel gas
pressure is $861.8 \mathrm{kPa}(125$ psi) or less. See Section 8.2 .5 for additional requirements.

Figure 54b-Turbine Driven Compressor or pump in an Adequately Ventilated Nonenclosed Area

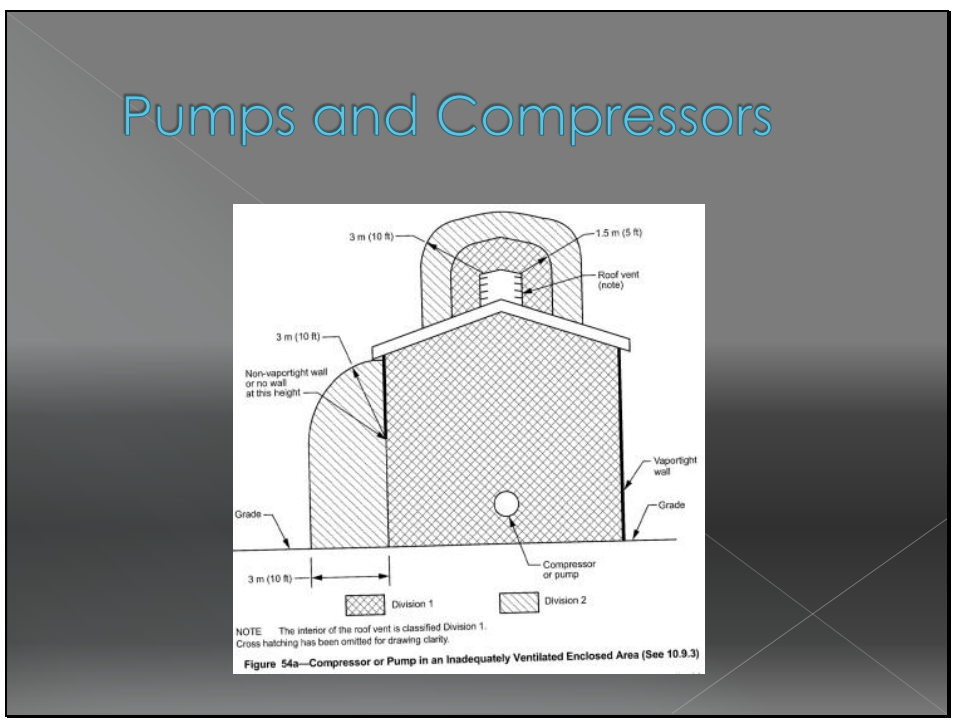



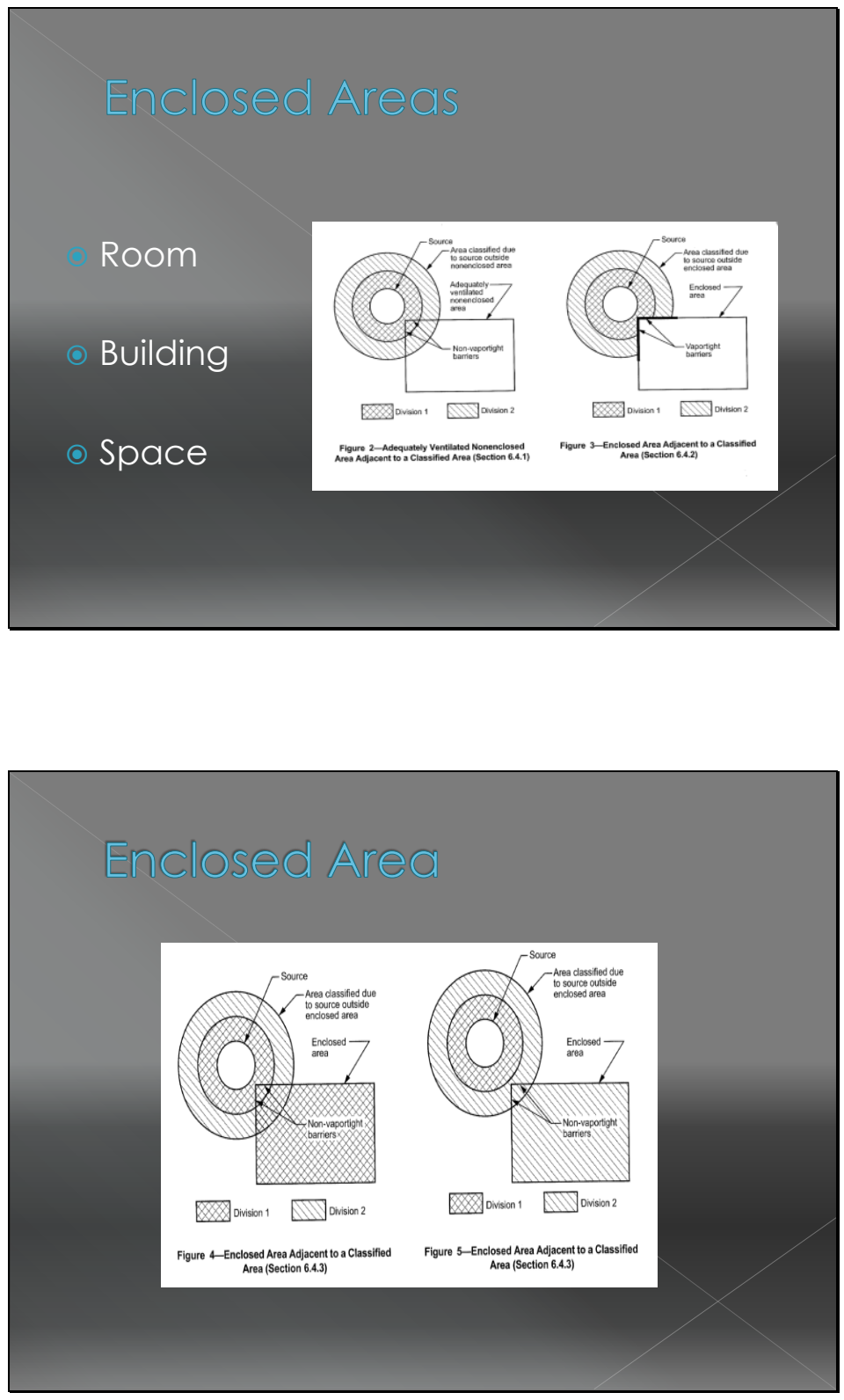

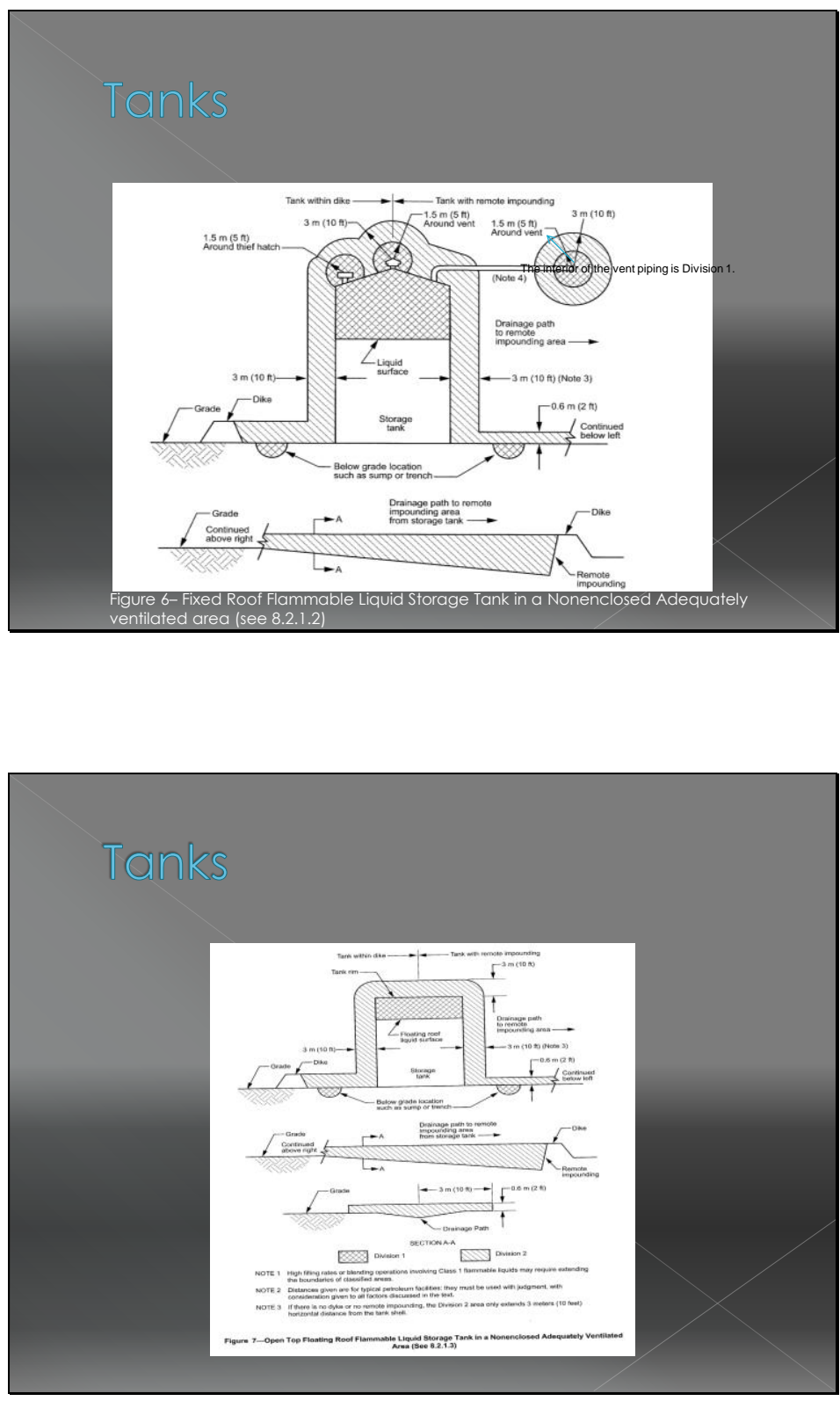

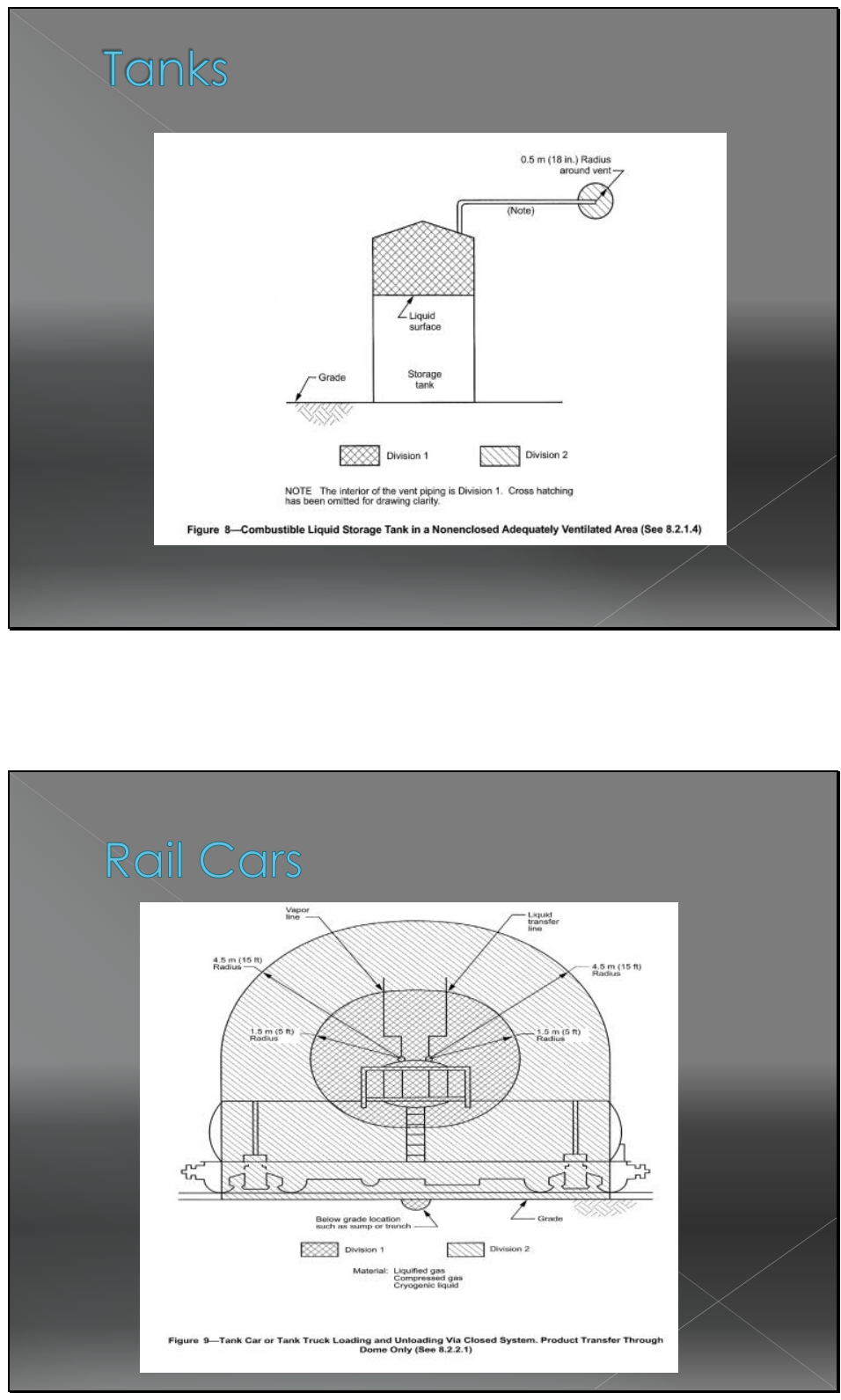

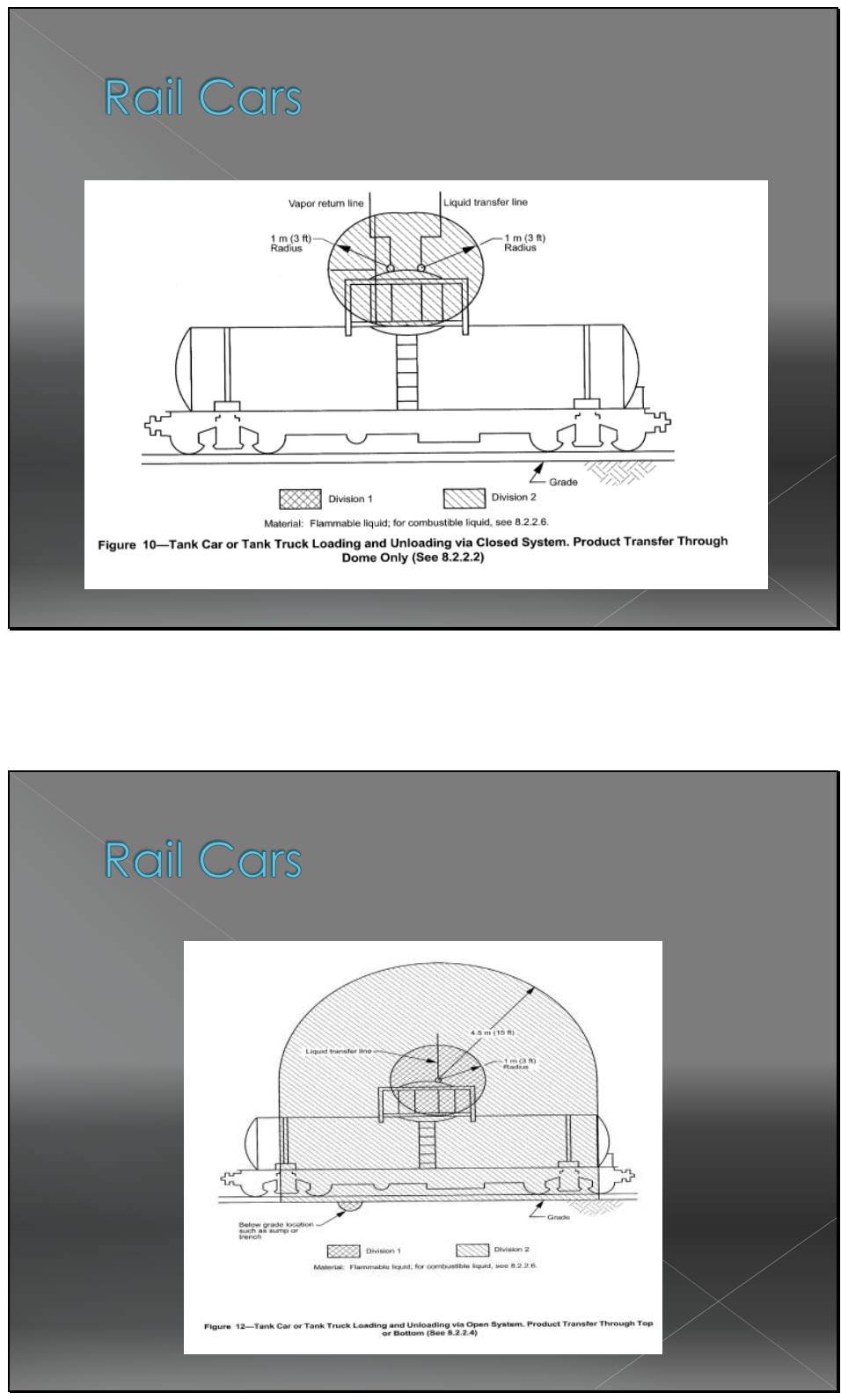

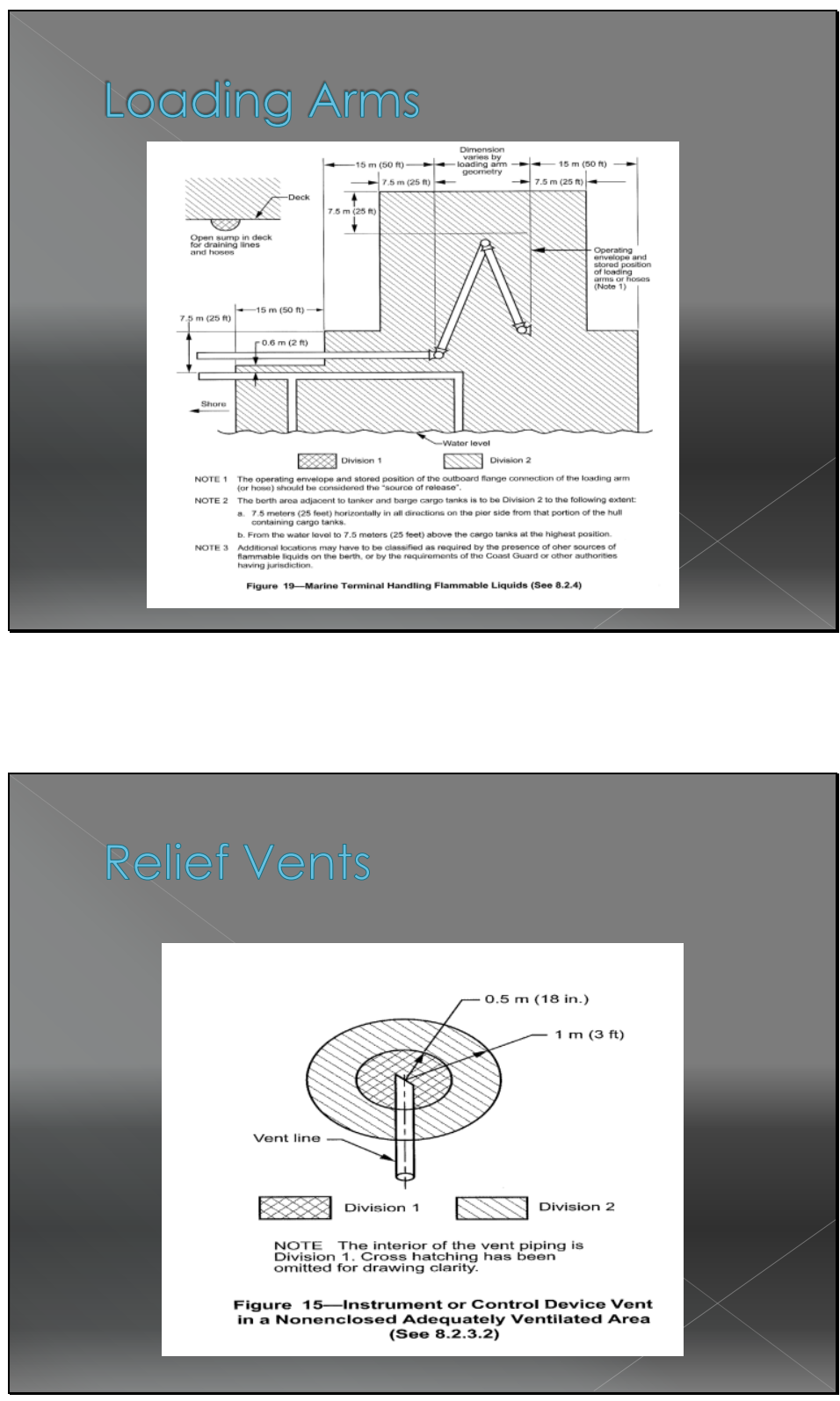


\section{Ventilation}

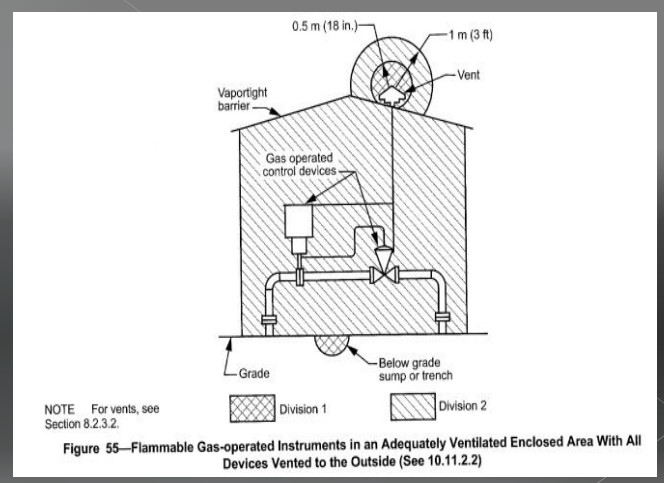

\section{Ventilation}

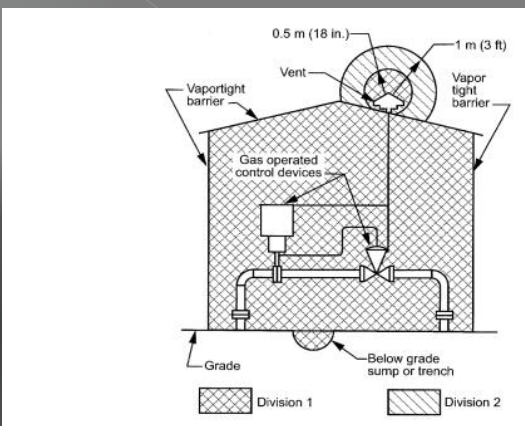

Figure 56-Flammable Gas Operated Instruments in an Inadequately Ventilated Enclosed Area 

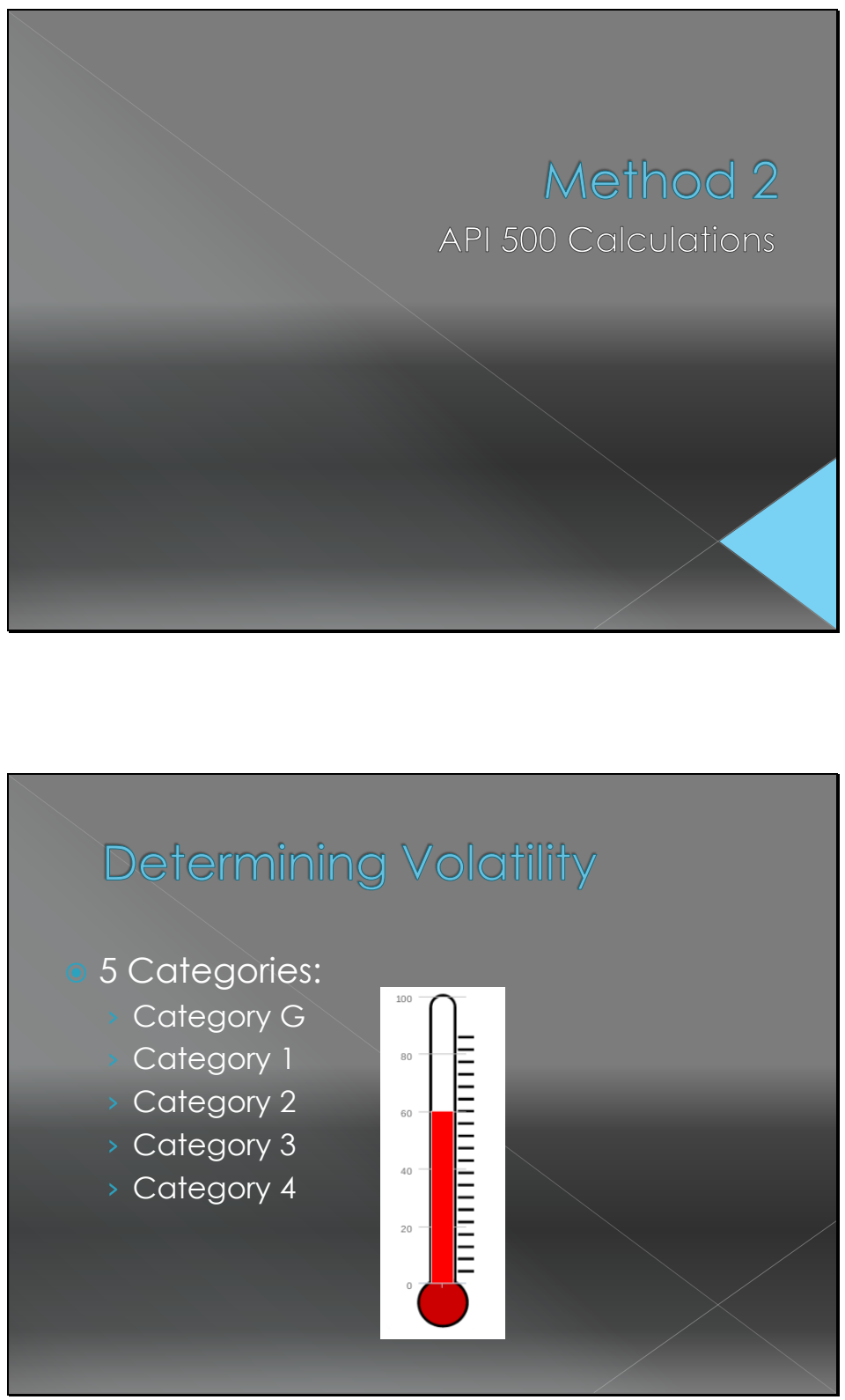

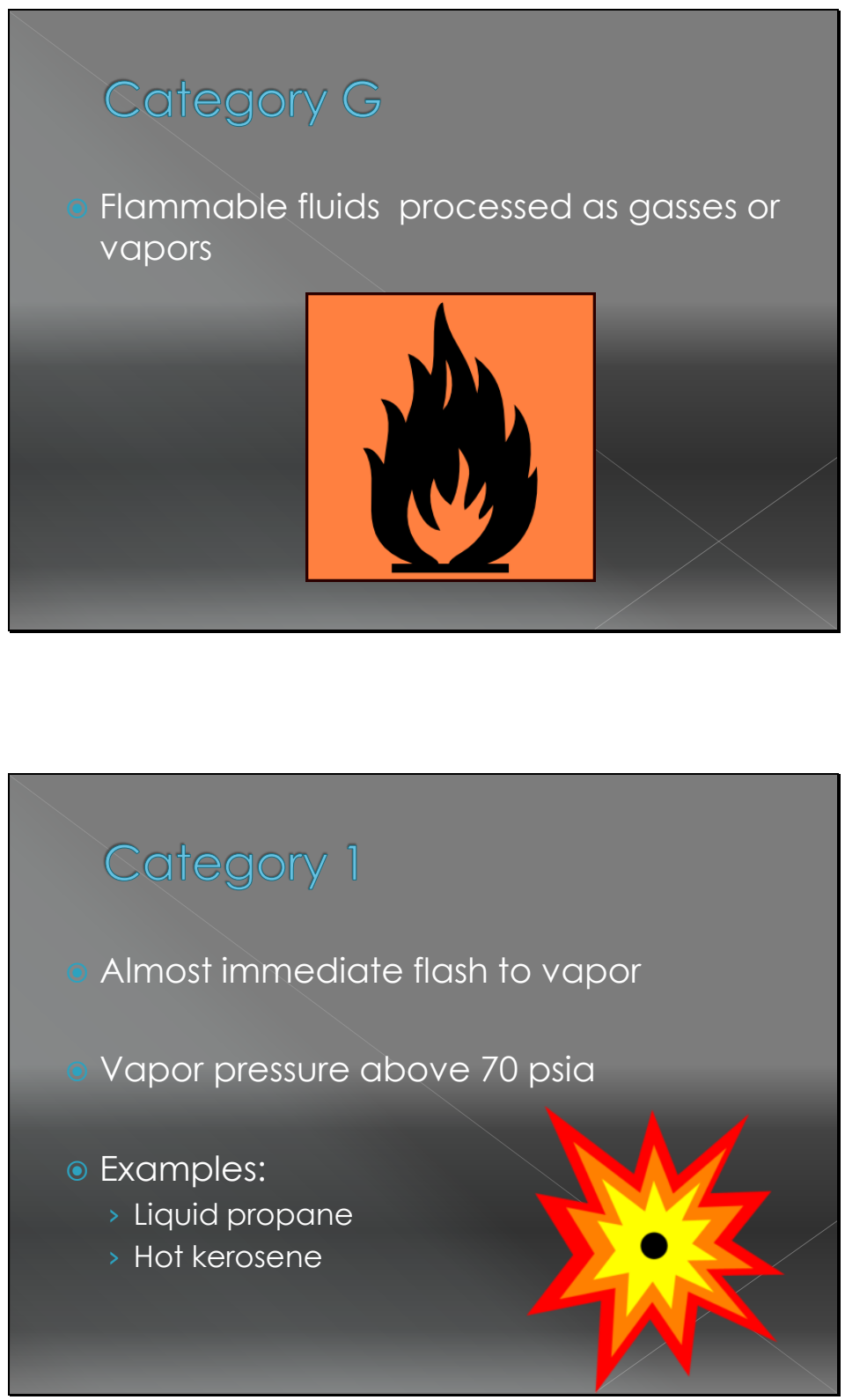


\section{Cotegory 2 or Class 1 A}

These chemicals will have a pressure of 70 psia or to 14.7 psia while being processed

- A leak will vaporize approximately $1 / 6$ of the material immediately and the resulting pool evaporates eventually

o Examples:

Pentane

Isopropyl alcohol above room temperature

\section{Category 3 or Class 1 B}

Processed at temperatures to produce less than 14.7 psia

A leak will flash very little vapor and the resulting pool has a moderate evaporation rate

o Example:

Kerosene at $150^{\circ} \mathrm{F}$ 


\section{Category 4 or Class II}

Materials processed below their flash point

Materials do not create a flammable fuel-air mixture when released

- Examples:

Kerosene

Lubrication oil

Asphalt

Diesel fuel

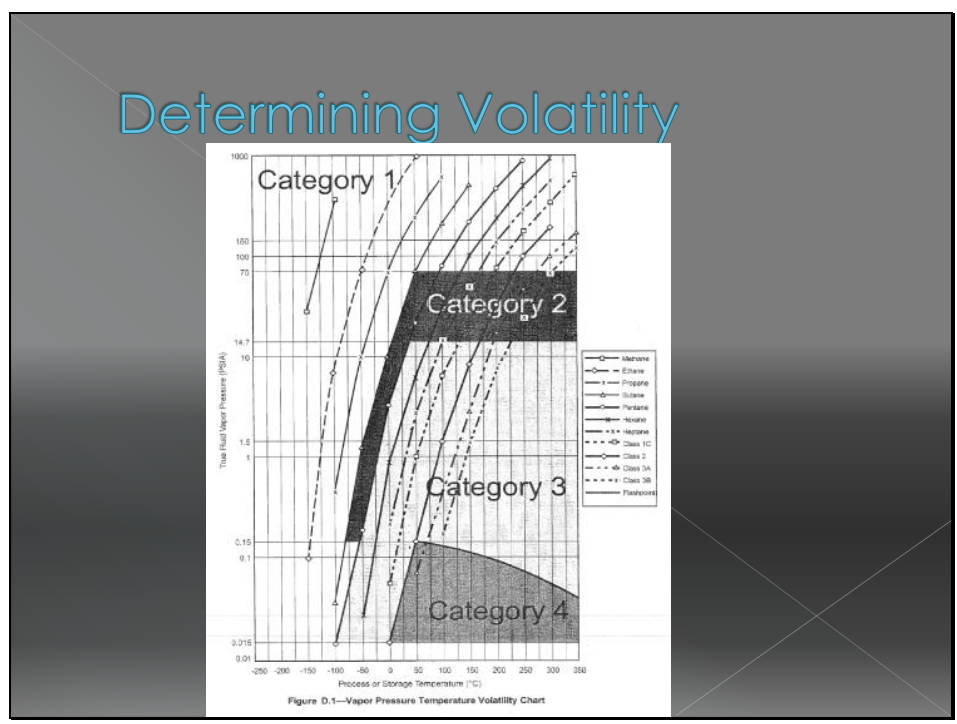


Determining the Hazard Radius Using API 500

After determining the volatility category of the material look at the appropriate chart for your source in the API 500 Appendix D

Determining Hazard Radius

Charts in API 500 will tell you a number (in feet).

This is not the entire hazard radius!

- After finding the hazard radius number consult Figure D.3 for the clearance measurements required for that source. 


\section{Example 1}

A pump that will move 550 gpm of hexane with a pressure of 150 PSIA at a Temperature of $175^{\circ} \mathrm{C}$. This facility is located at sea level. This pump will be newer so it has low seal emissions. How large is the classified area?

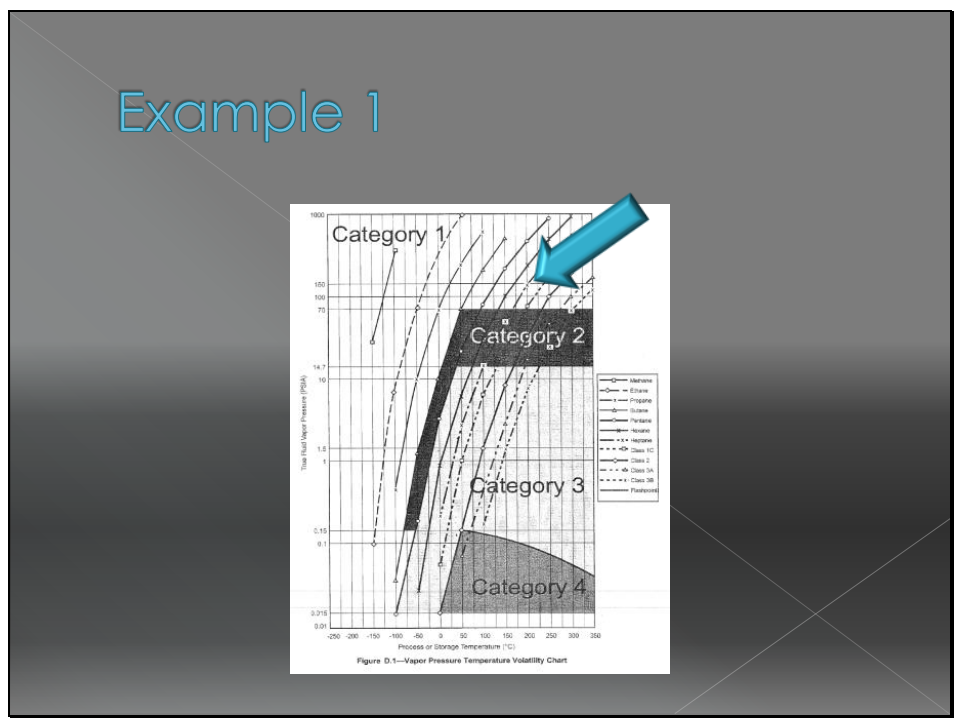




\section{Example 1}

Table D.1-Pumps Handling Heavier-than-air Gases or Vapors Located in Non-enclosed Adequately Ventilated Process Areas

\begin{tabular}{|c|c|c|c|c|c|c|c|c|c|c|c|}
\hline Pumps & Category & & $\begin{array}{l}0 \mathrm{WF} \text { Flo } \\
100\end{array}$ & & & ilum $F$ & $\begin{array}{l}\text { low } \\
\text { gpm }\end{array}$ & & $500 \mathrm{gpr}$ & & $\leftarrow$ Pump Flow Rate \\
\hline $\begin{array}{r}\text { Low }=<100 \text { psig } \\
\text { Medium }=100 \text { to } 500 \text { psig } \\
\text { High }>500 \text { psig }\end{array}$ & $\rightarrow$ & 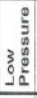 & 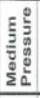 & 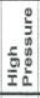 & 窇 & 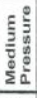 & 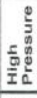 & 递 & 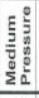 & 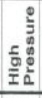 & $\leftarrow \underset{\text { Pressure }}{\text { Seal Chamber }}$ \\
\hline & 1 & 15 & 25 & 20 & 25 & 50 & 100 & 25 & 50 & 100 & \\
\hline Standard Pump & 2 & 10 & 15 & 25 & 10 & 25 & 50 & 15 & 25 & 50 & \\
\hline & 3 & 3 & 10 & 15 & 5 & 10 & 25 & 15 & 15 & & \\
\hline High Technology & 1 & 5 & 10 & 15 & 5 & 10 & 25 & 10 & & & \\
\hline Low Seal Emissions & 2 & 3 & 5 & 10 & 3 & 5 & 10 & 5 & 10 & & \\
\hline Pump & 3 & 3 & 3 & 5 & 3 & 3 & 5 & 5 & 5 & 10 & \\
\hline
\end{tabular}

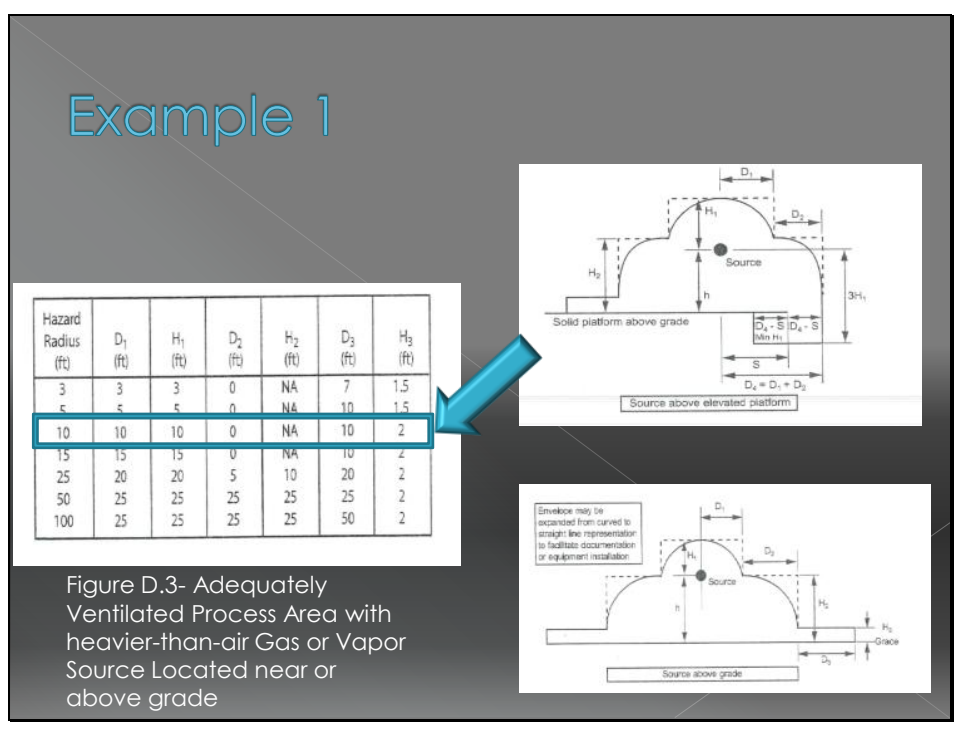




\section{Method 3}

Mathematical Models

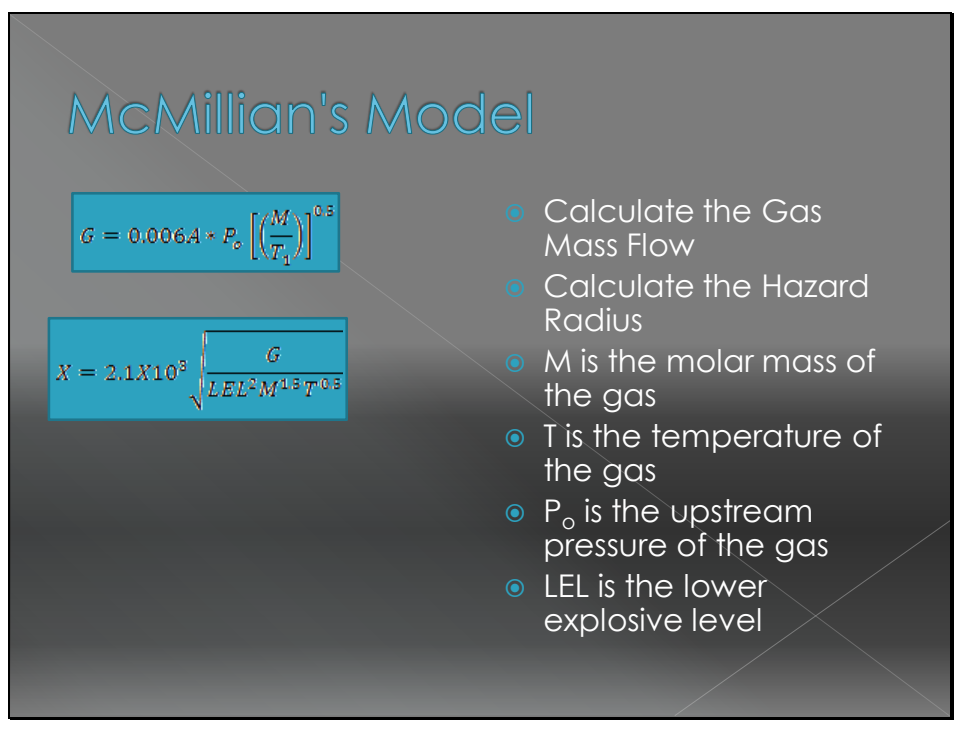



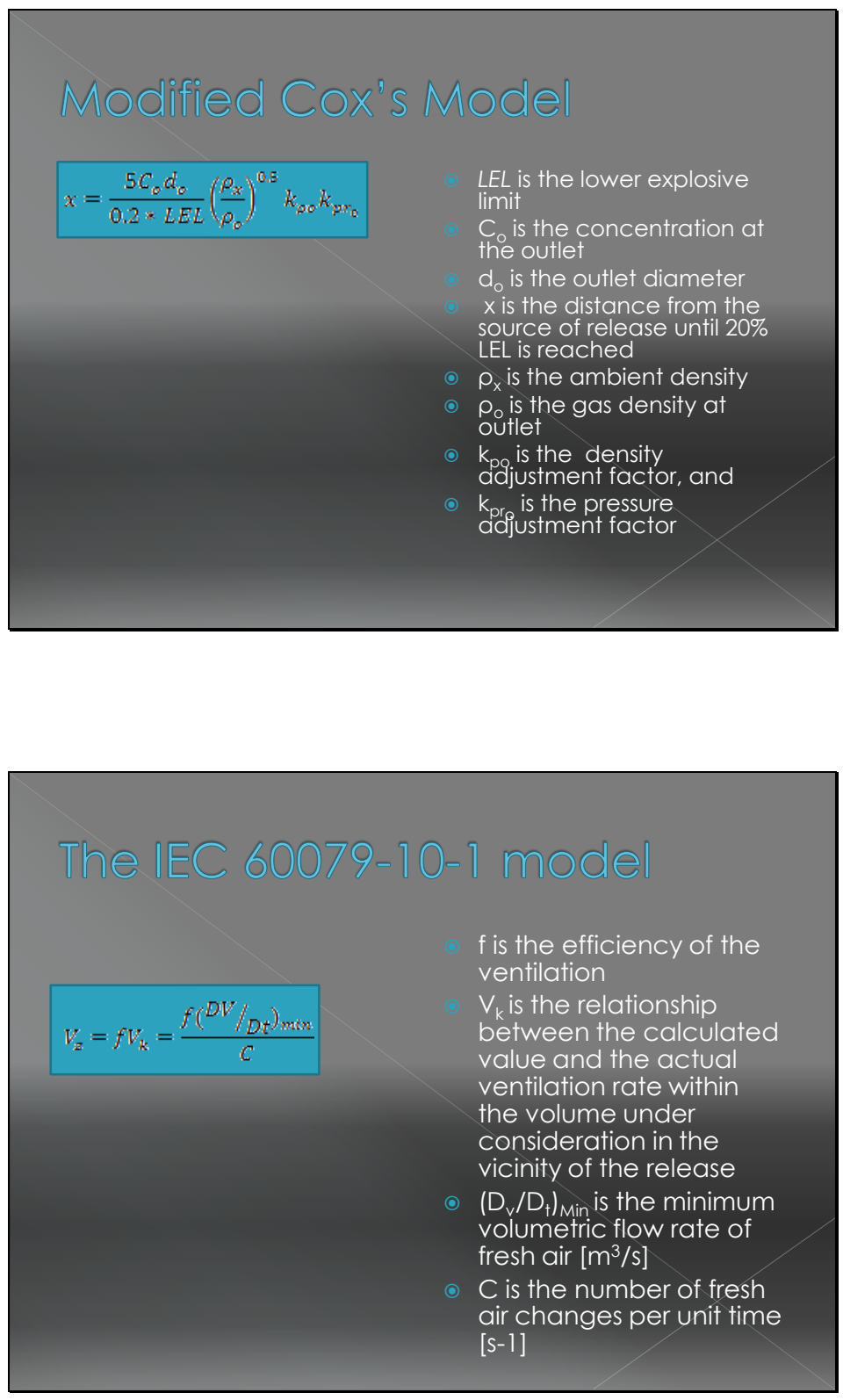


\section{Example 2}

A pump that will pump $148^{\circ} \mathrm{C}$ Heptane at a pressure of $5 \mathrm{~N} / \mathrm{m}^{2}$ in a $1 \mathrm{~m}$ pipe orifice. How large is the classified area?

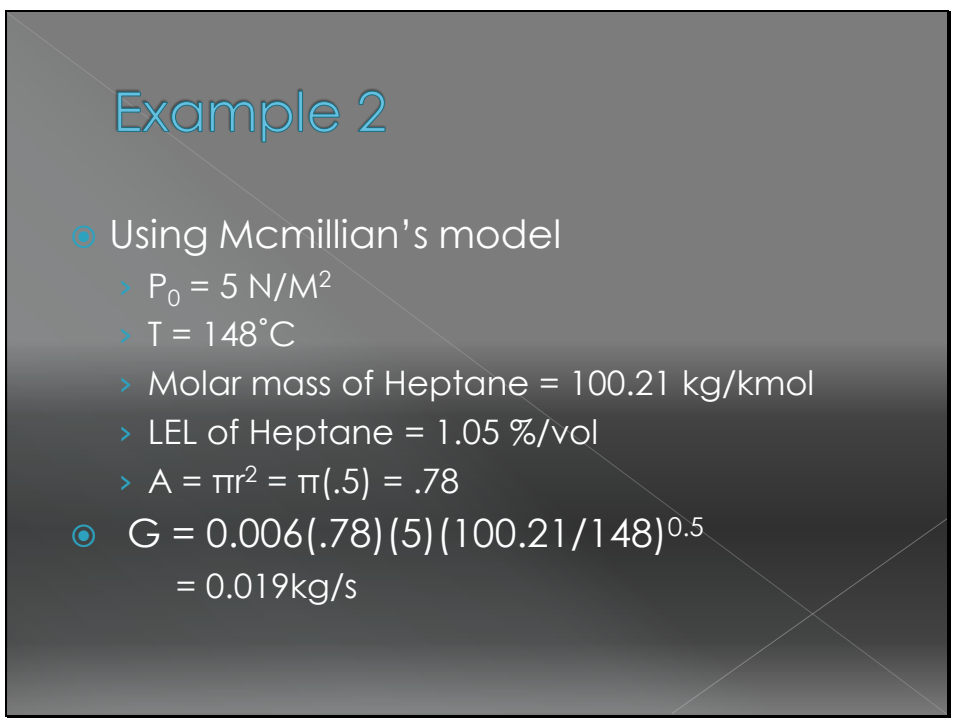




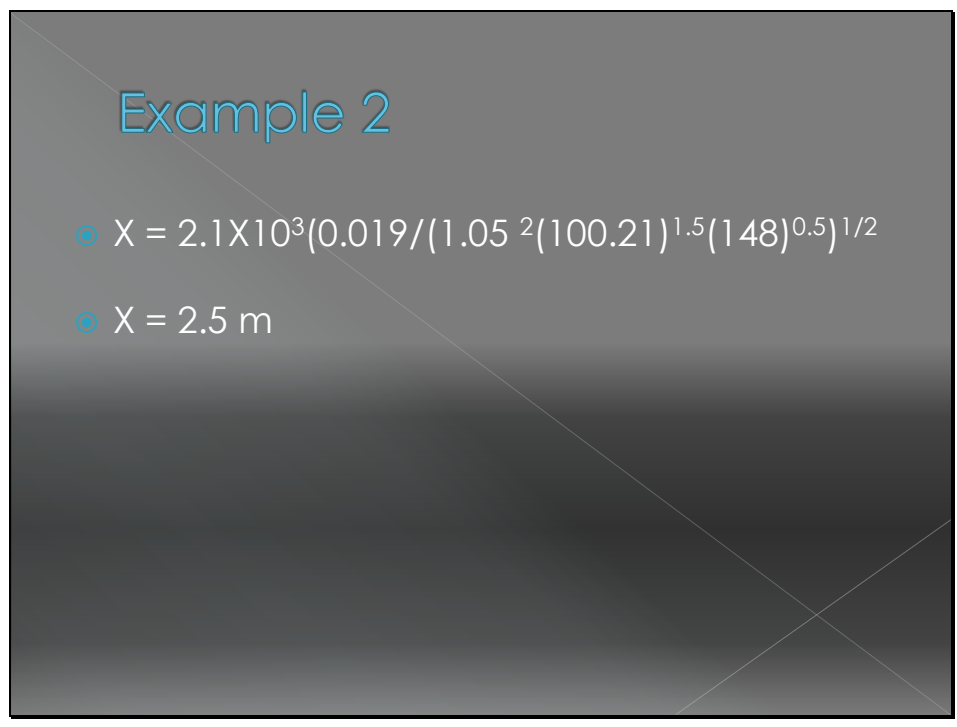

Quiz!

A pump that will pump $75^{\circ} \mathrm{C}$ butane (LEL:1.8 molar mass: $58.12 \mathrm{~kg} / \mathrm{kmol}$ ) at a pressure of $125 \mathrm{~N} / \mathrm{m}^{2}$ (0.0181297 PSIA)at a rate $1200 \mathrm{gpm}$. The diameter of the pipe is $2 \mathrm{~m}$. How large is the classified area? What class and division should this be classified? 